\title{
Linneuniversitetet
}

Institutionen för datavetenskap, fysik och matematik

\section{Sustainability of a web 2.0 application from the perspective of Actor Network Theory}

The case of LibGuide

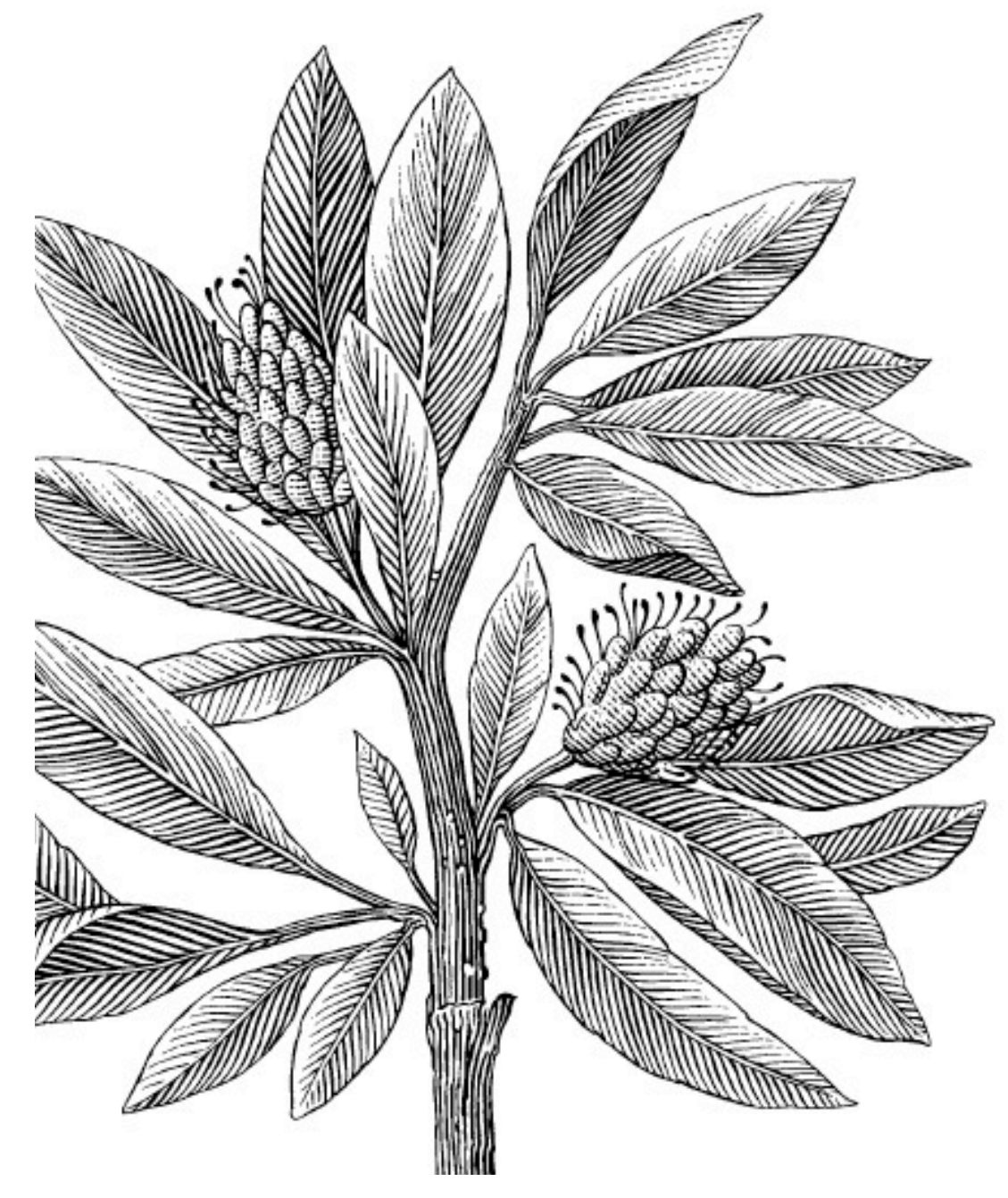

Authors: $\quad$ Sina Arasteh \& Andreas Koczkas

Personal No: 19840310 \& 19850318

Semester: HT11-VT12

Coursecode: 5IK00E

Supervisor: Håkan Sterner

Exeminer Prof. Christina Mörtberg

Subject: Informatics

Level: $\quad$ Master (30 credits)

Version: $\quad 1.0$ 


\section{Preface}

Writing this thesis has been more than just a writing process. We have shared all types of feelings through this journey that includes sleepless nights, doubts in our own work and capabilities, frustration and happiness. But in the end we can both conclude that it has led to an extension of our knowledge and experience when it comes to the field of Information Systems. We would like to take the opportunity to thank a number of people through this challenging act.

\section{Håkan Sterner our supervisor:}

An inspiring and helping hand throughout this entire process. Thank you for your constant support and believing us.

\section{All involved respondents:}

Thank you all for your participation in this research, without you wouldn't this be possible

\section{Professor Geoffrey C. Bowker}

Thank you sir for taking your time and reading this thesis, sending us some valuable comments, especially when it came to the question about the abductive reasoning.

\section{Professor Anita Mirijamdotter}

We are grateful for the guidance and the constructive feedback we received after the presentation which helped us to improve to make this even better, thank you so much.

\section{Professor Christina Mörtberg}

Thank you for all the guidance and feedback, this helped us in so many ways..

\section{Our beloved families and friends:}

For the constant support, love and motivation. Without you we wouldn't have the energy it took in order to write this thesis. 


\section{ABSTRACT}

Title:

Course:

Author:

Supervisor:

Examiner:

Date:

Language:
Sustainability of a web 2.0 application from the perspective of Actor-Network Theory 5IK00E

Sina Arasteh \& Andreas Koczkas

Håkan Sterner

Professor Christina Mörtberg

2012-09-09

English

This thesis aims to focus on relational controversy about the causes behind the inconsistency in number of students who use a Web 2.0 application named "LibGuide" inside the Linnaeus University and the attempts of program coordinator to develop certain strategies to perform a better use of it in a particular department of Healthcare. The nature of the problem will be discussed, suggesting that how the these strategies maintained a high significant of use in that department. The research foregoes, as it uses a process of translation which are the moments of struggles by a program coordinator to impose itself by its role to the definition of the situation. The research suggests a network within which the series of processes and interrelation of the sociotechnical role of each member is drawn and allocated.

Keywords: Actor network theory; Web 2.0 technology; LibGuide; Translation; 


\section{Executive Summery}

\section{Introduction and problem definition}

The use of Web 2.0 technologies nowadays inside any organizational contexts is a common practice. These technologies leave different users to share their ideas and thoughts and it creates an environment where the individual experiences become dynamic. This thesis found the role of these applications and particularly one of their species named "LibGuide" inside the Linnaeus University very important. Our observation and the conducted pre-studies proved that there is an ongoing problem regarding the inadequacy of using this application in different programs. However, we found that the department of Healthcare had a significant amount in frequently using this application which apparently made it sustainable by its use.

\section{Method, Methodology and Theoretical Framework}

For this study we have chosen an intepretevistic approach to look at the reality. To tackle the research questions have we an adbdutive reasoning where we float between the boundaries of inductive and deductive reasoning. To handle the data from the literature and our empirical investigation we captured the essence of the hermeneutic circle from Boell \& Cecez-Kecmanovic (2010), and our data analysis is concentrated around the idea of using themes and kalidioscope. We also made sure that the methodology which was chosen is appropriate for the theoretical lens we are investigating our case under. Once it was done, the use of the theory can be justified. Moreover, the theoretical framework we opted to look at the case was Actor-Network Theory as a sociotechnical theory which examines the dynamics of actions under a network. This theory helped us to analyze the arguments of both social and technical actors inside a setting. Therefore, we could treat all human and non-human actors equally and to avoid from either social or technical determinism. In addition, the data we captured from the methodology part is now capable to be put inside the steps within the theory. By this integration, we made a rational alignment between the method and methodology, the theory in use, and the final analysis of the case.

\section{Result}

The result of this thesis can be used in every organization where the sustainability of a certain technology is affected or dependant by a sociotechnical work behind it. However, it mainly directs towards IT managers or individuals whose work tasks are somehow related to the efficient and effective use of an already implemented technology. What we present is a result based on the premises of the Actor-Network Theory of how a certain technology is implemented based on its policies and regulation. Our findings show that a technology userfriendliness is equal in terms of it critical factor to sustainability as the policies and regulations behind it. Concerns like this cannot be studied in polarity, putting to much concern on either the social or the technical side of it. We hope that the result of this study will be either used as a follow up study with the objective to implement our findings in an other department which exists in the same context as we looked into, or to use the concluding remarks we put out when it came to the dualism of technical and social parts of sustainability of a technology in any organization. 


\section{Table of Contents}

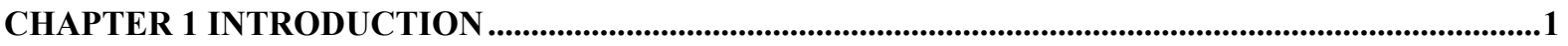

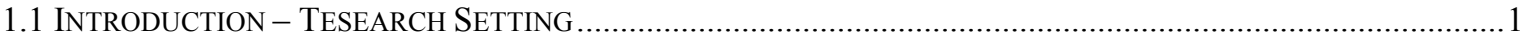

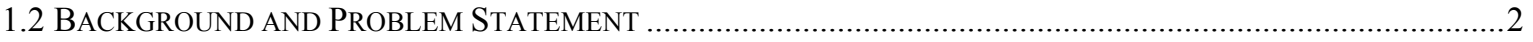

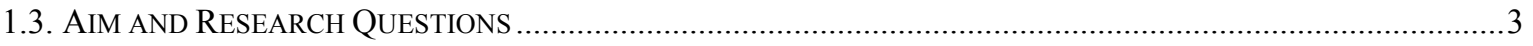

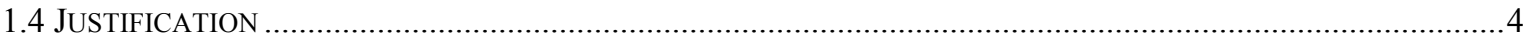

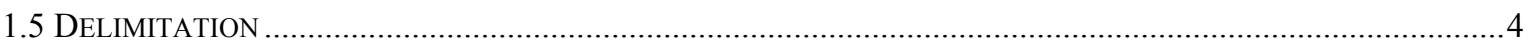

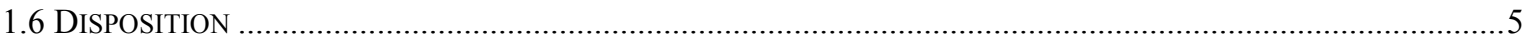

CHAPTER 2 THEORETICAL FOUNDATION: ...................................................................................................6

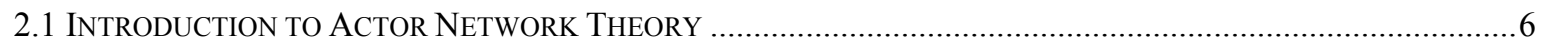

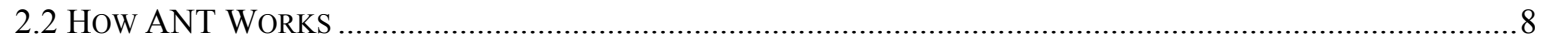

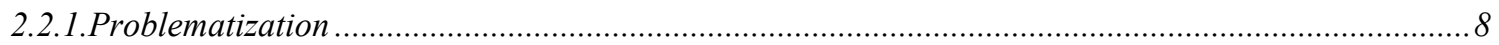

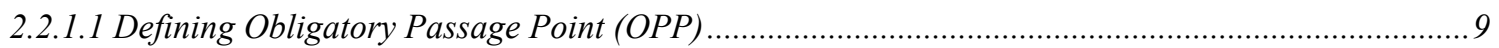

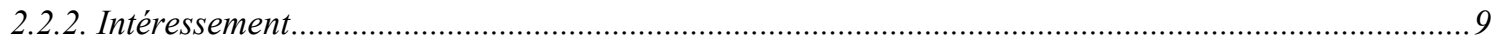

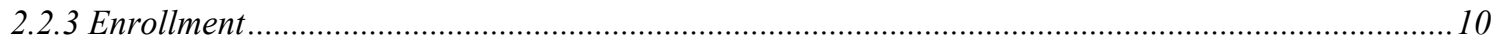

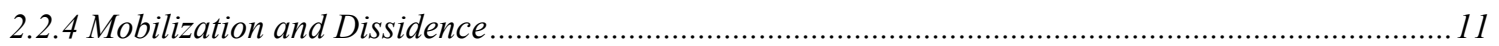

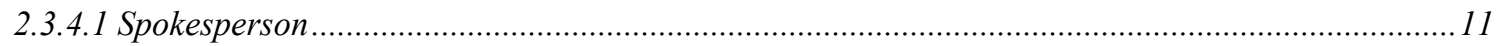

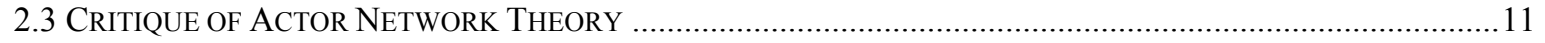

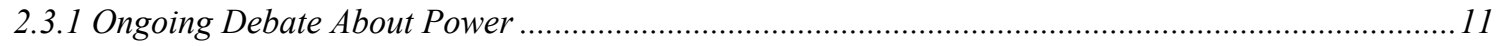

2.3.2 The Absurdity of Assigning Agency to Non-Human Actors ....................................................... 12

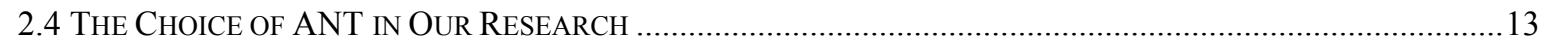

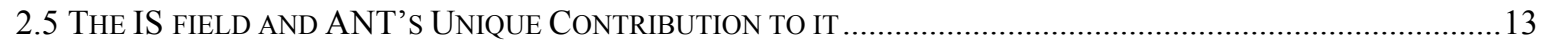

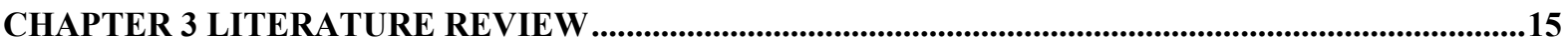

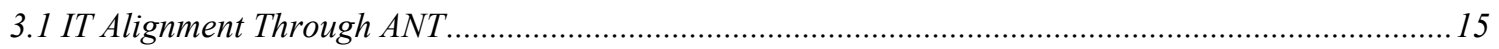

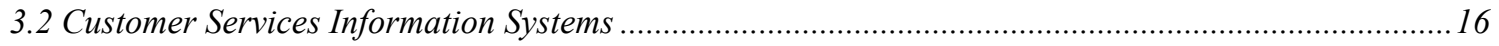

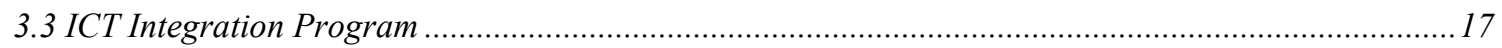

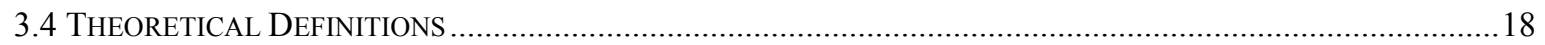

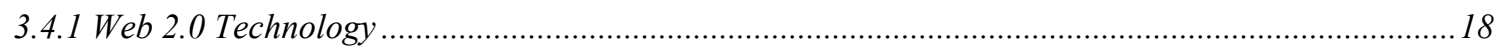

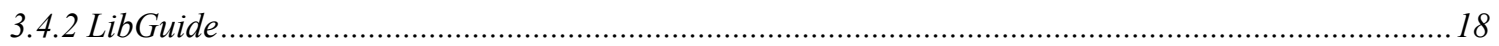

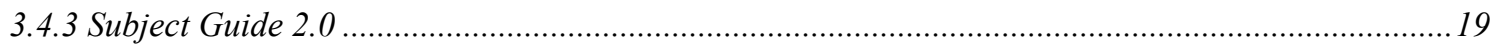

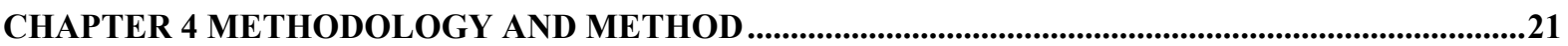

4.1 RESEARCH IN THE FIELD OF IS - EHE NEED OF AN INTERPRETIVE RESEARCH ......................................2

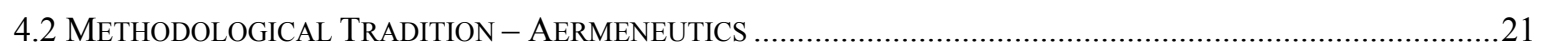

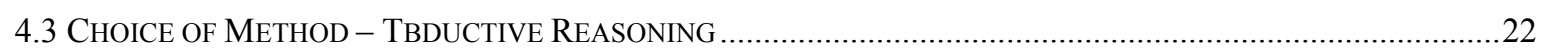

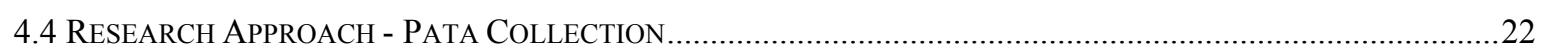

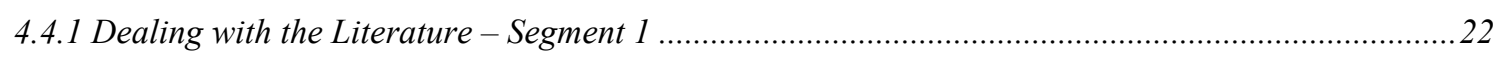

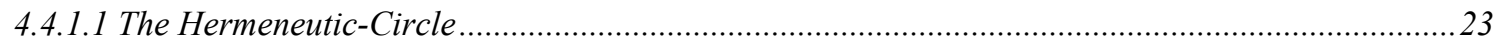

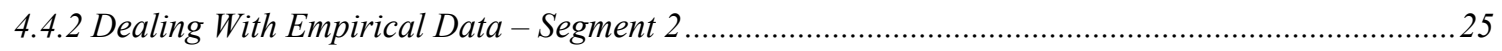

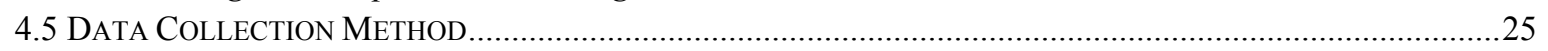

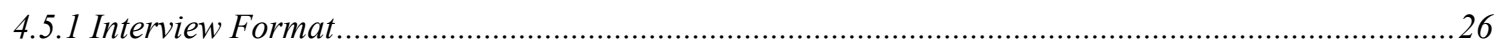

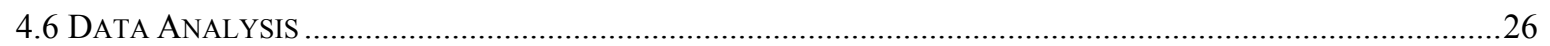

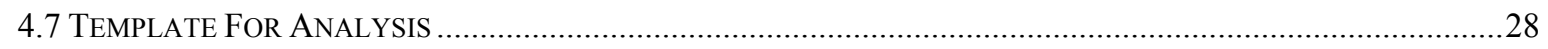

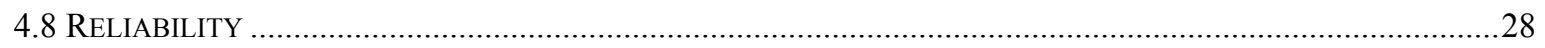

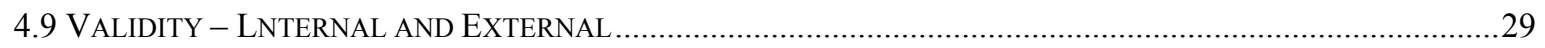

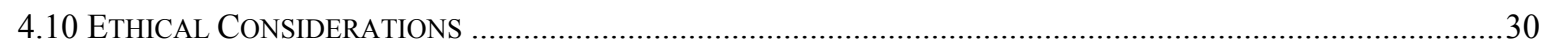




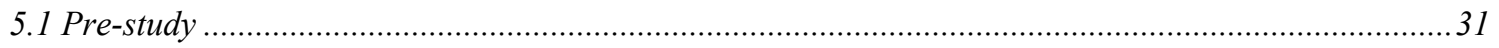

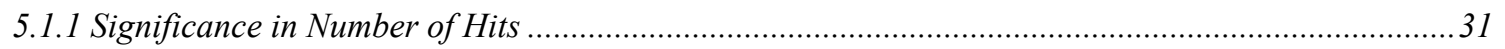

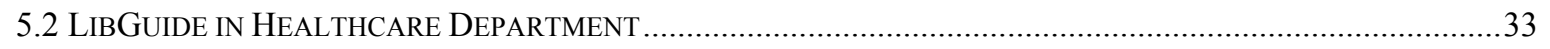

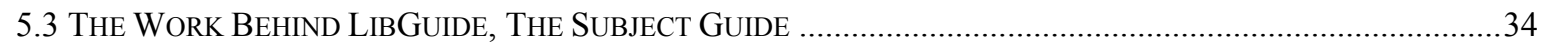

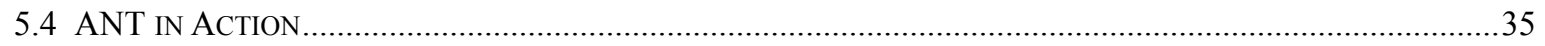

5.4.1. Problematization - Definition of Actors and How OPP Was Established........................................36

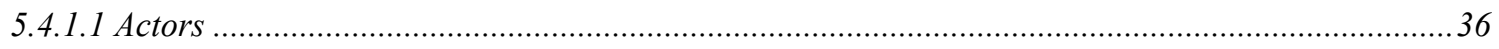

5.4.1.2 OPP - Obligatory Passage Point: What Bonded Actors to Use The LibGuide ...............................37

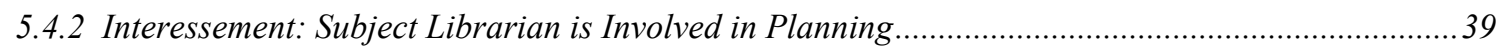

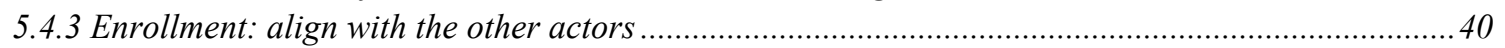

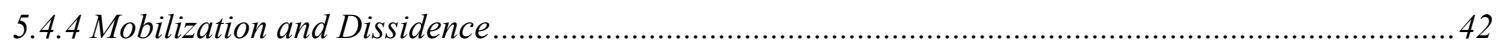

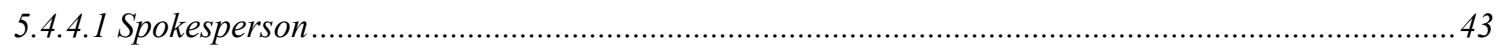

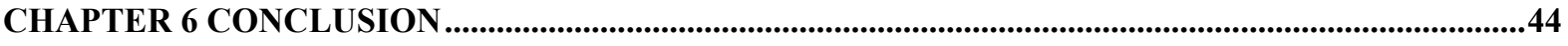

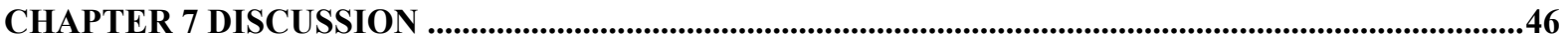

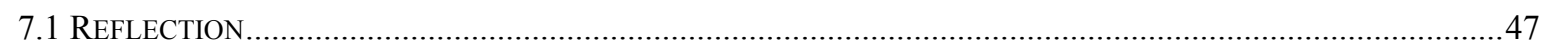

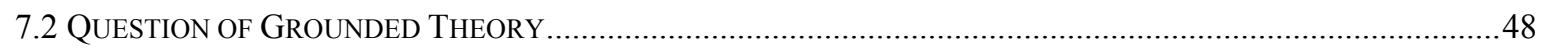

CHAPTER 8 LIMITATION AND FUTURE RESEARCH ................................................................49

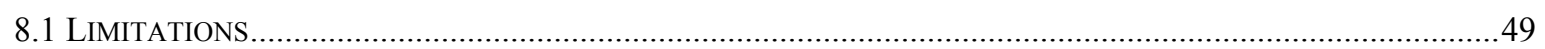

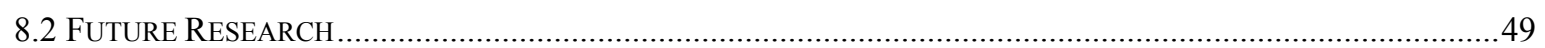




\section{List of Figures and Tables}

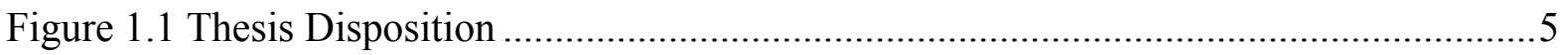

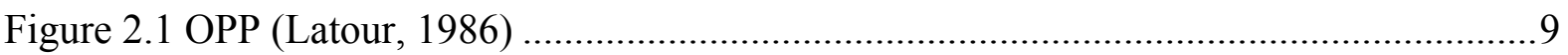

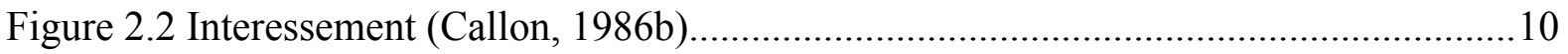

Figure 4.1 Hermeneutic-circle (Boell \& Cecez-Kecmanovic, 2010) ...................................23

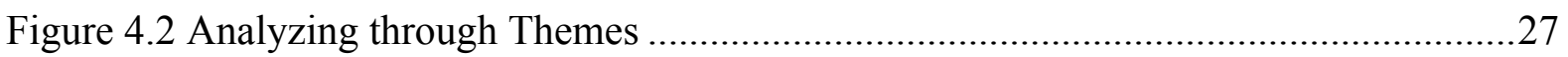

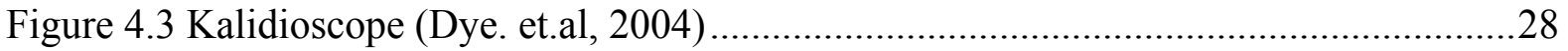

Figure 5.1 Toolbar for the HealthCare Departments Subject Guide .....................................33

Figure 5.2 HealthCare Departments Subject Guide's Frontpage ...........................................34

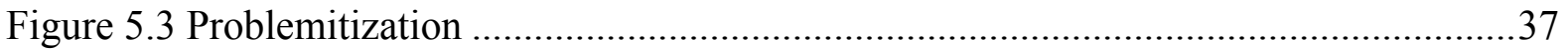

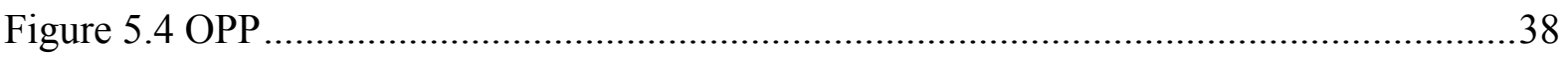

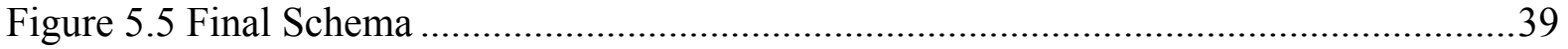

Figure 5.6 Involvment of the Subject Librarian............................................................. 40

Figure 5.7 How Subject Guide's Enrollment mett the Interessement ..................................41

Table 2.1 A summary of Basic Actor-Network Theory Concepts (Walsham, 1997)...............7

Table 2.2 Moments of Translation (Callon, 1986b) …...........................................................

Table 5.1 HealthCare Departments Subject Guide's Content ..............................................33

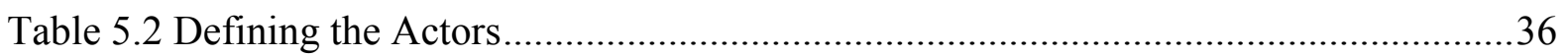




\section{Appendix}

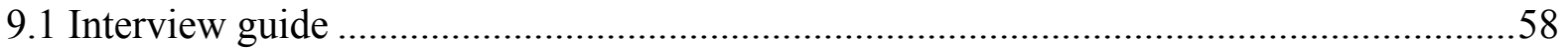

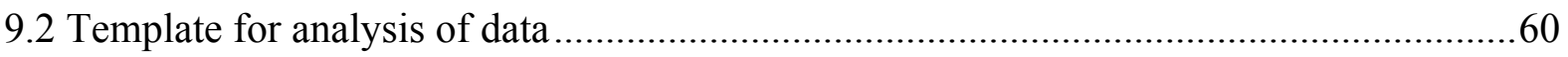

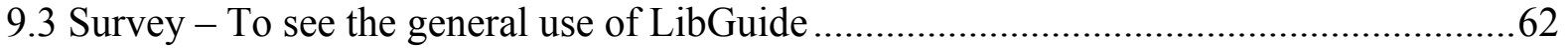

9.4 Survey - To see the use and impact of LibGuide for healthcare students .......................63

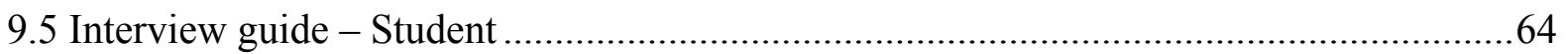

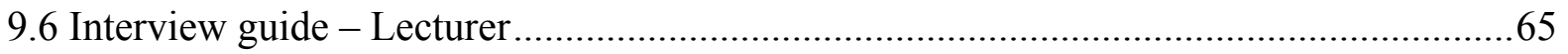

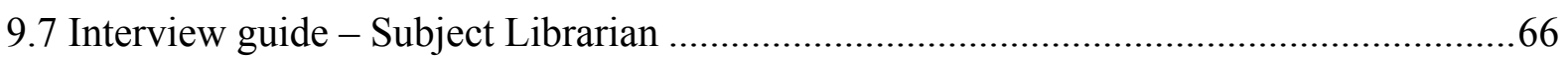

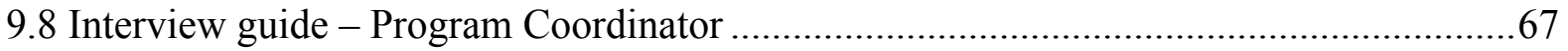

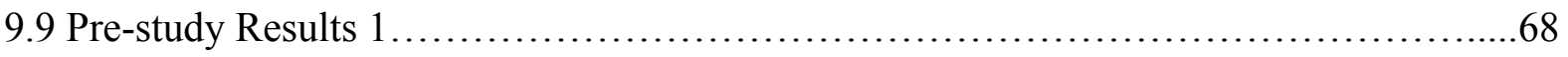

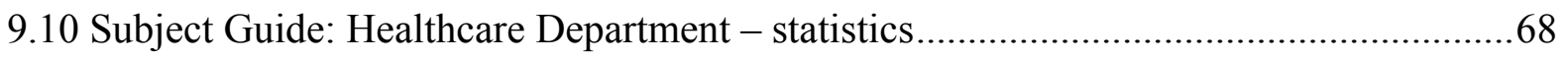

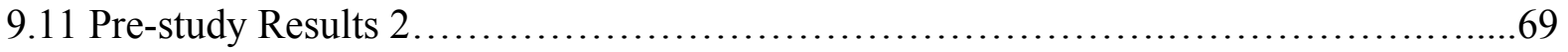


This chapter will give the reader an introduction to what the area of interest is, a description over the captured problem area, the research aim and objective and its limitation

\subsection{Introduction - Research Setting}

The academic library of any University plays a vital role in the students learning. It's primary a service which aims to support the learning and teaching activities by supplying access to a variety of information resources, hard, soft and digital (Pinfiled, 2001). According to Johnson et.al (2010) the definition of what we refer as the classic term library has evolved through time. The traditional meaning of the term only pointed at a physical space where thoughts could be shared and discussions to be held. Today's view of an academic library is much broader then before. The space has become more of a community driven where technologies plays a vital part in supporting the collaboration between the actors involved. Schultz (2010) talks about the library in a higher educational institution as a multidimensional context where we today have a multidisciplinary learning process that yields in the improvement of the individual student achievements and attitude.

With the evolvement of the academic library came also the role of the subject librarian (Martin, 1996). The responsibilities of the subject librarian has always differed from institutions to institutions. Martin (1996) lists a number of responsibilities that each subject librarian should be associated with. Some of them are user education, which refers to the introduction to the library for the newcomers in the university and the possibilities of interacting with the subject librarian during their time there. Other responsibilities comes with managing collections, which refers to as Martin (1996) states:

\section{“looking after a 'subject area' or 'subject floor', binding administration, conspectus activity, relegation of material etc" (Martin, 1996, p. 162)}

And maybe the most important of them all, to liaison with users: To focus on a particular set of students from a specific department with a specific area of interest. Pinfield (2001) describes in his article how the role of the subject librarian has changed over time. The author claims that today there is much more emphasis on the liaison. Old subject librarians expected that the users would come to the library for guidance, but however the new approach of the subject librarian is more aligned to "getting out there" instead of expecting the users to come to them. Instead of calling them a subject librarian, Pinfield (2001) would like to refer to them as learning advisors or liaison librarian which is more aligned to their interest today, to interact more closely with the users not only face to face but also through Web 2.0 technologies such as LibGuide. One of many ways to create a closer relationship between the users and the subject librarian is through technical tools as web 2.0. These web 2.0 tools play a highly important role for every library which is connected to a University nowadays and they are referred as LibGuide. Reeb \& Gibbons (2004) conducted a study to see how well students relate to LibGuide. They discuss that LibGuides can help librarians to introduce students to library materials and assist them in their search for information. In their research they examined and identified the reasons why students are disconnected that much from this discipline. Moreover, they discuss that subject librarians "reduce the workload by standardizing answers for complex questions". In their research they also referred to a recent research which was conducted by Emily \& Jackson (2004) at Duke University Library which illustrates the misalignment between students mental model of content and subject guides. They mention in their research that: 
" 53 percent had "never" used one of the libraries' Web subject guides, with 24 percent reporting use "rarely" (Emily \& Jackson, 2004, cited in Reeb and Gibbons, 2004, p. 124)

Moreover they also investigated how many hits the subject-guide content management tool got in the month of April in two universities. The result proved that there was a clear missing relationship here as well. Ken Klippel, a web-coordinator at Australia's University of New South Wales and Reeb \& Gibbons (2004) showed that 92.5\% of the subject guides received less then 300 hits during a month. This research was conducted in a University which had over 40.000 students and 160 subject guides. Yet another study by Reeb \& Gibbons (2004) in an American University with over 28.000 students received only 289 hits during the month of April.

\subsection{Background and Problem Statement}

The increasing focus of Web 2.0 technologies in libraries and the diverse scholarly written articles about this phenomenon which contributes to enhancement of students' learning inside academic institutions, has been debated in recent years among different researchers and academics (Perrone, 2005; Joint, 2010; Bryant, 2007). As a result, these technologies have been used significantly in a wide range in institutions. However, the impact of these technologies has always been studied in polarity, putting too much concern on either technological aspect of these tools or their social impact (Ouellelte, 2011 Morris et.al, 2010). This thesis, in contrast, aims to study how technological and social aspects can be investigated in parallel or how this particular technology is socially constituted. The thesis deals with social and technological aspects of Web 2.0 tools as putting them in the same level when investigating their impact. Apparently, having this perspective on technology, forces us to understand the interdependencies involved in social and technological aspects of reality. In this sense, we are ought to deploy a theory which rejects the priori notion of technology as something which we normally take for granted without any further investigation.

In a preliminary observation and interviews that we had with librarians, lecturers, program coordinators and students, it has been identified that the application is not used as frequent as it was meant to be. Students, from the other side are not motivated to use the technology as frequent as they are supposed to do. They are basically go to the lecturers and mainly read from the literature provided to them by teachers. Students, while finding relevant articles, do not usually ask for the help of their subject librarians who are physically (face to face) or remotely (using their subject guide) aim to assist them to find relevant literature as well as helping them with other questions. Subject librarians are expert in finding relevant resources which can help students to leverage their knowledge. They are trained to be in the right position and would serve the right amount of subjects which are assigned to them. In each subject guide page, each subject librarian posts relevant materials about the materials that students are studying. After our investigation, we found that, no matter how qualified the lecturers are, how elite students can be, LibGuide is an application which can dramatically help students in finding their relevant materials.

Having this in mind, we will neglect the presupposition that technology is something self-regulated which heads towards its very predetermined purpose without any intervention of social influences. In order to accomplish this premise, we chose to investigate the academic context of Linnaeus University, in Vaxjo, Sweden. Our main concentration, was a Web 2.0 technology that the students are practicing, named "LibGuide" as one of the socalled applications that has been used in the university's library webpage since 2010. The initial purpose of having this technology was basically evolved around the idea that, students from specific departments and program courses should be assigned to a person who is 
referred to as "subject librarians" according to Martin (1996), as an Information Liaison who is responsible to guide students in their current learning activity with the help of the technology in hand which was LibGuide.

As mentioned above, this thesis aims to adapt both technological and social perspectives of using an application. Thereby, a suitable theoretical framework had to be chosen to study both technological and social constitution in the process of understanding the implications of this technology. We argue that the use of a technology such as this is a sociotechnical system which subsumes human and non-human actors. Callon (1986ab), Latour (1987) coined the theory of Actor Network which criticizes the dominance of technological determinism by unearthing the social impacts of them. Human and non-human actors are what Callon (1986a) states as "actants", which comes from semiotics under the idea of interchangeability of things and people like a fairytale in folk tales and myths. This idea is in hope to produce an indispensable network of several actors involved and their interrelation which gives meaning to the LibGuide through inscription, translation and irreversibility.

\subsection{Aim and Research Questions}

This thesis aims to focus on relational controversy about the causes behind the decline in number of students who use LibGuide inside the Linnaeus University in Växjö. Relationships and interests of the individuals which form how a particular application is used and maintained effectively will be examined. We claim that how the LibGuide is being used, is a socio-technical term, hence it justifies using a theoretical lens which contributes to both social and technical aspects. We identify a network to understand first the misalignment of interests among any possible user of such system and how it created problematic situation, as well as how the chosen framework as a lens helps us to balance these interests and as a consequence creates a sustainable use of LibGuide. The thesis discusses that the integration and the alignment of the so-called users contributed to the more efficient process of using an application. The thesis complies with its promise, by negotiating individuals' roles and interests with a narrative manner who/which made an ally in constructing the network. Clarifying them, the need for change in the future use of such applications will be discussed.

For our purpose, we had to focus our study on, (1) to identify the actors and their interests during the process of introduction to LibGuide and subject librarians (2) to understand how these interests from actors can be inscribed into the use of such technology inside university, (3) to identify what policies was imposed in order to get the best out of what we try to investigate.

Also as an aim of this research is to illuminate how the use of LibGuide had become a common practice or in other words, how LibGuide had become sustainable in a particular department. Moreover, what made those policies and regulations achievable? In this regard, we use historical fact-based data using LibGuide in department of Healthcare by constructing a network of different users involved. This thesis, at the end describes what actions, regulations or strategies the Healthcare's department took in order to balance the interests and as a consequence constructed an acceptable network.

Considering the aim and purpose of the study, the research questions this study answers is:

Rq1. What policies and strategies made the role of LibGuide solid in Healthcare department?

Rq2. What influences did these policies and strategies have on actors' behavior in the construction of an actor-network? 


\subsection{Justification}

This research is worth pursuing since its approach in understanding the social influences of using technology is what makes it significant. There is no societal problematic situation which does not have any technological impact, nor the other way around (Howcroft et.al 2004). Many pedagogical researches have conducted the use of Web 2.0 technologies in universities to prove that these technologies can contribute to better learning, knowledge sharing and right use of references when students or academics perusing their literature (Gardois, 2012; Wang, 2011; Anttiroiko, 2011; Humrickhouse, 2011). From the other hand, these applications in terms of sustainability have also been studied from technological perspectives in diverse use and different organizations (Baue, 2011; Shepherd \& Aagard, 2011; Eccles, 2010). But what based the idea behind this research would be to think of how a Web 2.0 application in the context of a university library can contribute to something out of the box of regular pedagogic studies, and therefore to understand it from an information systems perspective. This way of visioning the use of an application, will apparently forces us to look at a university library more than a learning environment, but to think of it as an organization which has societal and technological sides. Therefore, in this research, classic way of looking at a library as a place just to learn and practicing literature would shift into an organization constituted by both technological impacts and social behaviors.

\subsection{Delimitation}

The scope of this research is bounded to the premises of its research questions. This research does not aim to enhance the essence of learning experience by just proposing how the certain technology is used, but to show that the certain socio-technical activities are hidden, or not gained enough attention while the actors are to be put inside a network of interests. This basically makes this research distinctive from the pedagogical or library studies, since it construct the network by its very Information System's theoretical framework. Answering the research questions would also contribute to understand how the social and technological aspects of certain activities might lead to better construction of Information System artifacts.

The other limitation comes from the identification of the actors who represent their interests. The research's time plan bonded us to certain interviews we could get to complete our research question about what we claim. Infromants apparently speak on behalf of themselves, and to generalize their true intention was an endeavor. Another important delimitation was the fact that different actors posed different gestures when talking about socio-technical phenomenon. For many of them, establishing a balance between these two terms was indigestible while compiling their interviews.

Another hard task was the fact that conducting the research on a phenomenon which asks us to claim no prejudice on either social or technological aspect of the artifacts. Finally, LibGuide as the technology could not represent itself by language, so we had to choose a person who could represent this application well enough to comply with the promises of the chosen theoretical framework. 


\subsection{Disposition}

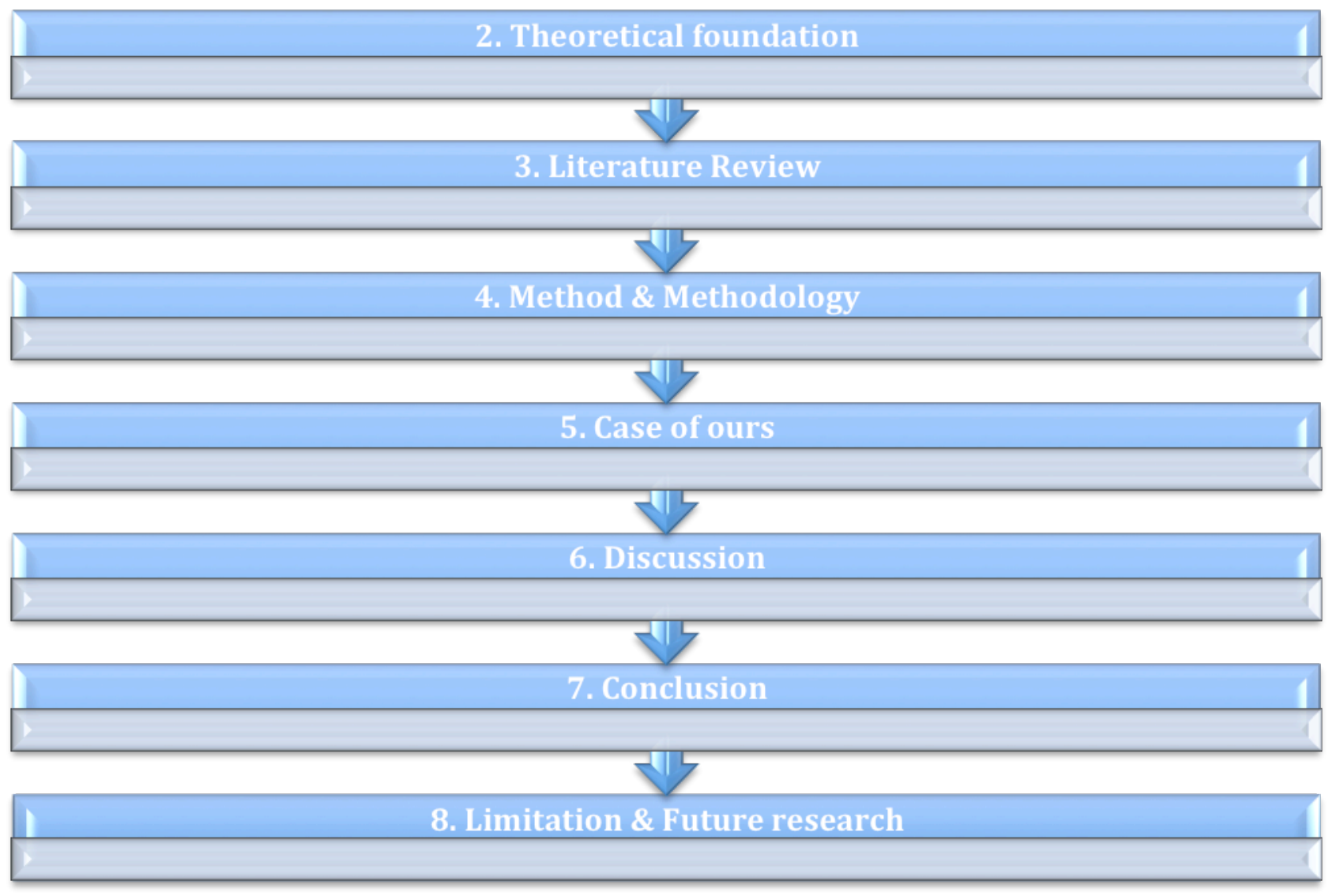

Figure 1.1 Thesis Disposition

The thesis has a containment of eight major chapters where we first start off with an introduction to the area of interest which includes a definition of what we define as the problematic area with some complementary statements done by other researchers in the same field. Moving on, chapter two is mainly an introduction to our theoretical lens, the ActorNetwork Theory (ANT). There will a definition over what this theory includes and the theoretical definition over its concepts and terms. This brings us to the third chapter and in this part of the thesis will we provide a brief overview to the reader of how ANT has been used in the field of Information Systems by giving a summary over different researchers work. In chapter four we will there go over our choice of methodology and the method in practice, areas such as what our methodological approach is, our techniques for the data acquisition and many more. The fifth chapter provides the reader with an explanation of how the theoretical lens was applied in our case and a presentation of the empirical data through the perspective of ANT. Moving on, the final three chapters of this research explains our thoughts as researchers through this journey, we will reflect upon our choice of methods to conduct the research, strengths of the theory of choice and much more. The last chapter provides the reader with an insight of what we found of suitable future research topics that takes on where we stopped. 
This chapter gives a historical background about the creation of Actor-network Theory along with a definition of its different concepts. These concepts will be discussed and explained as well as the stages that should be undergone.

\subsection{Introduction to Actor Network Theory}

Actor Network Theory is an interdisciplinary theory, which encompasses both social and technological sciences that coined from the writings of three researchers in science and technology studies: Bruno Latour (e.g. Latour, 1987; 2005), John Law (e.g., Law and Callon, 1992) and Michael Callon (e.g. Callon, 1986a; 1986b), who discusses how technologies have social aspects (Callon,1986b; Latour, 1987). Actor Network Theory (hereafter, ANT), examines the dynamic of actions by different participants who are involved in a procedure to construct a network and it offers translation, inscription and irreversibility which underpins the activities of the actors (Ruikar \& Pei-Chia, 2012). Translation includes non-sequential stages that Callon (1986b) interprets as moments of translation, which filters and distils loads of data in order to maintain a focus in processing a stable network. Stable network according to Whittle and Spicer (2008) is the one which its actors remain faithful to their promises.

Translation is about taking someone's (human or non-human) interests and translating them in such a way that a sociotechnical artifact is the solution (Walsham , 1997).

What is of interest in ANT is what different actors become when they are allocated in different positions inside a network of aligned interest. It is, therefore, a determination of their powers and responsibilities according to Greenhalgh and Stones (2010), from the interplay of configuration in humans and non-humans. According to Bled et.al (1992), in ANT actions are no longer identified as a mere representation of a particular intention but, rather, as a construction of the relations which occur in real life situations. The best way to understand the term 'actor-network' is to think of it as a network constituting the agencythe capacity to act or make difference according to Castor and Cooren (2006) - of some actor rather than as a network consisting of actors" Bruun \& Hukkinen (2003, p. 104). Callon (1986b) forged the definition with three fundamental principles for ANT: agnosticism (impartiality of a researcher towards humans and non-humans), generalized symmetry (researcher's commitment to treat humans and non-humans equally), and free association (eschewing separation between humans and non-humans) (Callon, 1986b). ANT researchers account for both human and non-human actors, investigating them from the same standpoint and treating them equally (Effah, 2012).

In ANT, firstly, actors' aligned interest, is identified and since these actants Callon (1986b) who allegedly refer to technology, people, routines, trainings, skills etc, as nonhomogenous natures are in interaction, then a heterogeneous network is created in which the interests of all parties involved is margined (Walsham, 1997; Latour, 1987; Callon, 1986b; Tatnall, 2009; Law, 1991). Heterogeneous network of aligned interests is what Mingers and Willcock (2004) discuss as the interest of both material and non-material to build alliance, as actors interact with each other to build a network through the process of translation. As a consequence, the interests of allies during the network construction will be transformed.

The final results of the translation which was mentioned earlier will be inscribed into the technological artifacts which is/will be used in the context. Inscription is a process in which scripts of actions and behaviors are imprinted inside technology (Sarker et al., 2006; Shin et al., 2010; Cressman, 2009). Many authors such (Akrich, 1992; Leonardi, 2009; Rodon et al., 2008) also discuss inscription as embedding these actions into technologies. Holstrom and Robey (2005) in the information systems discipline describe inscription as a lens with which actions and roles of individuals inside a network can be examined through 
different medias such as software, hardware, standards as well as process and procedures. Greenhalgh \& Stones (2010) found inscription useful for investigating a change in the behavior of a social practice which involves information technology. Since ANT believes that technology can not be isolated from its social aspect, then the technology is something which can not be detached from the social either (Ruikar \& Pei-Chia, 2012). This emphasizes on the socio-technical ground which is crucial to understand the use of technological design and its evolution trajectory for an application's sustainability as a socio-informatic system. We will illustrate the terms frequently used by ANT researchers since it draws on a number of concepts. The fundamental ones are summarized in table 2.1 A summary of Basic ActorNetwork Theory Concepts. It is worth mentioning that, this thesis uses not all of these terms since the use of them depends on the setting and the circumstances of the study. For instance, this thesis focuses on actants, actor-network, enrollment and translation, delegates and inscription.

\begin{tabular}{||l|l|l|}
\hline Actor (or actant) & $\begin{array}{l}\text { Both human beings and nonhuman actors such as technology, } \\
\text { people, culture etc. }\end{array}$ \\
\hline Actor-Network & $\begin{array}{l}\text { Heterogeneous network of aligned interest, including people, } \\
\text { organizations and standards }\end{array}$ \\
\hline Enrollment \& Translation & $\begin{array}{l}\text { Creating body of allies, human and nonhuman, through a } \\
\text { process of translating their interests to be aligned with the } \\
\text { actor-network. }\end{array}$ \\
\hline \hline Delegates and Inscription & $\begin{array}{l}\text { Delegates are actors who "stand in and speak for" particular } \\
\text { viewpoints which have been inscribed in them, e.g., use of }\end{array}$ \\
\hline \begin{tabular}{|l|l|l|l|} 
LibGuide in learning experience. \\
\hline Irreversibility
\end{tabular} & $\begin{array}{l}\text { The degree to which it is subsequently impossible to go back } \\
\text { to point where alternative possibilities exists. }\end{array}$ \\
\hline Black Box & $\begin{array}{l}\text { A frozen network element, often with properties of } \\
\text { irreversibility }\end{array}$ \\
\hline Immutable mobile & $\begin{array}{l}\text { Network element with strong properties of irreversibility, and } \\
\text { effects which transcend time and place, e.g., software } \\
\text { standards }\end{array}$ \\
\hline \hline
\end{tabular}

Table 2.1: A Summary of Basic Actor-Network Theory Concepts (Walsham, 1997). 


\subsection{How ANT Works}

Actor Network Theory, with its human and non-human equivalence, offers an interpretive framework as to how socio-technical 'humanchine' networks (humans and technologies as actors) convene, through translation, together at the behest of a prospective focal actor (Law \& Hassard, 1999). This consists of Callon \& Latour (1992) 'moments of translation' namely which involves the four stages which is explained in brief in the table below:

\begin{tabular}{||l||l||}
\hline \hline Mode & Description \\
\hline \hline Problematization & $\begin{array}{l}\text { lefining a problem for which a particular technology is a solution .A } \\
\text { focal actor, here, identifies other actors and their interests, proposes a } \\
\text { network 'obligatory passage point' (OPP) through which the actors can } \\
\text { accomplish their needs. }\end{array}$ \\
\hline \hline Interessement & $\begin{array}{l}\text { getting others to accept this problem-solution, when focal actor adopts } \\
\text { different tactics and strategies in order to make actors to accept the } \\
\text { innovation and the proposed roles. }\end{array}$ \\
\hline \hline Enrolment & $\begin{array}{l}\text { defining the key roles and practices in the network based on the outcome } \\
\text { of the interessement. }\end{array}$ \\
\hline Mobilization & $\begin{array}{l}\text { engaging others in fulfilling the roles, undertaking the practices and } \\
\text { linking with others in the network. }\end{array}$ \\
\hline \hline
\end{tabular}

Table 2.2: Moments of Translation (Callon, 1986b)

\subsubsection{Problematization}

In this first stage actors and their identities will be analyzed to create an obligatory passage point which underpins the network. Hence, this makes the actors inseparable or as Callon (1986b) claims indispensable, and be call it problematization which is a dynamic way of defining the problems in the identified problematic situation (Tineke et.al, 2010). Callon's (1986b) definition of problematization makes it even more clear when he argues that the problematization is not simplifying or reducing the problem into more constructed formulation but rather making sense of something which has a certain impact on both social and technological worlds. Tineke et.al (2010) also suggested that the word problematization is more appropriate amongst other candidate phrases, firstly, because the nature of problem is performance-based rather than perspective-based and secondly, the problem is not a single malfunctioning of a particular human or machine but something which happened frequently because practices are substantially dynamic (Tineke et.al, 2010). 


\subsubsection{Defining Obligatory Passage Point (OPP)}

Callon (1986) explain OPP as translating actors' interest in their required objectives can be solvable via technology, and if successfully established, will result to network stabilization. Callon (1986b) also discuss that the indispensability which was the result of an actors' gaining interest of others which can be named OPP. In this part, it has to be agreed by all actors that the plan that is about to be established is a common issue in the problematization stage. (see figure 2.1)

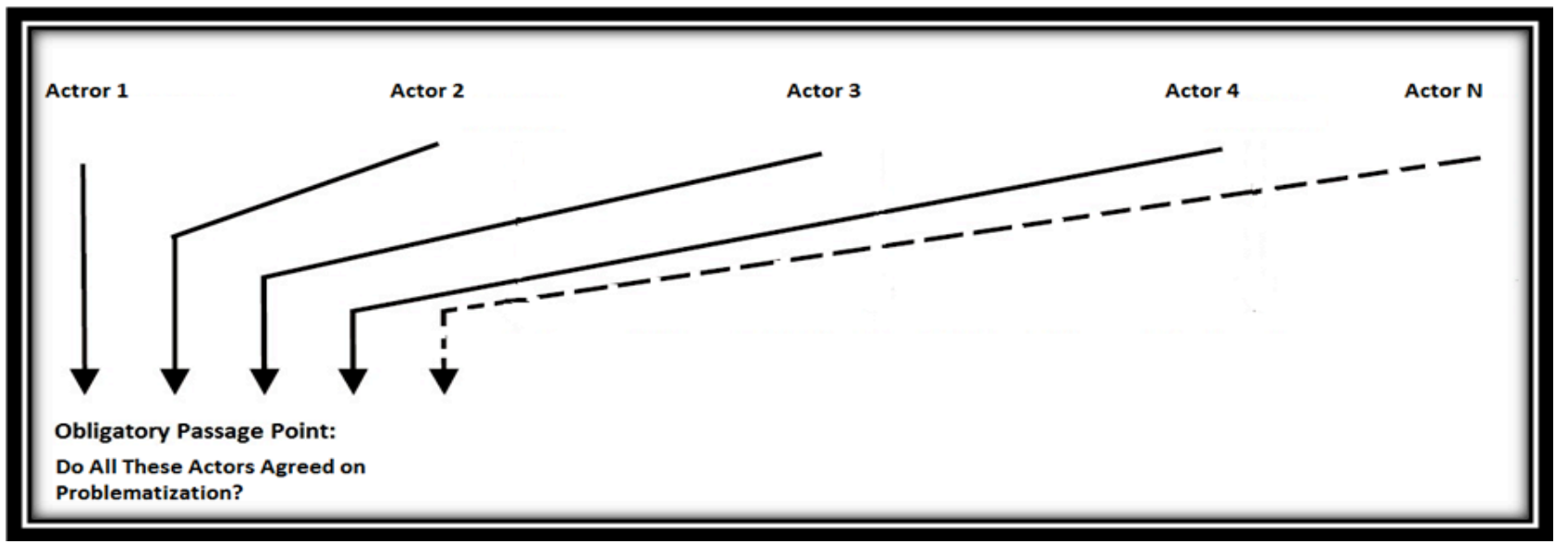

Figure 2.1 OPP Callon(1986)

\subsubsection{Intéressement}

Callon (1986b) explains the term as the set of actions and attempts which focal actor does to stabilize other allies through its problematization. This is basically what researchers have to do to persuade the actors which we find of importance in creating an stabilized network. Its identity is defined through the competitiveness. If an entity wants to interest the others to be ally with them in their goals, it has to establish itself in a connection in form of devices or actions with others and disconnects the other entities from giving certain definition to the targeted entity. Callon (1986b) calls this procedure between the entity that wants to interest another one, while disassociating other entities as triangle of interessement. Each entity enlisted as actor, has its own independent nature. They are either integrated to the scenario which is drawn or inversely avoid to be part of the purpose or the interest of the whole plan. However, as discussed earlier, it makes them void if we describe them independently, but rather we should investigate their roles inside their actions. The interessement whether or not happens to be successful, somehow shows that the problematization of finding certain alliance entities was valid (Callon, 1986b). 


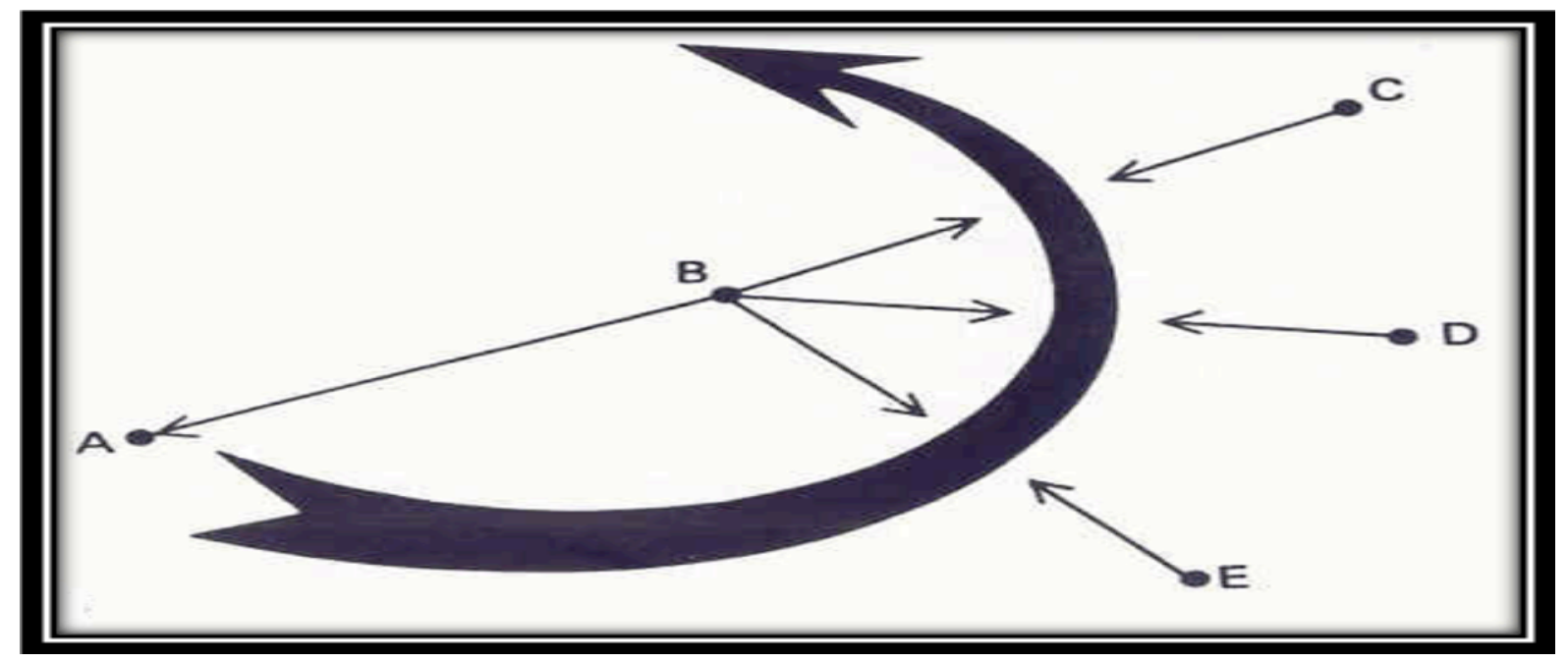

Figure 2.2 Interessement (Callon, 1986b)

Figure 2.2 illustrates how the interessement happens (Callon, 1986b). As shown in the picture, there are two actors of A, B and three distractive factors of C, D and E. A is the focal actor because it tries to capture the interest of actor B, hence, it tried to disassociated or makes the actor B reluctant to the interests, services etc. of the other actor. As can be seen, actor A draws a bold arrow which here represents the detachment of B from other actors' interests.

\subsubsection{Enrollment}

Enrollment can be explained as rounds of multilateral negotiations; trials of a strength and tricks according to Callon(1986b), by which the different actors commit themselves to the proposed interessement by discussing the elements of their strategies (Bled et.al, 1992). This is basically a phase during which the focal actor takes a set of strategies to ensure the actors actually accept and take on their roles no matter how convincing the arguments are (Callon, 1986b). The proposals which are derived from the interessement phase should now spread from the focal actor and evaluate it in terms of whether or not the proposed plan is accepted or denied by the actors in the network and if the roles of different actors can be coordinated. Zhan, A et.al (2010) also discusses these negotiations as discussions between actors to convince them to accept their roles inside the network. Walsham \& Sahay (1999), also discuss that enrollment is created from sufficient body of allies so that the actors will have willing to participate in particular way of thinking or acting in developing and maintaining the network. Koch (2001) also describes enrollment when he believed that the interessement was based on a change and that when actors are enrolled in a coalition, it is likely that the content of change program changes. Change programs emerge from the intentions of the actors in the network and the setting in which the network is constructed. 


\subsubsection{Mobilization and Dissidence}

Callon (1986b) discusses that to mobilize, as the word indicates, is to render entities mobile which were not so beforehand. This is the stage where the actors interests are displaced in favor of network's need. Law (1986) describes how mobilization materializes the physical reality through the displacements. By displacement, one would think of having the concentration of one single interest. Zhang A et.al (2010) also discusses that in this stage actors should act according to what they promised in focal actor's problematization. The authors explains that mobilization is based on the representation. Which means whether or not a certain spokesperson of a single group or portion represents the whole group rightfully. The challenge is followed by dissidence idea that emphasize that the actors may betray to the promise that they agreed on. Callon (1986b) brings forward fundamental questions about the representation. He asks who speaks in the name of whom? Who represents whom? Callon (1986b) continues that these questions should be answered if the network is to be stabilized. While these questions are being answered during mobilization, the network gets established as actor's interest aligned. Moreover, the enrolled actors after becoming spokespersons, persuading more actors to join the network.

\subsubsection{Spokesperson}

Spokesperson is what Callon (1986b) states as the representatives. He argues that this representation is focal actors' transactions with the actors involved in the network. It is in other words, not the whole mass of actors who/which are convinced by the problematization but some representatives who actually agree on proposing plans, or at least support the idea of the research. Nonetheless, few people or entities will show interest in the name of the masses they represent. The focal actor forges a relationship with those who only represent their whole community or mass. Representation in language of ANT means the ability to express yourself. This is basically an issue when a non-human is incapable of speaking on behalf of the mass it represents. Therefore, the human spokesperson is expressing themselves by speaking but non-human mass can only be representatives. Latour (2004) discusses this representation to the extend of political rights that non-human actor have, as well as what parliament of things look like.

\subsection{Critique of Actor Network Theory}

Further on, we argue two important criticizes that ANT researchers quote about the theory. The reason for such debate is to understand that any theory despite being very strong could be used absurdly if the strengths and weaknesses are not understood in advance. The criticizes will apparently helps us to use the theory in more comprehensive and critical manner.

\subsubsection{Ongoing Debate About Power}

One of the most controversial challenges between ANT researchers can be projected through ANT's commitment to 'radical symmetry', which is the result of visualizing the power of humans and non-humans as equal, ambiguous and debatable (Whittle \& Spicer, 2008). An early critique of the power was debated in Amsterdamska's (1990) review of science in action called "Surely you must be joking, Mr. Latour". Her point was that ANT, by its nature only studies the interests of the powerful (the focal actor). As Callon \& Latour (1992) state, there is no agential priority between human and non-human which means a machine can 
presumably be thought of having the very same degree of agency as a human. Moreover, as Whittle \& Spicer (2008) discuss, a symmetrical network acquires a heterogeneous engineer Law (1986) who collects and puzzles all materials and non-materials to form a stable network and has to make sure that the actors do not betray to their roles and promises. To make sure that actors do not step back from their positions and agreements, Latour (1987) proposes the "black boxing" strategy by which the actors are ensured to be enrolled in the existing network since they are enlightened that the cost of other alternatives will be high (Latour \& Woolgar, 1986). ANT, therefore, as Mutch, (2002) argues, the idea that natural objects and man-made artifacts have certain 'real' properties that justifies their actions, neglecting that those artifacts are actually made by human in favor of what they want to achieve.

In practice, a focal actor, therefore could have not been granted by any authority or power if we had only resorted to the fundamental ANT's ontology and as a consequence the research would end up in actors' deciding for themselves, each one picking a different path which in no way could satisfy the initial steps in moments of translation such as interessement in which the focal actor should impose norms or regulations to form the foundation of the network. Therefore, assigning the notion of power to the focal actor which holds certain authorities is inevitable to make a robust network. The lack of dispensability in the focal actor's power is also criticized by:

"What could conclude that in ANT, power no longer has a central authority but instead travels across a number of concrete-contingent actor-networks. Power is therefore 'always local; in situ rather than transcendent'" (Fox, 2000 p. 859)

The word transcendent glooms here since many ANT researchers argued that an actor apart from its nature should surpass in terms of given authority over other actors to stabilize the network. Why ANT is neglecting power in the first place might be due to ANT's main concerns.

"ANT seeks to resist explanations that appeal to the essential characteristics of actors." Whittle \& Spicer (2008, p.129)

It seems that it is not a premise in ANT to explain if an actor's behavior is the cause of its natural intrinsic. For instance, a technology do not make decisions until it is socially asked by its users and this is the nature of a particular technology to act according to what is being asked from it.

\subsubsection{The Absurdity of Assigning Agency to Non-Human Actors}

Actor network theory, from perspective of many scholars misses the central notion of networking organization, such as "trust", "reciprocity" Alter \& Hage (1993, cited in Ruikar \& Pei-Chia, 2012). Therefore, as Engestro and Escalante (1996) state, the end users' interests might be considered at the early stages but not fully achieved at their favor when the network is frozen. ANT perceives the line between social and technical as a border of negotiations that assists researchers in balancing the concerns between agency and structure (Latour, 1999b). But many ANT researchers criticize this as stating that if a human would be an agent of technology, then the technology is only represented through human needs, hence, this can not be a legitimate representation of technological artifacts (Whittle \& Spicer, 2008). 
Moreover, ANT also exposes intention as a main force behind any individual human actions unlike materials who have no agency but only a behavior (Latour, 2005), which makes a key difference between human who is empowered with intention and a material world full of causal relations. Mutch (2002) discusses that while ANT invites non-human into the network, it displaces the definition of human characteristics as purposeful and meaningful.

"humans deserve ontologically distinct category for their ability to use language and other symbolic forms to interpret meaning." (Whittle and Spicer, 2008 p.621)

Their quote shows the challenge of Whittle \& Spicer (2008) in criticizing that ANT degrades the state of humanity to something which acts meaningfulness, which runs the risk of the intention of human to be considered void.

\subsection{The Choice of ANT in Our Research}

Translation within the field of information systems is found quite useful in investigating development of systems and their implementation and their use (Tatnall, 2009; Walsham and Sahay, 2006; Walsham, 1997). The development ANT was followed by the idea of heterogeneous networks of aligned interests. The actors who shape the network who have same interests in what they are achieving. This justifies why Callon (1987) states that the technology can not be developed in favor of social needs until its building is agreed among the actors who have the same interest in constructing it. The result of such consensus can be imprinted and as Callon (1987) states, inscribed into the technology which is required to tackle the issues inside a network. ANT, is not accused for its over-stress on social determinism, and believes that the social choices should not be selected in the expense of technology, and this is the best way to treat technology to see how it can be more effective and useful in hands. In other words, ANT refuses to resort itself in a form of methodological dualism which as discussed is making of a priori distinction between what is technical and what is not (Howcraft et.al, 2004). As the result, the choice of using ANT as a theoretical framework in the investigation of our case, can be well understood, and justified, since the rejection of so-called social and technological determinism and avoiding methodological dualism let us to look at the technology and social in the same scale without any prejudice or presumptions which apparently helps us in a unique way to open the black box of technology for sociological investigation.

As mentioned above, one of the efficient ways to see what technology truly brings us is to investigate it from social perspective. ANT, empowers our thesis with its sociotechnical perspective to understand what actors had done or what was the implication of their actions and the strategies of a focal actor to bond others in accepting something which strengthen the link between what we presume as human and non-human. With this, we can make sure that technology has a voice and it is to be heard by humans. The idea behind choosing such theory was basically embarked from our interest between natural and social sciences. Callon (1987) categorized natural science under what we studied as technology. We found this fact very appealing to what we were studying since technology could be a legit alternative to natural science.

\subsection{The IS field and ANT's Unique Contribution to it}

Hanseth et.al (2004) discuss in their article how actor network theory (ANT) contribute in its unique way to the field of information system (IS). The answer to this question first calls out for a definition over what the filed of IS stands for. According to the authors has there been a global discussion over the concept itself. There has even been some past claims that the field 
of IS cant be treated as a major discipline in the research field, however Baskerville \& Myers (2002) claims that the field of IS has now reached a level of maturity so it can be considered a reference discipline as many others which contributes to different filed of interest. In our case, we chose to define the field of information systems according to what Hanseth et.al (2004) writes:

"Research in the information systems field examines more than just the technological system, or just the social system, or even the two system side by side; in addition, it investigates the phenomena that emerge when the two interact" (Hanseth et.al, 2004, p. 26)

Hanset et.al (2004) wants to highlight the uniqueness with the field of Information System, this due to several misunderstandings that the field of IS should somehow imbedded in the field of Computer Science, which is not true. Information System is accepted as an own genre in the field of research (Hanseth et.al, 2004; Brooks et.al, 2008). Many scholars applied the structuration theory founded by Giddens (1984) as a lens to analyze and investigate upon situations where technology had been applied from a social perspective. However compared to the actor network theory there is a vital difference in-between them. The structuration theory doesn't address the role of technology instead it almost neglects it. ANT covers this gap by treating the technological and the human (social) equal in relation to each other and helps us to understand the relationship between them, and through this contributes in a way to the field of information system. Actor network theory offers a new socio-technical approach where you establish a network that is consisted of a number of actants and through its rich set of concepts helps us to explain why and how an actor acts in relation to the other actants involved in the same network (Latour, 1999a). In summary we believe that researchers that strives to examine the field of information system should not only focus on the technological system side of it or nor the social system side. The field of information system is often a merged context of these to systems and we agree with the writings of Hanseth, et.al (2004) that the actor network theory with its powerful concept can help us to understand the complex situation such as the implementation, development or the use of IS, when technology and social interacts.

There is a general agreement among both strategic management and information systems scholars that process studies provide better understanding of how and why things evolve over time (Langley 1999). We argue that ANT is a qualified theory to illuminate the strategy implementation processes since recognizing that actions drive the processes requires not only the human agency but the collective agency of both human and nonhuman actors (Karyda et al. 2005). 
In this chapter, the use of Actor Network Theory and its eminent role in scholarly written literatures in Information System's field will be described and explained. Later in this chapter, we define the concepts and their theoretical definition to the reader.

\subsection{IT Alignment Through ANT}

Martins (2009) used the ANT as the underpinning theory to analyze the sustainability of the IT governance, or what they call as ITGOV. In his attempt to find the balance between the different interest of the actors, he discussed that the long term decision making for IT governance is something which can be analyzed better in the network of aligned interests. For instance, when an application or software (actor), is introduced to a user (actor), they might refuse to utilize it, and this might be diagnosed when the role of each actor is designated inside a network.

Martins (2009) depicts a comprehensive step-by-step walkthrough of how ANT is practically used. The researcher found that the university's significance is in the majors of Computer Science programs. Students and teachers frequently complained about the low memory capacity, as well as the computer processors' speed. This case was basically studied in the computer laboratory. They defined the IT cycle of the university, including all actors (human and non-human) without any discrimination on their nature. Thereby, they portrayed the whole cycle and the actants and their relationship followed by the identification of the focal actor which in their case was the head of computer science department, who was also in charge of the computer laboratory. Therefore, the first stage of the ANT is done through problematization.

The head of department (the laboratory manager), had to buy the new equipments in order to comply with the requests coming from the students and the teachers about upgrading the computer systems. The campus manager, however, used to buy the computer systems from a local supplier, and this would basically ended up with purchasing low specification systems which would not satisfy the need of teachers and students. The head of department, here, had to convince the business sponsor to inscribe the supplier's new proposal in the system, which would apparently convince the campus manager to buy high spec systems. In the language of ANT, this is called interessement. Hence the interessement is not necessarily a device, which was basically the foundation of this term when Callon (1986b) described the towlines and their collectors which would seize the larvae's anchorage to the net, but a step ahead to convince the others by proposing a change which can gain others agreement. In his article they called it the approval stage.

In the next step of the analysis, the Dean of university should be enrolled and approve the proposal, despite the other competitors (universities) who wanted to be competitive in their region. The Dean refused to this investment since he believed the investment should not only be delegated to this department but all the other departments and current budget limits them to take this action. However, the decision was basically agreed to be approved but delayed. This meant to Martins (2009) that the enrollment phase did not acquire enough attention so it failed. This delay needed to be rooted back to identify the underpinning assumptions which made the delay in making the decision. Martins (2009) now, divided the actors who involve in decision making into two separate files. Business Team and IT Team. They conducted semi-structured interviews under the categories of IT Knowledge, Decision Profile and Level of Influence, each one by giving significant point to the actors whose answers prevail. At the end, they found that the IT Team as expected has better knowledge in IT field comparing to Business Team; Hence, the barrier to the decision is identified. 
Martins (2009) also found that the business team is not willing to assign prospectors to the problem and this yet created another barrier. With this clarification, the Dean and it's financial assistants, in particular, were gradually coped with the situation and the enrollment was likely to happen.

Once the enrollment achieved, all the actors saw their interests in the proposed plan. In ANT language, we can conclude that the network achieved its equilibrium and was now mobilized. As ANT claims, the final steps is to understand if the actors did not betray to their previous promise and this was also studied by a team of common users and revealed to be null.

\subsection{Customer Services Information Systems}

Mohammad \& Richardson (2007) also conducted a research from the ANT perspective, by providing the story of GM university's (UK) Information Service and Technology Division (ISTD) which was manly in charge of library services, ITdesktop services, PC hardware support, campus telephony network. According to ISTD management, the department was not able to carry out its required tasks efficiently, and the level of responsiveness to customers were not as it was ought to be. The management of ISTD basically blamed helpdesk call management service for being outdated and unsupportable. After some workshops and interviews, the consultant who was assigned to tackle the shortcomings of current system, convinced the management that the radical change is possible through a change program which they called customer resolution information services project (CRISP).

As ANT's initial prerequisite, the actants should be identified. After analyzing the interests of different actors involved, the consultant designated some actors like the senior management team, the software vendor, service support appHcation (SSA) and business support systems (BSS) packaged systems, ITIL standards, users group, ITIL training organizations, etc (Mohammad \& Richardsson, 2007).

The consultant later justifies his choice of actants by implying on what senior management asks a system to be. The effectiveness, of customer support, key performance indicator information, to migrate to activity-based costing to control the resource allocations were main objectives. Thereby, these aims would be in the same level of interest for other actors such as vendors, process management software, ITIL training providers and so forth.

The enrollment happened during the time different actors were introduced to the interests of the others. The article raised a very critical statement: ANT understands the strategy as an outcome of negotiation of interests between actors, rather than an outcome of rational decision making process. However ut depends on how one clocludes the analysis of aquired data. This well justifies that ANT captures the interests of the network as it is, not as its ideal performance, and this makes ANT notable in its approach. The device of interessement, while not indicated directly but, could be interpreted by the external technologies as something which brings more allies to this project and as the Director 1 mentioned:

"We also get external change coming upon us, not least technology. Technology continues to change at a vast rate and it is difficult at times to integrate this properly into what we do, and I think we have to acknowledge that."(Mohammad \& Richardsson, 2007, p.5) 
The reason behind choosing this article, if it was not solely based on how ANT was implemented by its translation stages, showed that the strategy content at the first stage could not be opened as a black box, and later on with contribution of other project manager who understood that the resources are not that much available and focused on internal organization's culture alongside the political environment, it was found that the radical change which was proposed by the former project manager was not something ephemeral and should be managed wisely. The second project manager criticized the first one with lacking conservation in its approach and having weak voice to persuade other actors in his process of negotiation. The article at the end claims that using ANT as a framework helps consultants to understand the insights into the process of implementation of strategic contents in a specific content. The major weight of this article was to illuminate the role of negotiation and how a black box could be opened for further investigation of building network of aligned interests.

\subsection{ICT Integration Program}

Elgali and Kalman (2010) carried out a research with the use of the ANT to conduct a comparison between the national and municipal program of ICT integration in the educational system in Israel. Their aim with the research was to investigate why the national ICT programs had such a high rate of failure aligned to it compared to the municipal, and in order to conduct this, the authors used the rich flora of concept that ANT provides you with in order to modulate the networks. Their empirical material consisted of an analyze of documents and policies as well as interviews with what they identified as the most important actants in the network. In addition to this, they tried to establish a sense over what differences there were in the relationships between the actants in two networks. The analysis proved that there was a significant difference in terms of relations between the actants. For instance: The national program compared to the municipal even lacked the interaction of an actant that was proven to be vital. Yet another factor that could have led to the high rate of failure for the national program was aligned how the teachers between the programs perceived the technology. One of the main strengths of ANT is embedded in its philosophy to put technology and humans on an equal level and to investigate the interrelations between them. In the municipal program Elgali and Kalman (2010) could identify a sense of pride and ownership to the computer while in the national program they identified a relation which was characterized by trepidation and antagonism. Elgali and Kalman (2010) also indentified a difference in terms of evaluation and assessment between the networks. The municipal system seemed to have a well documented history of evaluation for previous implementation while the national system seemed to lack of it. This is just a small chunk of examples compared to what was actually found in the study.

The presentation of the study was finalized in a visual presentation of the two networks. Elgali and Kalman (2010) had then mapped the relation between the identified actants and described the differences among them as well as investigating in the flow of information and several other aspects. ANT was in this research used to visualize and investigate upon two similar networks which were identified on different levels. The purpose with the network was the same, but the relation differed. ANT played an analytical role to see what factors that could have caused what the authors referred as a failure for the national system of ICT integration. Another aspect to highlight through this research is Elgali and Kalman (2010) discussion of the strengths of the ANT. They say that the theory is a perfect methodology to illustrate and unearth things that often is taken for granted in a sociotechnical context.

The outcome of the article showed that the power of an actor would be increased when the other actors in the network supports his/her believes regarding some specific issue. 
Yet another thing the article shows is that ANT is a theory that can be used to analyze the actors relationship in a network and try to reach a general agreement of the usage of an existing technology.

\subsection{Theoretical Definitions}

By conducting our literature review we came in contact with a number of other subjects we found of importance to define. What Web 2.0 is and what the theoretical definition of LibGuide and Subject-Guide is some of the terms a definition called up for.

\subsubsection{Web 2.0 Technology}

Tim O'Reilly (2005) the term and meaning of web 2.0 through an attempt of describing new ways of make use of existent technologies in everyone's everyday living. He ment that the Internet now should function as a platform which involved the end-users on different levels. Instead of only reviewing the material and taking part of it, O'Reilly (2005) had a vision that the end-users themselves should be able to produce, publish, criticize and interact with online contents. Hence Web 2.0 differs from the classic idea of creating a webpage or a forum. With the 2.0 technology a user does not need any prerequisite skills in web programming and publishing skills in order to participate. This makes it easy for everyone to communicate through the new technology. As pointed out before the functionalities are many and can be used in almost every context. For instance at the University are these tools used to communicate and reach out to the entire academic community involving students, teachers and administrators (Rajshekhar, 2008). Wikipedia is one of the most common examples of this. This is a perfect example where the participation of the end-users in a knowledge database that is possible to change by anyone who thinks they know better about a subject.

\subsubsection{LibGuide}

LibGuide, is a tool which basically has been used by more than 2000 academic libraries worldwide. It allows librarians to create high quality portals to quality researches. LibGuide, enables librarians to create content-rich multimedia guides (SpringShare, 2012). But does this technology help librarians? And if it is used, in what way they do they create knowledge? There are many tools and systems to create a web space for subject guide librarians, or in other words liaison librarians, which inhibits dynamic nature for those static interactions of earlier subject guides. One of these tools which is known recently and has received significant amount of attention is LibGuides. Foster et.al (2010) defines it as a content management system (CMS) with wiki-like features, allowing users to comment on the information, give suggestions for future content, and rate the material. It's an online service and therefore are there no needs to be monitored by an internal IT department. Lewis \& Griffin (2011) discuss that librarians as the main users of this system do not need to know any specific knowledge about programming like HTML, XML, etc. Sullivan (2010) explains that the features in display setting along the privacy can be set by the administrator of the webpage. Hamilton (2011) in her article challenged the need for having such system, by asking "what kind of teacher are you?". She argued that school librarian helps students to think better and be more motivated to read about their subjects. They help students to read and define what they want to know. She also discusses that library's earlier notion was to be an information center or a data warehouse and this view should be changed as participatory culture is something which is happening inside libraries. LibGuides are easy to use and expandable in scale according to Verbit \& Kline (2011). They also discuss that LibGuides 
offers two user roles with related access levels to create and manage content: administrators and librarians. Administrators have all the privileges to the system and hot to modify it in order to suit them better, but librarians only have permission on the pages which are assigned to them. Before using LibGuide, number of design settings should be selected. It is very user-friendly and different schemes of colors, fonts and any other layout can be chosen easily through option box menus. There is an API defined in the LibGuide which allows it to be linked to other systems like Blackboard or Moodle.

Once a basic page structure is set up, the page can be easily contain the contents of each course material. In LibGuides you can select boxes with predefined types of library content: links and lists, RSS feeds, podcasts, widgets, embedded media, search boxes, polls, user feedback, books from the catalog, etc (Verbit \& Kline, 2011).

\subsubsection{Subject Guide 2.0}

During recent years Web 2.0 Technology has gained great attention from libraries standpoint. Many other scholars have used this terminology in relation to libraries by inventing catchy disciplines like "librarian 2.0", "OPAC 2.0" Kroski (2007), or "Subject Guides 2.0" (Farkas, 2007). Prior to this, Subject Guide as a discipline was known to most librarians from early 1990s Yang (2009) and they were powerful asset for librarians to highlight subject-based library resources and to enhance the learning process in an academic organization Yang (2009). Like primary 1.0 technologies in Webpage development, subject guide was a static webpage written in HTML, therefore was not quite satisfactory in its user-friendliness. There is not much valued researches on how much this system might had been used in frequency, but they became obsolete just a while after it had been developed. It has been found that this obsolesce should not happen to subject guides 2.0 since it is believed to be from one hand, the IT-enabled learning process which prominent in information exchange, and from the other hand, librarians right use of the so called technology can enroll them as one key agent in the development of a healthy learning environment. Yang (2009) also discusses that this system is not yet used frequently and pessimistically implies on it as a decoration shelf inside libraries.

One of the most enthusiastic scholars who investigated on the need for using Subject Guides 2.0 is perhaps Meredith Farkas, whose contribution to this discipline can be found in her article "Long Road towards Subject Guide 2.0". She states that students are not using subject guides as frequent as their Liaison librarians ask them to do and metaphorically quotes that:

$$
\begin{aligned}
& \text { "for everyone, subject guides are more of a "when I have free time" sort of } \\
& \text { task" (Farkas, 2007, p.23). }
\end{aligned}
$$

This is perhaps lies behind the notion most students or possibly lecturers have toward the use of such system. It has been claimed earlier that if the librarians are exposed better in the learning process, better learning environment will yield inside academic organizations. As a consequence, the current Subject Guide which is implemented inside a University can be interpreted as a medium which fulfills this underrated link between librarians, students and lecturers.

It is not the aim of this research to explore the features within the Subject Guide 2.0 but they are just worth mentioning to illustrate the ideas behind the research rather better. There are 
numerous articles containing (Yang 2009; Andrychuk et al, 2007) who state the characteristics of a Subject Guide 2.0 as follows:

- Multimedia

- Multi-formats

- Collaboration

- Ease of Use

- Global Change

- Search Box

- Browsing

- Link Checking

- Social Bookmarking

- RSS Feed

- Tagging

In this chapter, we tried to understand how the ANT had been used in different literatures.

We also tried to illustrate the theoretical definitions of the terms we are using in this thesis in a frequent basis. These terms are basically what we found in other literatures which are solely describes the definitions independent of what we described in our case. This will be followed by methodology and the method we used to look at our context to investigate in and they way we collected our data. 
In this chapter the reader will be guided through our methodological decisions that have been made for the research. Our research will be divided into two major phases when it comes to the research approach. First will a literature review be carried out and secondly the empirical questions and analysis. The following text will discuss and arguer for our choice. But first, some reflections over the research field of IS.

\subsection{Research in the Field of IS - The Need of an Interpretive Research}

Propert (2004) interprets the works of Theodor W Adorno and raises the idea that the field of IS cant be viewed strictly as a positivistic or an hermeneutic context. Neither approach is enough to describe what he refers as the complexity of this field. The essence and meaning of the term philosophical worldview is explained by Lee (2004) as the way the world being perceived with an additional statement that there isn't a legitimate answer of what is the best way of perceiving the world, which leads us to the reasons why different philosophical worldviews exist.

Propert (2004) want to enlighten the reader that IS involves more then just the theory of computers and technology; it also involves the schools of social norms and political aspect as well as economics. By this complexity, the field of IS then needs a more interpretivistic worldview to it, to understand a specific context and its phenomenon, and suggests that the researcher should go in open-minded and chose the worldview based on the research question.

\subsection{Methodological Tradition - Hermeneutics}

Positivism and hermeneutics are the two major philosophical worldviews. They are divining in to several underlying worldviews. Positivism claims that all scientific researches are rooted in the same reality and that the outcome of a research reflects in one single absolute truth of the reality. The main goal of from this view is to come up with an absolute truth (Creswell, 2009)

Hermeneutics differs positivism in a variety of ways. One of the main differences comes from the fact that hermeneutics claim that the researcher can never conduct an objective study of the reality; each case is an interpretation of the world and that means the absolute truth does not exist. Instead the researcher interprets the worlds and bases their findings on that interpretation (Creswell, 2009; Johansson \& Liedman, 1993, Propert, 2004). The philosophical stand we chose to found our thesis on is grounded in the hermeneutic way of perceiving the world, namely the interpretivistic tradition. This is based on the arguments that the research aims to understand how the use of LibGuide had become a common practice or in other words, how LibGuide had become sustainable in a particular department

One of the main reasons why we chose not to base this research from a positivistic stance was due the fact that the context in each academic environment will differ among each other and through this it yields an interpretive approach to understand the particular context. Every different academic organization will have an unique understanding of how the world is perceived by them.

The interpretivistic tradition also rejects the concept of the existence of an absolute truth, which in our case doesn't exist. Bryman (2008) defines the interpretivistic tradition as a view that interprets another person's interpretations, which also can be understood from 
Walsham (1995) following definition of an interpretivistic researcher:

"Interpretive researchers are attempting the difficult task of accessing other people's interpretations, filtering them trough their own conceptual apparatus, and feeding a version of events back to others, including in some cases both their interviewees and other audiences" Walsham (1995, p.142)

\subsection{Choice of Method - Abductive Reasoning}

Charles S-P coined the meaning of abductive reasoning when he looked at the scientific process with a guess-based intuition and observation. What he referred as a guess here is one example of what an abductive reasoning stands for. Abduction is a definition / explanation for what might be and not the explanation of what is or what's been (Josephson \& Josephson, 1994). The choice of taking an abductive approach in this research, is based on the fact that it let us move freely between the boundaries of both inductive and deductive reasoning. Since our aim of this research is to explain through the lens of Actor-Network Theory what had happened in the case of the LibGuide will we take more of a focal point to the deductive side of abduction. In addition to this a deductive reasoning takes it ground in already established theories (Patel \& Davidson, 2003), and hence we used the Actor-Network Theory that was already established and verified as a theory. When we are dealing with empirical findings we lend more to the inductive way of reasoning. Abduction reveals the prevaricate discussion of using both deduction and induction (Josephson \& Josephson, 1994). This, however, meets the demands of this thesis, since the main idea of using a framework which is tested and confirmed scholarly in a dissertation is deduction. Meanwhile, the findings and the definition of different terms inside this theoretical framework, requires the researchers to define the steps inside this theory themselves, in order to makes sense of them. In ANT, usually it is the researcher who tells the story, then, they are defining the actors and their problematizations Latour (1987). The idea Josephson \& Josephson (1994) represents, illuminates the fact that the researcher's discretion is involved thought defining the whole network construction. This can be claimed that the researcher is limited to set the definitions in the theory themselves. Hence, making the process of the investigation inductive, since the researcher is inducing some factors to be put later on inside the theoretical framework. We can argue that when the inductive manner of defining the moments meets the deductive way of conducting the research by using a theory which is established already calls out for an abductive reasoning.

\subsection{Research Approach - Data Collection}

In the thesis we will deal with two sources of data, the one from literature and the second from our data acquisition. The following two parts called segment 1 and segment 2 will describe how we dealt with the data.

\subsubsection{Dealing with the Literature - Segment 1}

The first and prior task of the research will be to conduct a literature review over how the ANT has been applied in the field of information system and why it suits well in the context we aim to carry out this study with its research questions.

In order to manage this we first carried out what we referred as a theoretical analysis over a large scale of today's academic literature of actor network theory.

The approach we took on to look at the different sources of information came from Gadamer's (1976) idea of hermeneutics. Boland (1991) interpreted his work and claims that 
hermeneutics is an worldview that provides the researcher with a better understanding of how specific information is interpret and generates a lower level of abstraction of the functionality of information systems.

Yet another researcher that interprets the work of Gardamer (1976) is Boell \& CecezKecmanovic (2010), which, explains, that hermeneutics is mainly concerned with the process of creation of interpretive understanding. They claim that the nature of understanding a thesis or subject is never isolated; the understanding is a process of going through a number of related sources of information that in its turn influence the past understanding of the subject. Boland (1991) explains that when a researcher takes on a hermeneutic approach to understand a phenomenon it is vital to differentiate between the whole and the segments. To start off, it is necessary for the researcher to acquire some general information/knowledge of the organization that can be defined as the whole. Later on when the researcher goes into more specific detail such as annual reports and interviews is she or he going into depth/detail, which can be defined as segments of the whole. This interactive process of going back and fourth between the different thesiss (segments) is referred according to Boell \& CecezKecmanovic (2010) as the hermeneutic circle, where texts can be seen as a type of parts of a whole body of relative literature.

By conducting the literature analysis through the hermeneutic framework can we create and establish a "common ground" of how ANT theory has been used in the field of IS/IT and then interpret it to fit our claimed purpose to apply it and argue for the advantages of looking through the context by this lens.

\subsubsection{The Hermeneutic-Circle}

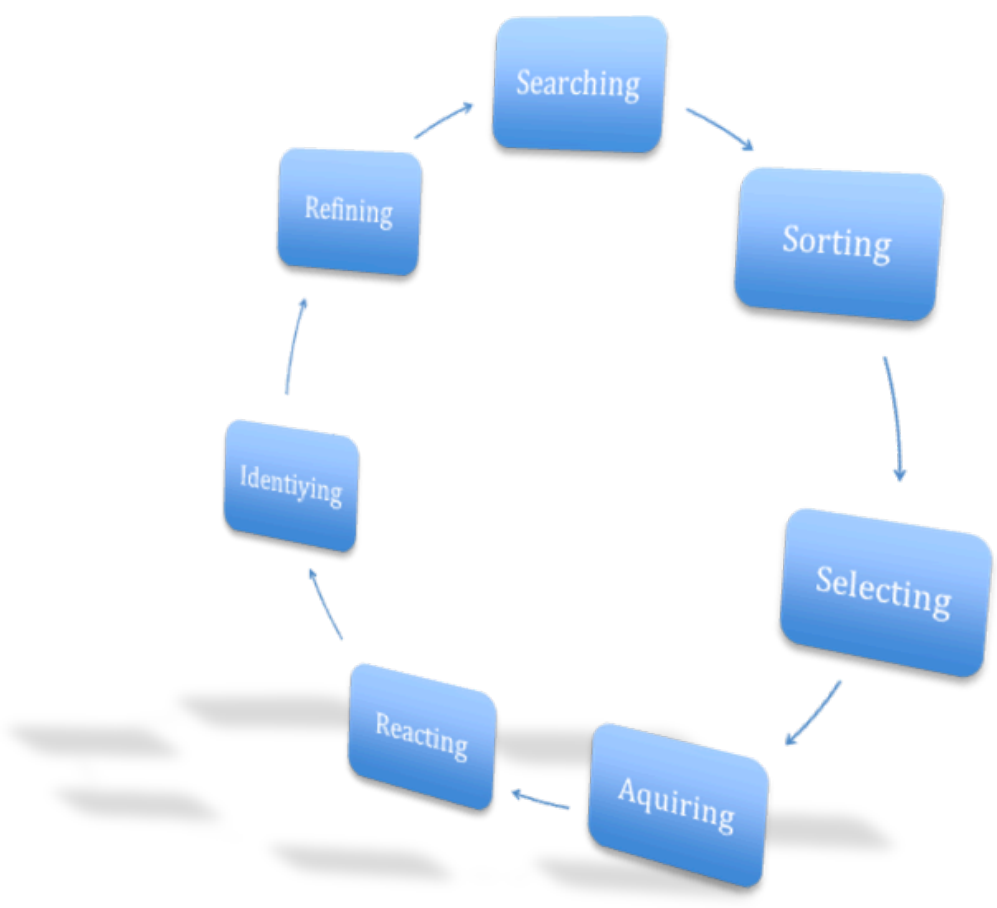

Figure 4.1 Hermeneutic circle, with inspiration from Boell \& Cecez-Kecmanovic (2010, p41)

Boell \& Cecez-Kecmanovic (2010) offers a guide to apply the hermeneutic circle when dealing with a phenomenon. The guide consists of seven activities and as explained as 
following how we applied them in practice.

1. Starting to look for literature: The initial activity in the circle tells the researcher to first review the area of interest, for instance informatics, to create an overview of common research topics and problems which has been investigated there. When this basic understanding is established you should think of what area you would like to investigate further in and see if there are any previous studies of a relevant type to this area. This justifies the relevance of the study and calls for a further investigation in the concerned area of interest. Through the search of literature you will then develop a sense of what the key words are for the research. In our case our keywords became actor-network-theory, sustainability in IT artifacts, LibGuide, subject guide in relation to students and moments of translation. We started to narrow down our search down to a significant lesser amount of literature.

2. Sorting search results: The next activity in the hermeneutic circle takes on where the initial phase started, narrowing down your search to a reduced number of literatures and analyzing them. By looking at what year they were published and what relevance they seem to have (by looking at how many cited the article) you could conclude whether this article was relevant to your study or not. We adopted this idea by searching for the original authors of the actor network theory in order to understand it. We found this of great importance since every theory can be interpreted in an in individual matter which affects the understanding of it.

3. Selecting search results: the third activity of the cycle is to conduct as fast review over the selected resources of data by looking at the title of them and reading through the abstract. By conducting this you can select which of the texts that are relevant to investigate further, and read to complete text since it will contribute to the whole. What we also stressed of importance was which journal the sources came from. During our literature review of how actor network theory had been used in practice, we narrowed down our search criteria to only journals and articles that had been published in databases which were aligned to our subject: informatics, since we wanted to compass how researchers in our field had been using ANT.

4. Acquiring relevant documents: The next activity in the hermeneutic circle takes of different types of literature and the acquirement of them. Not all sources of literature are available in an electronic format and some might require a visit to a library in order to access the wanted literature. In our case we had some interaction with our subject guide who kindly recommended some valid sources of journals and articles that were more than. However, when it came to the work of Latour and Callon we sometimes needed to go visit the library in order to read the book which wasn't published in an electronic format. What is worth mentioning here is that we applied the phases of the hermeneutic circle in an iterative way, the process of understanding a subject is far from a "straight line" of text and interpretations, and that some of the phases are almost interweaved with each other.

5. Reading of identified publications: 5'th activity of the circle involves reading of the previously selected material. Boell \& Cecez-Kecmanovic (2010) points out that this is probably the most time-consuming activity since there are often a large amount of resources that has to be read through. Throughout this activity, you are supposed to develop a great understanding of the theory you read and the concept it consists of. In our case, the text of ANT involved the publications from Latour (1987) and Callon (1986ab) and some practical examples of how ANT has been applied. You then established a sense of "know-how" of how to apply it in our context and why it fits well. This activity can be crucial since this is when you also reflect upon the use of theory and how well it serves the initial purpose. 
Another aspect Boell \& Cecez-Kecmanovic (2010) points out in this phase is about note and quotation keeping. It's a good strategy to write down keyword and definitions while you are reading and also to keep track of who said what, since all academic texts must keep a good level of referencing to them, and we constantly made notes and definitions over what the ANT meant.

6. Identification of further literature and search terms: Next task to carry out is to investigate even further for others sources of literature. By analyzing the references and citations the authors from a relevant study to your research you can get a hold of other relevant material. However the negative aspect of doing this is that you can only go back in time, not forward. In this research we often investigated into the sources other authors referenced and cited to. This gave us a broader understanding.

7. Refining searches: The seventh activity of the circle tries to go beyond the boarders of what you defined as prior reading. Through the process of establishing a well rooted understanding of what the concepts stands for, you then might extend your boarders and search for key words that weren't defined from the initial phase of the circle. This can help you to cover the last "gaps" which calls for an academic definition.

\subsubsection{Dealing With Empirical Data - Segment 2}

The second part is gathering and analyzing the required data in order to answer the formulated research questions. Since the research attempts to understand and visualize the status quo of an application in the academic context of Linnaeus University in Växjö from the actor network theoretical lens in an interpretevistic manner, we chose to base our empirical acquisition on a qualitative basis. Denzin \& Lincoln (2000) describe the qualitative research approach as a situation where the researcher seeks to interpret material practices and activities to make the world visible. Once this has been carried out Denzin \& Lincoln (2000) then claims that the world will be transformed. This approach of interpreting the world fits our case since we are dealing with a context that calls for interpretation as we previously claimed. Hoepfl (1997) talks of the differences between the qualitative and quantitative research approach. In the quantitative approach seeks the researcher to generalize (causal determination) the result, this compared to the qualitative approach where the researcher seeks to understand, interpret and illuminate of the same context. In addition, Eisner (1991, cited in Golafshni, 2003) tells us that the essence of a qualitative study is to provide an understanding of a situation that otherwise is enigmatic in its nature.

One of the reasons we are certainly bound to choose qualitative an approach comes from the choice of our theoretical framework. As stated before, ANT makes the allies and examine their behaviors by process of translation. In the translation process interpreting other actors' need to make an alignment between that actor and others who are in a network is something which the researchers should concern about. Negotiation is another phase in which the objective of shared benefits by complying with the proposed solution should be negotiated between actants. To achieve this, the qualitative technique allows us to go more deeper than what meets the eyes. Thereby, showing agreements and allies interests by graphs or numbers will be hardly possible (Ponti, 2012).

\subsection{Data Collection Method}

The data will be collected through a number of semi-structured interviews with lecturers, 
students, subject librarians and program coordinators and in addition to this some observation of this phenomenon was crucial. The main reason why we chose semi-structured interviews was to give us as the researcher the freedom to modify and make changes to the interview guide as the interview progressed (Bryman, 2006). This involves cancel, add or modify the questions over time, in order to get the most nuance answers as possible that calls for reflection. Since we want to tell and define the moment of translation according to the premises of Actor-Network Theory, many aspects and questions needs to be answered. The interview guides will therefore be structured in a way that it will almost look as a discussion rather then an interview with all the additional follow up questions. However, in order to provide an explanation to the moments of translation we found it of great relevance and importance to proceed like this since we are not sure what question/s would be the keyquestion/s which made the respondent tell us what in the end could be referred as highly important.

The sample technique to pick the respondents came from what Creswell (2009) call quota sample. This process of selecting the respondents is based on the desired characteristics from the researcher. In our case will it be participants have more then 1 years of experience in lecturing, studying or working at the library. Sampling of the participants in our research is interpreted as what Patton (2002) describes as purposive which has the meaning that there is a significant less emphasis on generalizing the sample to population. You will instead give a greater attention to the sample purposely in its selection to yield and insight from its illuminative and rich source of information.

\subsubsection{Interview Format}

The interviewees were given the opportunity to skim through the questions before the interview. We sent the interviewees an email with the questions for the interview approximately 3 to 5 days in advance so they had enough time to prepare themselves. All the interviews were made in person and after permission recorded on a device, however, as a compliment to this we also took some notes. The duration of each interview ranged from 20 minutes to approximately 40 minutes depending on how many follow-up questions we asked. At the end of each interview the interviewees were given the opportunity to receive the transcribed material from the conversation and review it, to either approve or disapprove with our interpretation from the interview (appendix 10.2).

\subsection{Data Analysis}

The main objective of the data analysis is to capture and understand the actors in our identified network as well as the actions taken to tell the whole story, which by definition is to interpret their behavior and how their role was exposed in an application's sustainability. By this we used ANT as a framework to create a theme separately for each moments inside the translation phase (Walsham, 1995).

As we stated previously there will be a number of semi-structured interviews to collect the empirical data and it will call for an interpretive way of analyzing them. We adopt the same way of thinking as we did in our literature analysis, the hermeneutic circle. In addition to this, we will also be using the idea of analyzing through themes. The process and fundamental meaning can be explained and visualized as the following figure 4.2 presents. 


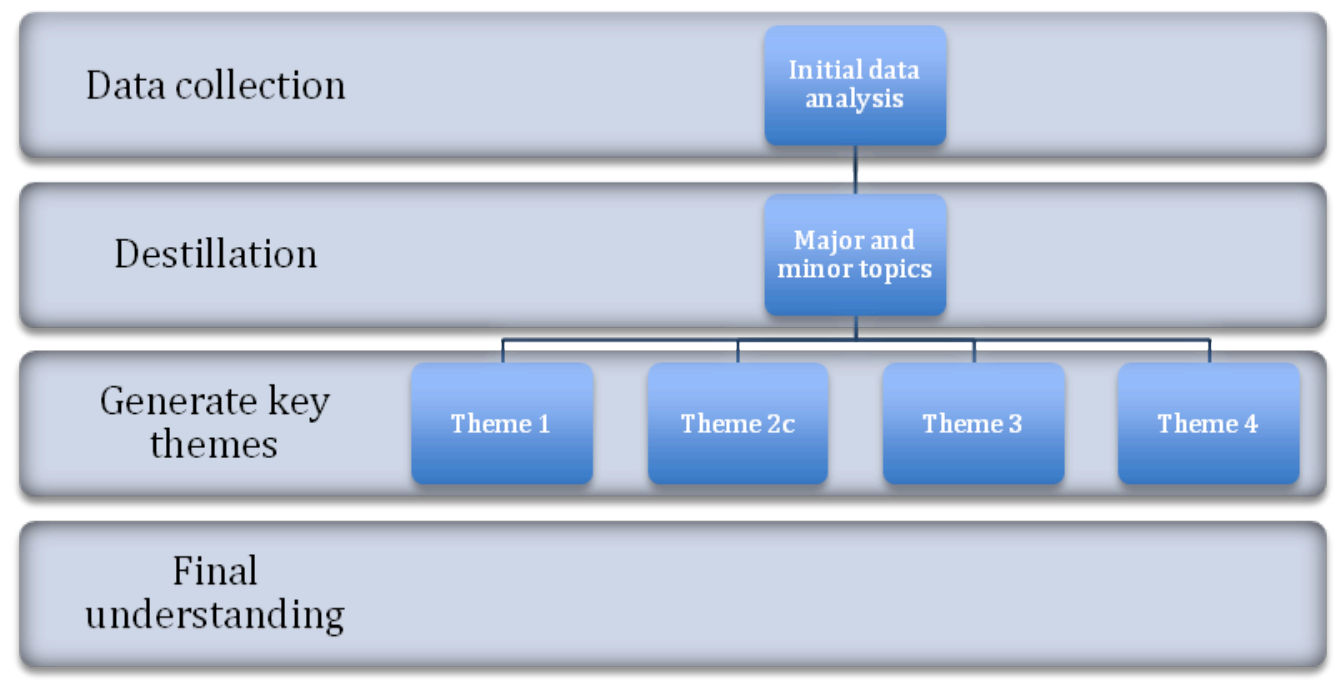

Figure 4.2 Analyzing Through Themes

The data analyze will start off with what the picture presents as data collection, the initial data analysis, which is the process where the interviews are transcribed to achieve an initial understanding/overview of the collected material. With the adaption of the hermeneutic-circle this will be an iterative process where we as researchers will take part in a discussion over what is relevant and how we understood it. The next activity is to go through the distillation activity where we distill the data we find of relevance and data we don't find of any use to get a better overview of the collected data. The next and last phase is the generate key themes and this is what Dye et.al (2004) want to describe throughout his metaphor; kalidioscope is the generation and creating of themes. The authors mean by grouping what you refer as similar bits of the data in the distillation phase, which is by definition data considered being related to each other. Dye et.al (2004) means that by doing this will you finally end up with something called "subpiles" which eventually generates a pattern they share. This process is iterative and takes its ground in the hermeneutic circle what of thinking. By continual going "back and forth" (as the concept of the hermeneutic circle describes) you will finally end up with your themes, or as Dye et.al (2004) want to call it, "concepts". This way of analyzing the data will be our aiming and starting point in this research (figure 4.3). 


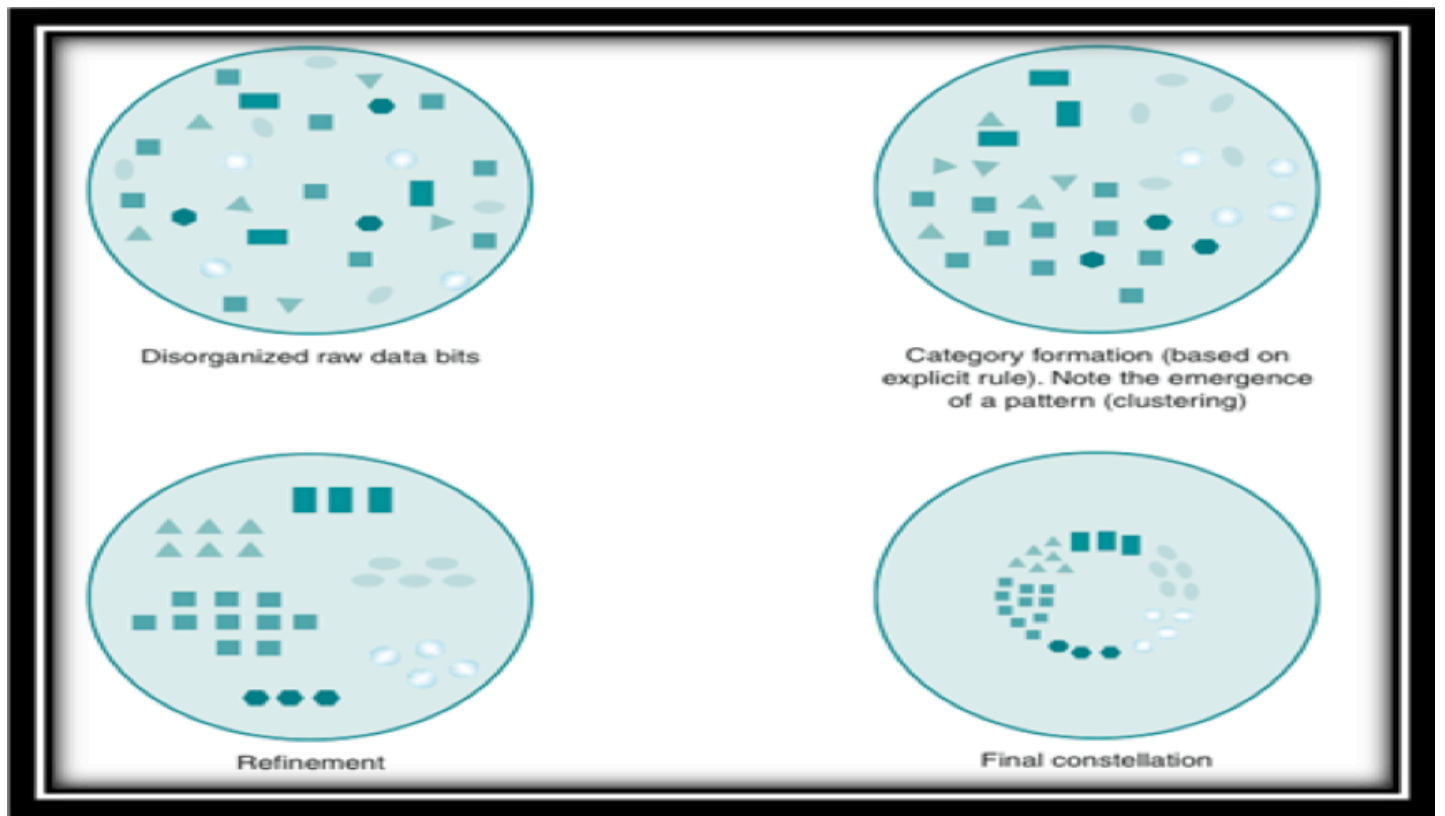

Figure 4.3 Kalidioscope, with inspiration from Dye. et.al (2004)

Our concepts or themes will be through the lens of ANT, the moment of translation which includes the themes:

- Problematization

- Enrolment

- Interessement

- Mobilization

\subsection{Template For Analysis}

In order to analyze the collected data from the conducted interviews we then created a template of analysis for this cause, see appendix 2. By writing down the questions asked to the informants along with the given answer we will then by the use of our created themes distil some information we found of great interest and connect them to what we claim to fit in the moment of translation.

\subsection{Reliability}

Golafshni (2003) states that reliability is a common concept used to test or evaluate the work of a qualitative study and whether the findings are repeatable or not. As a secondary purpose the reliability in a study serves the purpose to evaluate and define the overall quality of the text. Golafshni (2003) and Eisner (1991) distinguish between these two concepts: reliability and quality in a qualitative study. They mean that when a research is written in terms of a high reliability it has then transformed an enigmatic situation to become more understood for the reader (explanation). The term quality is more aligned to what extent the research manages to provide an understanding for the reader. Further on, Golafshni (2003) provides a discussion regarding Campbell's (1996, cited in Golafshni, 2004) ideas of how reliability can be shown in a qualitative study. According to Campbell (1996, cited in Golafshni, 2004) is it a matter of consistency where the reliability can be verified through an investigation in the researches raw data, process notes and data reduction process notes. 
Shenton (2004) continues the discussion of how reliability in qualitative research has been under questioning, especially from the positivistic perspective. He provides some specific criteria of how to evaluate the reliability in a research.

The first phase is to evaluate the research design and implementation, by this means to look at what was planned and then se how it was executed.

The second phase is to investigate in the details of data gathering, to see if the questions from the interviews captured all needed information to carry out the analysis and if it was enough to answer the research question.

The last phase is to evaluate the effectives of the inquiry taken. This will later be discussed in the last chapter where we provide our reflections of how the research was conducted and what obstacles we faced during the way and not the least, how we tackled them.

\subsection{Validity - Internal and External}

Bryman \& Bell (2007) claim that validity in a research is aligned to the conclusion generated at the end from the analysis of the empirical data and that it is probably the most crucial criterion for a well conducted research. However Golafshni (2003) and Stenbacka (2001) discuss the relevance of validity in a qualitative research and weather it needs to be reworked in order to suit a research of this type since validity often refers to the measurement of something and in a qualitative study from an interpretevistic approach is it hard to measure the findings. Creswell and Miller (2000) however claim that the concept of validity is not applicable in a qualitative research, but they don't neglect the need of having a qualifying check to assure that the research reach a certain standard. However Bryman and Bell (2007) argue that the internal validity in a qualitative research is of importance. The meaning of internal validity in connected with the level of probability of the findings and in this thesis it can be discussed and seen form a variety of aspects. The first action to take in order to strengthen the internal validity was aligned to the informants agreement of our interpretation of the interview. In order to relate our data to our findings we asked each informant to review our empirical findings and to guarantee that what was written was a direct reflection over what the he or she stated. They agreed with the transcription and told us that this could be used in our research if wanted so. By doing this we could ensure that our findings were based on the collected data. Further on, to strengthen the internal validity we followed Bryman \& Bell's (2007) instructions of how to handle the informants before starting the conversation. The authors stress the importance of creating an atmosphere where the informants can speak freely without fear for what the possible consequences could be if someone identified the informants and his or her explanation of the discussed phenomena. As a result of this we gave all the respondents the opportunity to be quoted anonymously. This however doesn't ensure us that the respondents will provide us with the most truthful and well describing answers, but we believe that our actions will increase the possibility of achieving this. As we discussed previously there is an ongoing discussion weather external validity can be applied to a qualitative research or not. Bryman \& Bell (2007) claim that the result of a qualitative study can never be generalized since the contexts with its elements can never be the same and the identical situation can never be faced again. However, Alvesson \& Sköldberg (2009) argue that the result from a qualitative research can to a certain extent be "generalized". They claim that the results from a research could likely be generalized if the context you address is similar to the previous one. The context can most likely be identified in other cities where an academic university library exists, and where the relationship between students and LibGuide/subjectguide are similar. 


\subsection{Ethical Considerations}

One of the most common reasons why ethical dilemmas hinder the work in a research is aligned to how the study is presented to the informants. If you choose to keep the purpose undeclared you will then most likely face a common ethical issue, to get the agreement of the participation in the research. By not declaring the purpose will the asked person not be able to know what type of research she or he takes part of, and what the data from the interviews is supposed to result in according to Jacobsen (2002). It is also important when you present the purpose of the study to at same time inform the informants regarding anonymity for their part of the research.

Moving on, the participants were also given the chance to review and either approve or neglect the conclusions coming from the interview. As stated previously, all the respondents were given the opportunity to review the transcription from the interview and either agreeing or disagree with our interpretations of the data.

Continuing, in our case we informed all the participants what the purpose of the study was and how the data was going to be treated. We kept all our respondent anonymous and showed them our conclusions based on the interview session. The idea behind using the Healthcare department as the main focus of this study was not degrading the quality of other department. The high amount of the hits in Healthcare's subject guide was mainly the interest of this study. Moreover, we have decided to take the other department's hits hidden since we would not want to judge the quality of a department based on the number of hits their specific subject guide received. 


\section{Chapter 5:}

Case of Linnaeus University - Subject Guide

This chapter starts with the description of the conducted pre-study followed by SubjectGuide and LibGuide meant in our case. This will be followed by the case description in which the moments of translation will be put into action. Finally, the different stages in ANT theory will be elaborated and explained particularly in our case.

\subsection{Pre-study}

In order to justify and establish the relevance of our proposed study, we had conducted a presurvey study to investigate how well students at the Linnaeus University in Växjö relate to their subject guide or their subject librarian. In order to achieve a high response rate, which is a crucial factor in order to capture and represent the result, we handed out the survey sheet in practice, face to face to all the 50 respondents. The sample was done by the use of what Bryman (2007) calls a random sample technique. The reason why we chose this technique is due the fact that we couldn't reach out to all the informants, and by choosing a random sample technique we believe that we represented the informants in a fair matter. Through this we then accomplished to get a $100 \%$ response rate which illustrated and captured students interrelationship with the technology LibGuide and their subject librarian. Out of the 50 respondents who participated in the survey $30(60 \%)$ stated that they had some experiences with LibGuide by using the www.lnu.se site or through face-to-face contact with their subject librarian. $22(40 \%)$ answered that they didn't had any experiences with the technology. (see appendix 10.9) Although, when the results were analyzed together with our contact persons at the library we clearly saw some misinterpreted data in the conducted study. We looked over a document which showed us all subject-guides and their number of hits. Hits are defined as the numbers of times users visited the subjectguide every month, this is to keep track and store statistics for all the subject guides with the purpose of seeing how frequent they are used. We went through all the subject guides and could then draw the conclusion that this result didn't represent the correct reality. Some subjectguides had a higher amount of hits compared to other subjects and clearly our survey study didn't involve the students who were connected with those subjectguides. However many subjectguides had a significant difference in their hits compared to others and the result we got from our survey study captured that there is one particular department which had different number of visiting users every month comparing to the others. This drastic difference between the number visiting users showed that the LibGuide has been used more efficient in one department in comparison to others.

\subsubsection{Significance in Number of Hits}

The survey was conducted and we could collect the information regarding how many students that was familiar with LibGuide. But the story began when we went to library and asked for actual collected statistics to make sure our claim was legitimate. Library's Dean and subject librarians were keen enough to provide comprehensive statistical data about how many hits each subject guide page received in specific period of time. After receiving and analyzing the statistics we then realized that what the pre-study showed us was in contrary with the data given by the subject librarians. The data presented all subjectguides in relation to their number of hits over a year. See in appendix 10. 
Further investigation of the statistical data gave us an overview about all the subjectguides and their amount of hits. In total there were 92 subjectguides, equivalent to number of subjects being represented in university and it came to pass that the hits differed dramatically among the subjects. This data included all years of 2010, 2011 and 2012. However the data is not supposed to be disclosed without library's permission and by this we were given the information that it needed to be treated confidential. The main interest was the frequent use of two subjectguides and their good interaction between students as the main cause of such significe in terms of hits, namely Hälso- och vårdvetenskap (Healthcare science) and Företagsekonomi (School of economics). Nevertheless, we would also like to point out that by reviewing the document we also came in contact with other subjects like Informatics and could review the number of hits based on that department. There was a great difference compared to the example of healthcare but the need of the service LibGuide seemed to be equal based on the dialog with a key person at the library. However, we resort ourselves only to investigate the number of hits and the interaction of students and LibGuide in the Healthcare department since the ratio between the numbers of students was proportionate to the number of hits in most of the departments, including Healthcare, except Economics who had more students compared to others.

We then conducted a survey study that involved 50 students from the healthcare department and asked them the same questions as stated in the previous managed questionnaire, with the only difference that we now asked it in Swedish. This was grounded in our conclusions from the previously conducted survey study where we asked 50 students from a random sample that some might had misunderstood the questions which affected the overall result. Since we now reached out to Swedish speaking students we saw no reason of having the questions in English. The result from the survey is presented in appendix 11. All the 30 students answered yes that they had some past experience with the tool LibGuide. For the second question the 30 students who participated stated that they had some past experience with their subject librarian. The result from the last question is illustrated in appendix 10.11 . 


\subsection{LibGuide in Healthcare Department}

The LibGuide at the Linnaeus Univeristy contains over 88 guides that are organized into different schools and 22 of them are written in English (Linnéuniverstetsbiblioteks årsberättelse, 2011). In general, the guides consists of a set of links to the most important databases in their specific subject, electronic encyclopedias, the contact info of the responsible subjectlibrarians and the subjectlibrarians own recommendations of books and articles which she or he find of great relevance for the subject (Linnéuniverstetsbiblioteks årsberättelse, 2011; Linnéuniverstetsbiblioteks årsberättelse, 2011). When first entering the page through the webpage www.lnu.se/ub and then clicking on one of the subject guides you will then see the guides sorted in their aligned schools. Any person can enter these pages but you need to be a registered student in order to get access to the articles and books from the in the databases.

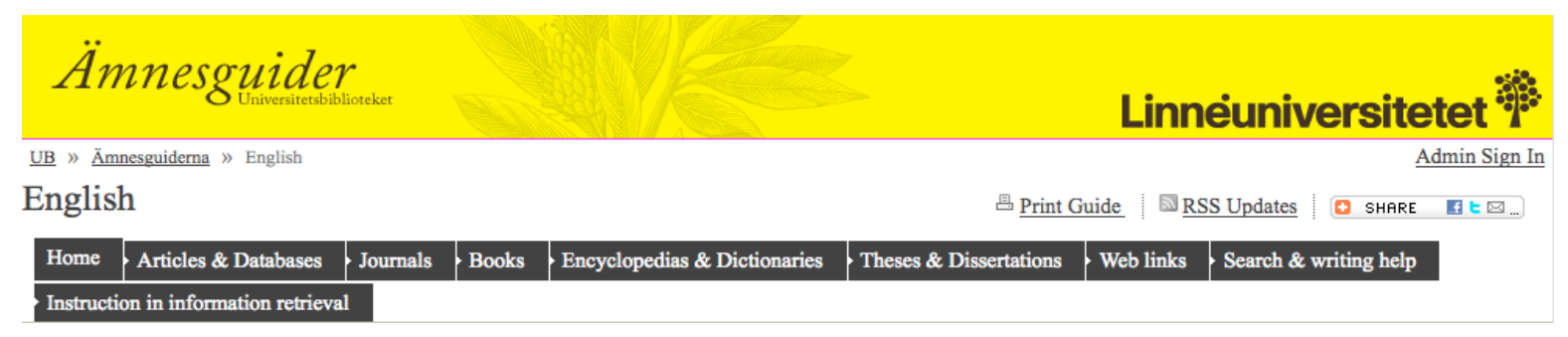

Figure 5.1 Toolbar, Subject Guide HC-department

The top toolbar gives the user the possibility to go through a number of different functionalities in her or his subject guide. The following table (5.1) illustrates the available functionalities.

\begin{tabular}{|l|l|l|l||}
\hline Articles & & Databases \\
\hline Journals & & Books \\
\hline Encyclopedias & & \\
\hline Weblinks & & Theses and Dissertations \\
\hline
\end{tabular}

Table 5.1 HC-departments subjectguide

What is worth mentioning is the fact that the start page of each subject guide is created in the same nature as a blog. The editor (responsible subject librarian) can enter the page as an administrator to edit the page with ease. With this comes also the possibility for students who are connected to a subject to RSS-follow the subject guide. By this they can receive updates when any changes are done by the subject librarian. During the interview with one of the informants which was a student, she said the following:

"Subject guide is a nice tool for us students, but sometimes I get stuck in the choice of which database to search in and what my search criteria should be. 


\section{I know that there is a possibility to book a session with my subject librarian but for some reason I never take the time doing it"}

Since the platform is constructed on the premises of web 2.0 technologies which by definition allows you to customize and modify it so it fits your desired needs took the assigned subject librarian to the healthcare department it one-step further. They do now offer their services for problems like the informant previously stated regarding booking a face-to-face meeting by now giving the possibility to chat with the subject librarian during working hours. This is a service they offer to the students when time allows it.

When a user clicks on the tab articles the page which is presented in figure 5.1 is shown. The page gives the user a number of databases with some additional information of what kind of articles to find by searching in them. This is something the assigned subject librarian is responsible of. By comparing this subject guide to another we identified that the information differs from one subject guide to another. Some didn't have this kind of information, by particular what type of theme the articles had in their databases. In Figure 5.2 a screenshot is presented from the healthcares subjectguide.

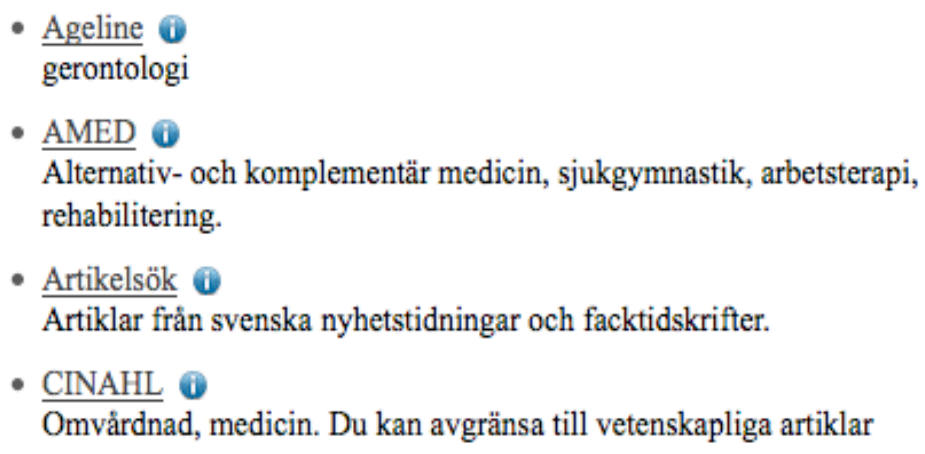

Figure 5.2 HC-departments subject guide, FrontPage

The last thing we would like to describe is the tab called "Mesh". MeSH® stands for Medical Subject Headings and is a controlled vocabulary thesaurus of the NLM (U.S National Library of Medicine. It's a search engine to find definitions of medical terms. This is only one of many features the subject guide of healthcare department consists of.

\subsection{The Work Behind LibGuide, The Subject Guide}

The subject librarian is a personal contact for each department's students and staff who have as main purpose to anchor and integrate the work of the library with the research that is done in the University. Their main task is to provide lectures and tutoring in the task of searching for information, and as a secondary goal to handle the acquisition of media and literature between the department's demands in relation to the library (Linnéuniversitetsbiblioteks årsberättelse, 2011; UniWeb, 2012). Each subject librarian creates and shapes their work based on the prerequisites and demands given by their department they work with. For the period of 2011-2012 twenty three different persons worked as a subject librarian at the Linnaeus University (Linnéuniversitetsbiblioteks årsberättelse, 2011).

To the help with search of information are all students, researchers and lecturers given the service to book a face-to-face meeting with their assigned subject librarian. During this session they can go over topics such as: 
- Evaluate and criticise articles and other recourses

- Come up with adequate keywords based on their problem description or area of interest

- To go over different types of search techniques in databases and journals

- Questions about publishing and other aspects that comes with that

The initial purpose with this service is to provide the students and staff with a set of tools that make them able to search, evaluate and use the information in a correct and effective manner (UniWeb; Linnéuniversitetsbiblioteks årsberättelse, 2010, 2011).

\subsection{ANT in Action}

With introduction of subject guide and subject librarians to the different faculty members and staffs inside the Linnaeus University's library, many would think of this application as a breakthrough and some as a random application. Linnaeus university established a contract with Springshare in 2010. The initial aim for this plan was to introduce students and lecturers to the a new Web 2.0 Technology which would allow students to get the relevant literature information from the librarians named subject librarians to the students programs. The idea came from the discussions with a subject librarian whom we had ongoing conversation during a month. We identified that neither students, nor lecturers are using their specified subject guide page frequently. LibGuide, although might have been used to some extend, would never reach its desired state if its use was ended to be like that. The Linnaeus University library apparently made the contract to buy the LibGuide technology in order to make a distinction in terms of searching for right information. Not only from subject librarians perspective, but also from lecturers and students opinions, it could have been concluded as a common concern, if not a dilemma. Librarians, as those who were interacting with system more often than others inside the university had agreed that the numbers might be acceptable, but it was not the ultimate state of what the students and lecturers can benefit from such an application. It was here that the subject librarian contacted us about something which could be of interest in what we were looking for. He printed all the information about the months and number of hits (with the permission from the University) and we met each other during some sessions. He said the following:

What is interesting is why the Healthcare department has such a huge difference in their number of hits compared to other departments"

We were totally amazed to see such difference in the numbers as we collected all information and represented them by graphs and charts to see the real exposed difference. We asked ourselves, what made this application so popular in Healthcare department? This drastic difference is not accidental and we wanted to know what made it like this. The whole journey of this story became a complex social and technical discourse after collecting the empirical findings during interviews, web conferences and phone calls which apparently had to be supported by an appropriate theoretical framework to understand the stages and both social and technical side of it. The first question was if the story behind this number can be applied to other department or not? To explore this we used ANT and its moments of translation. 


\subsubsection{Problematization - Definition of Actors and How OPP Was Established.}

Actors are those participants of a network who share their interests, while trying to persuade other actors to align their interests with them (Callon, 1986b). In the problematization stage, the focal actor - the actor who wants to spread the words of interest, Callonm 1986b) defines the identities of those actors who might have the shared interests just like theirs. Thereby, it establishes itself in what Callon (1986b) states as Obligatory Passage Point.

\subsubsection{Actors}

Before starting the analysis, we should, first, define the actors. This will help us to see whether or not the network is constituted by wrong elements. The actors are not merely those who directly affect the network, but also those which while we narrate the story, will be provided into the network after commentaries and researches. By what we were told, it was rather simple to drop three actors into the case instantly. LibGuide as an application, students who made such number of hits, as well as subject librarians who runs the steers' of such application. Subject Librarians, Students and LibGuide.

The actors were identified and we found those who directly use the system. But as the interviews were conducted more findings were disclosed. Hence we found that there are more sides to this story which are hidden from our eyes. As we claimed, this number of hits was not accidental, so we tried to investigate more and even more to exploit the communication and influences all the story might be affected by. No matter how convincing the story was, there are hidden hands behind the curtain that we cannot observe. We were told that two program coordinators of the department of Healthcare had a considerable attention on the implementation of the LibGuide. These two program coordinators, with their power in hand to choose the pathways and missions were then identified as the. In addition, lecturers are constantly reviewing the program materials. Therefore, two more actors were identified as Program Coordinators and Lecturers. Actors involved are in Table 5.2 listed in the left column and how they are defined to right.

\begin{tabular}{||l||l||}
\hline \hline Actors & Definition \\
\hline \hline \begin{tabular}{l|l} 
Subject \\
Librarians
\end{tabular} & $\begin{array}{l}\text { They are to be called Liaison Librarians, those who are assigned to one } \\
\text { particular program and work as a mediator between students and the } \\
\text { LibGuide application. The reason behind choosing them is rather obvious, } \\
\text { because their carrier is an interest of the application and the students' use } \\
\text { of the application. They are also responsible for the application for which } \\
\text { each program LibGuide's page. }\end{array}$ \\
\hline \hline Students & $\begin{array}{l}\text { As one of the main users of the LibGuide application stands the students } \\
\text { who have actually used the application. While talking generally about the } \\
\text { students of the Linnaeus University. Monthly, many students are } \\
\text { contacting their Subject Librarians and using LibGuide no matter how } \\
\text { frequent they use the system, they are perhaps the main users of it. }\end{array}$ \\
\hline \hline \hline LibGuide & $\begin{array}{l}\text { Like students, this application is a main actor which interplays in the story } \\
\text { strongly mainly due to its use. }\end{array}$ \\
\hline \hline
\end{tabular}




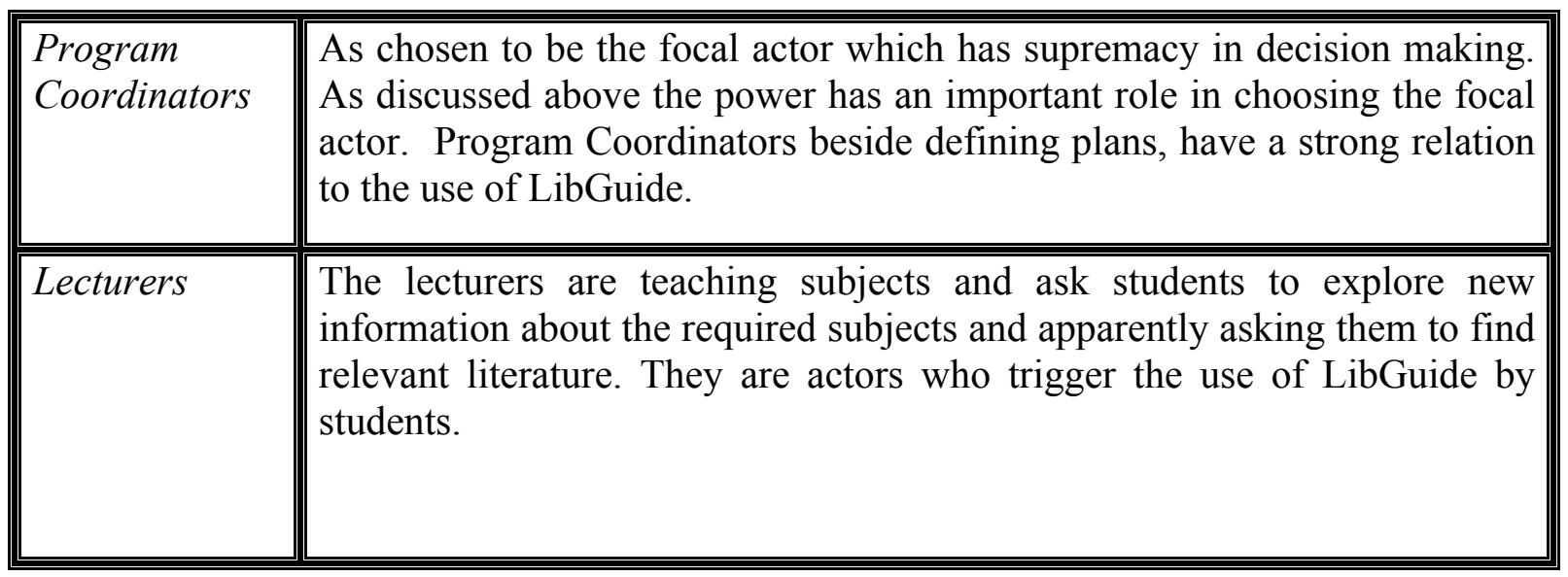

Table 5.2 Defining the Actors

We also found that the problematization is also well understood if we could portray what it looked like before we assumed other actors, and those who were directly drawn in the network. The process is illustrated in Figure 5.3.

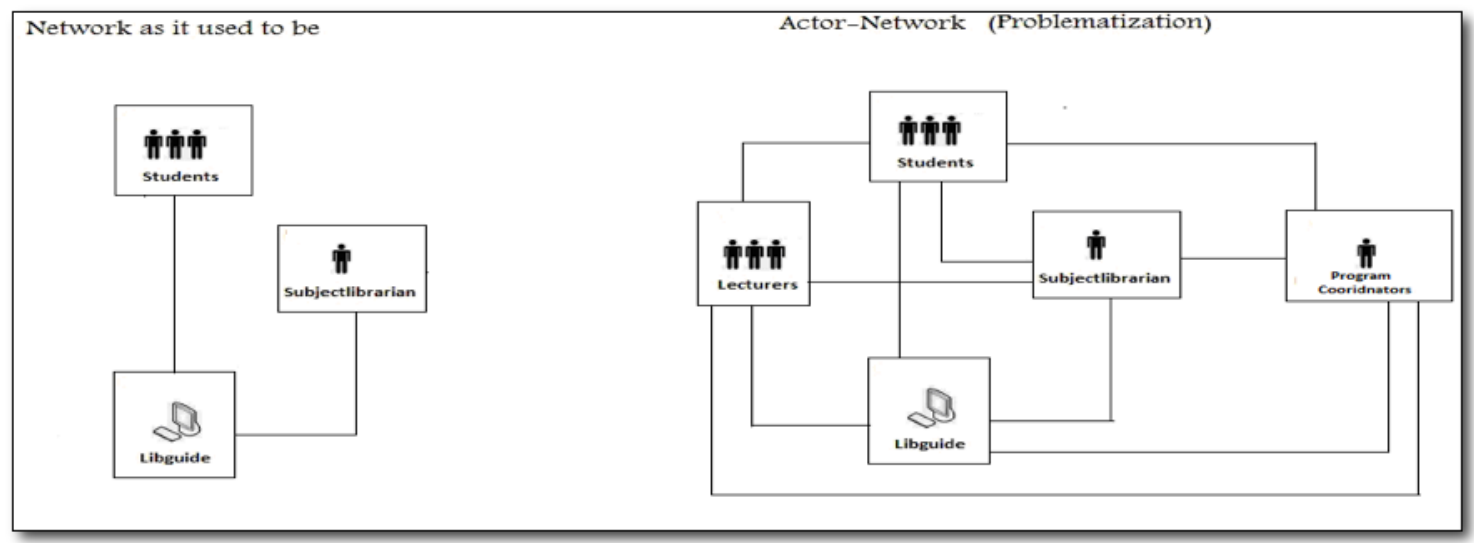

Figure 5.3 Problemitizaton

Those actors who were mentioned to be instant objects when we heard the story had now expanded to not only the numbers, but also in the interrelation which was figured after their problematization which all of them have with each other, no matter they are human or nonhuman.

\subsubsection{OPP - Obligatory Passage Point: What Bonded Actors to Use The LibGuide}

We could have limited ourselves just to identify number of actors, but we had to be sure that what program coordinators assumingly proposed had been admitted by those who were sharing a network of same interest. We had to frequently come up with some questions that needed to be asked beforehand such as: If the students in other departments use LibGuide in the same way of what Healthcare students did? If LibGuide is admitted to be used and wants to be used? If lecturers are willing to admit that the hyphen between them and subject librarians is not drawn strong enough? Moreover, the students, subject librarians, lecturers and LibGuide can not fully attain what they want since they are confronted by complexities that could refrain them to get to their desired state. The students might not use the right form 
of literature when they are searching in search engines, and this in a long haul effects their learning quality. The lecturers might feel that the use of subject librarians are unclear and their students do not deliver what they want from them to deliver. The Subject librarians feeling their role in the education should be more exposed as it was before. To answer such questions we should have answered in prior what bonds actors to use the LibGuid? The figure below shows the forged alliance of all actors (see figure 5.4).

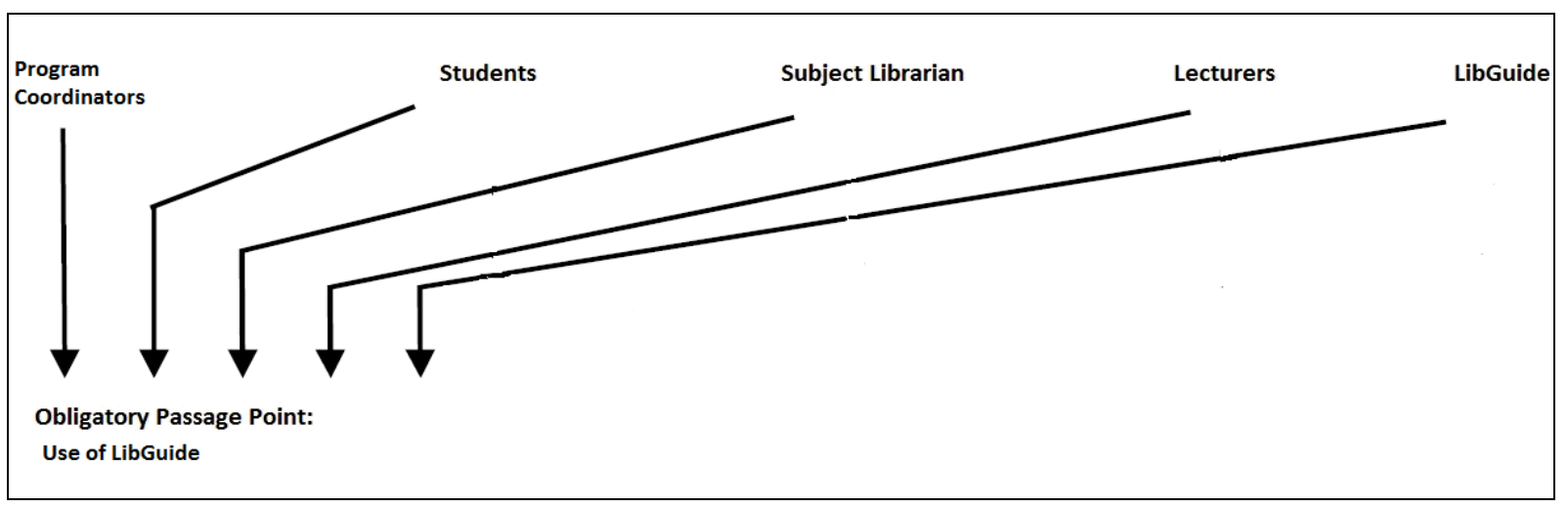

\section{Figure 5.4 OPP}

The question we raised, aims to show that, it is not the matter whether or not an actor fails or succeeds in aims but rather if they "want" to achieve their aims, and as a consequence build the consensus although their converged interests lie under their heterogeneous nature of human and non-human. The focal actor - program coordinators, had expected other actors to follow the use of this technology. Two program coordinators established themselves in an OPP, or made themselves indispensible by planning and influence they had on the LibGuide technology, since other actors - students, subject librarians, lecturers and Healthcare's subject guide, acknowledged that subject guides as a technology is what all other actors can benefit from, which is to say, everyone agreed that it contributes to better search of information. The subject guide still can not claim its own interest so they need a spokesperson(program coordinator) on behalf of them who can talk about their aim and goal. The final part of this phase is the holy alliance all actors participating in hope to create a consolidated network. In this schema, the definition of the actors based on what they "want" is again exposed. To answer our primary question in order to engage more departments to use the application this alliance should be formed in advance before taking off to another steps. This is illustrated in Figure 5.5. 


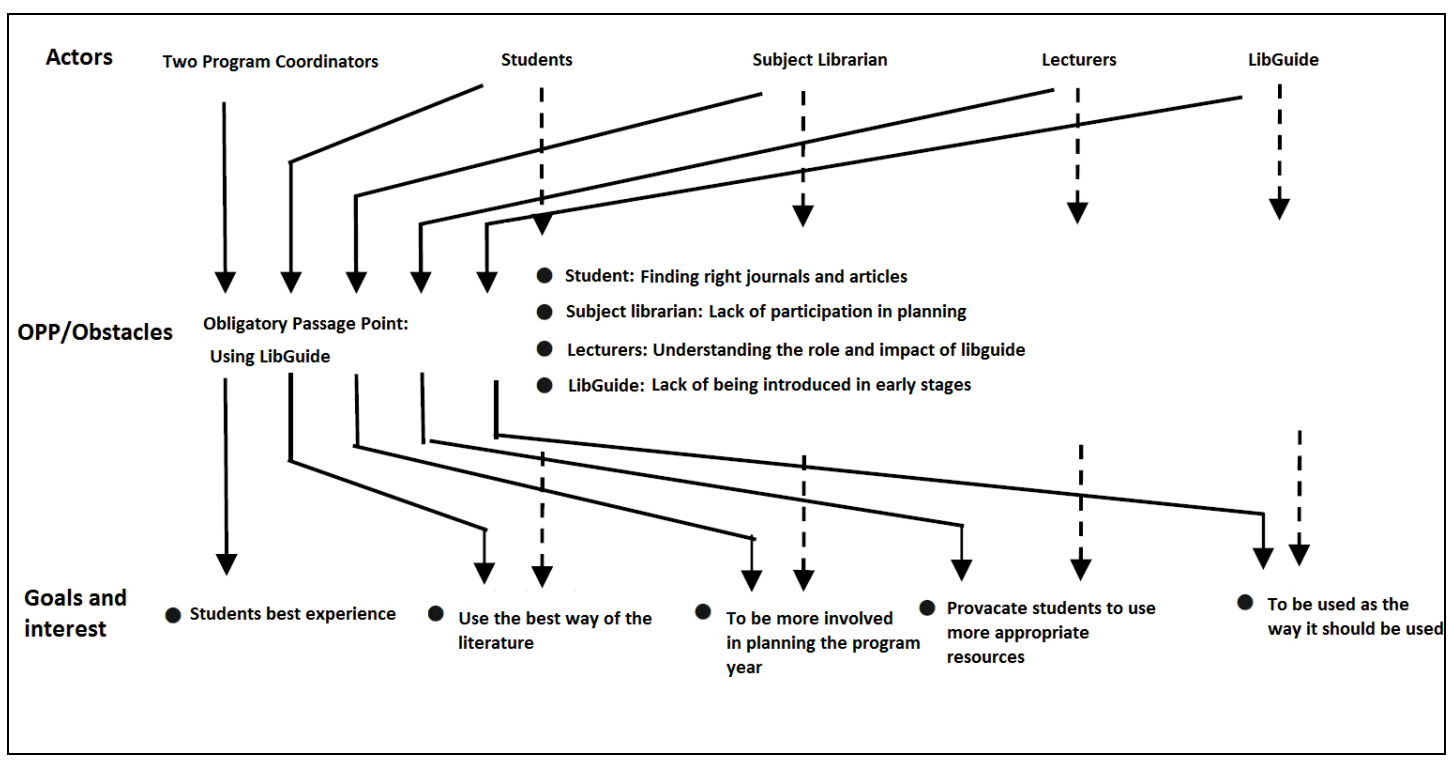

Figure 5.5 Final Schema

\subsubsection{Interessement: Subject Librarian is Involved in Planning}

The interessement is when the focal actor imposes the identity of other actors in its own problematization. In this stage study how two program coordinators as the focal actor had appointed certain identity to the other actors who already agreed upon their interests in order to stabilize the network. We argued that it is very unlikely that before the network was constructed, all the allies had already close problematization. It had to be understood that what was the concern of silent Healthcare's subject guide, was exactly the main concern of other actors such as subject librarians, lecturers and students. Before giving a robust definition of interessement in our case, the process of planning the year should be described. Program planning includes all lecturers and program coordinators of each department to discuss and evaluate the previous year. Through the evaluation they can see what deficiencies and strength certain program had. They can modify certain course materials based on their evaluation and updating the literature considering what students are expected to learn. Course meetings contain planning and scheduling the time and the assignments for each given course. Lectures contain evaluating tasks and assignments as well as monitoring the presented materials. As we figured out, the whole planning is a complex three layered process which diffuses the main strategies of the whole program year. However, what was in the interest, was the role of subject librarian.

Two program coordinators enroled the Healthcare's subject librarian in different levels of instructions as we mentioned above, program planning, course and lectures. Figure 5.6 illustrates all the levels the Healthcare's subject librarian assigned to participate in. The subject librarian, therefore, is detached from its rather classic definition and was enroled in the planning. Therefore, in the language of ANT, the involvement of subject librarian in planning the program year is interessement. With this strategy, program coordinators ensured that during all activities of planning proposals LibGuide has a voice and exists (if not physically). In addition, students were then disassociated from using common searching techniques using the library only. Lecturers also, were somehow limited to plan a program year without use of such an application when their spokesperson existed in their meetings. 
What came up as interesting was our primary question which could now be claimed rightfully. Yes, the whole plan can be applied to other departments since they have all the required actors in planning their program year including program coordinator, lecturers and subject librarians (if the same strategy from their program coordinator is applied to all their departments). This, however had drawn the bold link between subject librarians and other potential actors who had interests in using this technology which consequentially made LibGuide more dynamic in terms of planning a whole program year. Program coordinators set this regulation as a new common practice for the Healthcare's subject librarians to be involved in the planning the whole year in Healthcare department. If the other actors accepted the proposition, then the devices of interessement is even more distinctive and supportive as it was before. However, not all the actors shared their interests to the proposing plan, interessement helped the entities involved in the plan to be enrolled in the network. Hereby, the structure of Healthcare's subject guide which compromises both social and technological aspects is shaped and will be consolidated if the enrollment would have been successful.

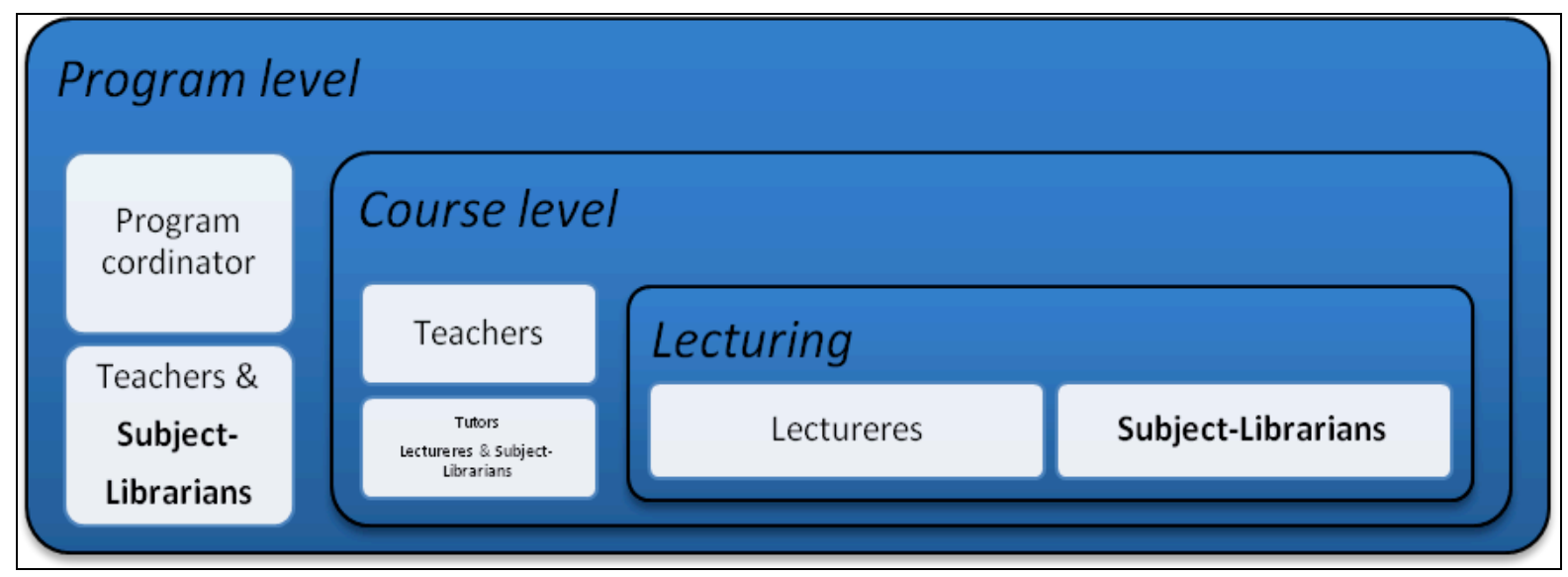

Figure 5.6 Involvement of the Subject Librarian

\subsubsection{Enrollment: align with the other actors}

The third step of translation is enrolment, during which the focal actor takes a set of strategies to ensure the actors actually accept the interessement and take on their roles (Callon, 1986b). The issue here is transformation of our question into series of other statements which could be certainly answered. Healthcare's subject guide is used! and if students and lecturers would actually use the application! In this stage, the process of enrollment asks to involve some prevaricate negotiations between the actors who were identified in the focal actor's problematization. Each actor in this stage, can now choose to accept or to refuse the constructed actor network. The question would be rather easy. How can we make sure that what two program coordinators imposed as "the involvement of subject librarians in the planning year" relates to better use of LibGuide? Therefore, the negotiation between two program coordinators and the LibGuide was sparkled from here. The subject librarian said as following: 
"We found that the best of making the Healthcare's subject guide page to be used by students is when we put all modules at the front page without making the process of finding relevant articles sophisticated. We also found that articulating specific databases for particular medical terms is what students found interesting".

It was found that when subject librarians were more involved in the lecturing part such as participating in sessions regarding how to search for information and other interesting topics regarding the writing of their thesis. Also to give introduction sessions about the use of the subject guide in Healthcare's department. Therefore, then the relevant materials that later should be put inside the front page was higher. They observed what articles are more used and what journals students are looking for in order to find out the relevant materials. This means, two program coordinators decided to make the role of the subject librarians more active in the lecturing part. As the result, the subject librarian gathered the information based on their lecturing observation about what is needed to be put in the LibGuide to help them to make Healthcare's subject guide more usable for the students in healthcare department. The negotiations between the two program coordinators and the LibGuide was apparently represented through the Healthcare's subject guide's spokesperson who was the Healthcare's subject librarian. What has been claimed can be easily understood through simple illustration. See Figure 5.7.

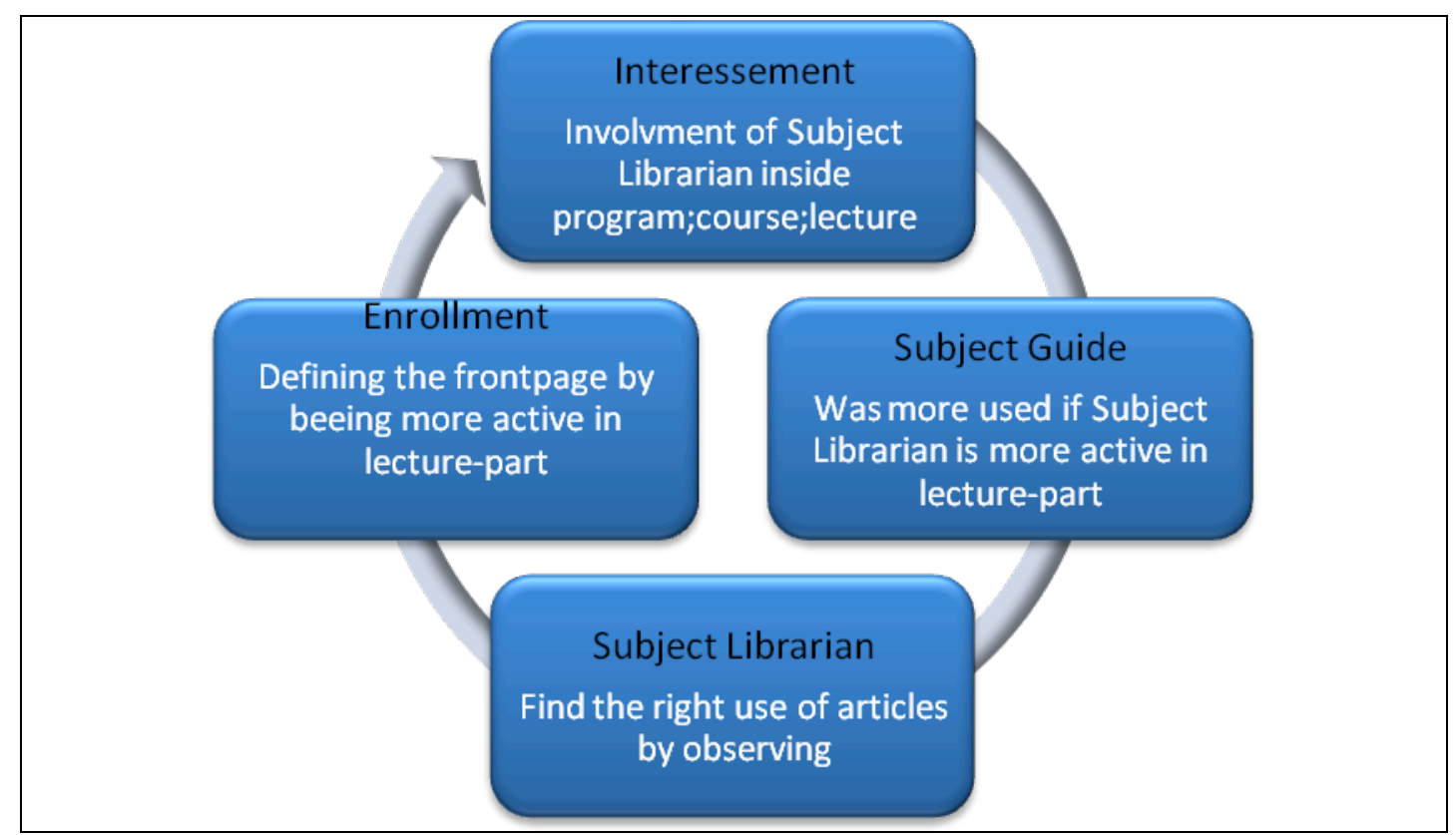

Figure 5.7: How subject guide's enrollment meets the interessement

The second round of the negotiation happened between program coordinators and lecturers. The same question should be answered here as well. How lecturers tuned themselves to the proposed plan? As the new regulation imposed, the subject librarians are now participating in the students' program year instruction, which means the subject librarians should confirm that particular plans have met the required use of the Healthcare's subject guide. The Healthcare subject librarian explained: 
"We are in many related areas helping lecturers in marking the assignment in terms of the right use of the literature and referencing"

He discussed that the lecturers saw marking as something merely in their authority, leaving them less influence in marking the students' thesis. But as the negotiations progressed, the program coordinator explained that the use of the subject librarians is quite constructive in terms of finding out the relevant literature when it comes to marking. Healthcare's subject librarians who also reviewed the references, found that the right materials are chosen from students after the imposed regulation. He said the following:

"As a subject librarians we first check the references to see whether the right databases and journals have been used"

From the perspective of the program coordinators, the negotiation was successful and lecturers were enrolled in planning the new year's materials. We would also like to argue that, if the students use their healthcare's subject guide higher, it means the subject guide is being used more frequently. The other statement would also be true, which means if the subject guide is highly used, then the students had used it more frequently. This will set the problematization of both the subject guide and the students rather close. It means that the negotiation between two program coordinators with students is as same as the result of their negotiation with subject guide. In addition, the negotiation between two program coordinators and Healthcare's subject librarians is void, since they are actors to whom the interessement is dependant. Subject librarians were those who actually committed to plans way before other actors had accepted it.

\subsubsection{Mobilization and Dissidence}

The final stage of translation is mobilization where the focal actor then ensures that the other actors behavior are now according with their agreement and would not betray them (Callon, 1986b). This moment basically captures the idea that the mobilization of certain enrollment is based on the representatives of the groups, who may not properly represent the idea of whole and might even betray to what they agreed upon earlier. As described in the interessement and enrollment, some portion of actors were active in constructing the network, whether students of Healthcare department, subject librarians or lecturers.

One of the crucial questions the program coordinator had asked from themselves was whether students who might be representative of their own studying year are legitimate to agree on something which might not be the same interest of other upcoming or prospect students in the coming years? The years will pass and things will change. Who knows, maybe the next batch of students in upcoming years do not agree with what current students seemingly accepted. Maybe, they don't want to be the part of the current plan anymore, since the subject librarian told us the frequency in using the LibGuide is inconsistent in different academic years. Focal actors had to make sure that mobalization makes the use of LibGuide consistent for current and prospect students And also maybe the future lecturers and subject librarians might not have the same constructive commitment as they had in their negotiations later on. Law (1992) claims that embodiment of actor's relational pattern in inanimate and durable materials is perhaps the best way to guarantee their mobilization. Back to our case, to forge the mobilization we had to first understand who represents who? The program coordinator was a unique sound of itself with the power in hand. Lecturers were those whom with the program coordinators discussed in their rounds of negotiation. Subject librarians were those who 
controlled the LibGuide application. But what about the non-human actor LibGuide? Below we will discuss the role of the spokesperson for LibGuide.

The last part was the open-ended discussion groups initiated by two program coordinators to evaluate the efficiency of using Healthcare's subject guide, and if other technologies are also suitable in order to consolidate the current network. By this the focal actor - the program coordinator can ensure that the idea of having such network will not be betrayed by its initial actors, but the alternative technologies could also be studied. This means, the network will be remained as same, the promises will also be the same, but maybe other alternative as technologies might be proposed as we discussed that years pass by and there will be new technologies in this course.

\subsubsection{Spokesperson}

Healthcare's subject guide was well visited when program coordinators had imposed the interessement. This fact should be considered that Healthcare's subject guide was available for Healthcare students as much it was for rest of the departments. Healthcare's subject guide can not express anything itself, however like other actors in the network, they had their own authentic spokesperson. As we remember, the negotiation between two program coordinators and Healthcare's subject guide evolved around the question that how many students used the application? Let us return to our case, when at first, the Healthcare's subject guide was used to be visited, subject librarian drew a graph and presented it to the program coordinators who was the main gateway to proceed the policies of Healthcare's subject guide that had to be used thereafter. So the questions is, if the number of hits which were presented by subject librarians were judged to be high enough, then a subject librarian is authorized to speak for the Healthcare's subject guide (LibGuide) and they can claim that : LibGuide (and its Subject Guide) for the Healthcare department is visited significantly.

However, it is a fact that speaking in behalf of something which possesses no articulate language is hard and devastating. Two program coordinators now takes the action and they become the director of the network. Subject Librarians had now become influential and their words are listened because they made themselves spokesperson as a good representation of the Healthcare's subject guide, metaphorically they now gave a "head's up" to whole community. So far we can claim that, the intermediaries of each community including, Program Coordinators, Subject Librarians, Lecturers and LibGuide made a progressive mobilization by rendering this proposition that "LibGuide has been used significantly". Now the mobilization is adapted to the mechanism of the network.

It was then that we can claim that LibGuide was transformed to be a sustainable application used frequently by students. In other words, the LibGuide which was presented by Subject Librarians had displaced from an application which was on the shelf as a decoration to a sustainable , usable Web 2.0 which actually meant to be one. The Subject Librarians could then take the LibGuide and start to analyze the use of it, having discussion about the silent application. This means the number of hits from Healthcare department is now mobilized and have been displaced from the server to be printed into charts and graphs for further investigation on its usability analytical perspectives. 
In this chapter, we stress the importance of writing this thesis, and conclude that the materials we had provided throughout the dissertation is completed enough to be represented as a whole.

This thesis aims to focus on relational controversy about the causes behind the inconsistency in number of students who use a Web 2.0 application named "LibGuide" at the Linnaeus University and the attempts of program coordinator to develop certain strategies to perform a better use of it in a particular department, namely the Healthcare department. This will be conducted by answering the two questions: What policies and strategies made the role of LibGuide solid in the Healthcare department followed by what influences these policies and strategies had on actors in the construction of an actor-network. The study has an intepretevistic approach since we used Actor-Network Theory. By interpreting the story of a number of informants we managed to give an answer to previously stated research questions.

We have found that the program coordinator of Healthcare department assigned new tasks to the subject librarians by involving them throughout the whole planning of an academic year. By this strategy the program coordinator could make sure a legit representative of Healthcare's subject guide is present in the whole year and all are bound to consider whether the Healthcare's subject guide should be included in their program planning.

We examined different actions that actors posed socially while these strategies and policies were being enforced. For instance rounds of negotiations occurred to convince different actors to comply with program the coordinator's premises.

In this thesis, we tried to expose the social dimensions of a Web 2.0 application to understand how gearing technical aspects to social ones can help those applications to succeed in their environment. Grounding this sociotechnical investigation on ANT we were able to find out the misalignment between actors who were directly and indirectly dragged into our analysis as well as finding the decisions which were taken place to balance the interests of all participants in the network. In this regard, we analyzed an application which had been used at a university library in Sweden with an exploratory way of describing the case. This experiment, led us to understand how a model of actor-network can map the main promises of a framework within which the social and technical behavior of a group of humans and non-humans can be examined. Our findings revealed some practical implications. First to mention, the decision making ability and the concept of agency that a human as an actor beholds. Second, the participation of all actors who were found to be involved in this process of constructing the network and how their interests were mobilized under the impression of decisions. Third, the inscription of a sociotechnical endeavor of sustainability into a technological artifact (LibGuide). Last but not least, the social barrier in the way of applying the decisions in the approval level and how negotiation can handle the situation and balance the interests. Since the actor network was constructed, a progressive mobilization in embedding the application' use inside the decision levels was obvious. In fact, the case clarified the idea that how looking from the ANT perspective can result to an application's sustainability in a sociotechnical environment.

From the analysis of the case, we concluded that the sustainability of a particular application in a social environment which embodied through the moments of translation. We argued that significance of use in a particular application was not something accidental and it might had been effected by certain strategies that had been imposed to their sociotechnical behavior. With the help of Actor-Network Theory, we constructed a network of different 
participants, in which each member of the network as a single node expressed their behavior towards the problematic situation for which a strategy or strategies could be a solution. We discussed that different actors pose different gestures when they are put into a network, who follow different aims but within the same criteria of interest.

This thesis examined the fact that the certain application in a department inside a university could have been influenced by some rules and regulations which might be applicable to other departments in order to increase the number of interactions the students may have with that application. This significance in using an application by a particular department provides a highly relevant examples of how an application can become sustainable and therefore to be used frequently. It can be clearly concluded that the sustainability of an application as a technical artifact, is mirrored though the social representation of it. Those actors who had been bonded to using certain application is the result of having the power of making right decisions. We conclude that the sustainability of the Healthcare's subject guide or the frequent use of it, succeeded in its translation by understanding some principles such as the Healthcare's program coordinators eminent role in persuading other actors to use and application as well as establishment of a sense of alliance between those actors who had been defined to have a common concern about using a particular application. Mobilizing their actual enrollment was the last part of this endeavor by the program coordinators who actually made sure the certain regulations are mobilized and displaced as well making sure that the actors are not refraining to what program coordinators made as an alignment of their interests. 
This chapter opens a discussion about the essence of the research. We debate on the pros and cons of using ANT in our case as well choosing the method of logic, followed by argumentation about the results.

In this thesis, we used a sociotechnical theory named Actor-Network Theory to understand the social contributions of using a particular technology. However, we have to discuss that ANT possess a narrative and descriptive way of a phenomenon, rather than an explanatory approach. ANT aims to deploy associations of social and technology and this might be claims to be worth being descriptive without any explanation (Latour, 1999a).

Apart from what mentioned above, describing needs a researcher's discretion in understanding the nature of entities, whether be a human or a non-human and this could jeopardize the choice of this method since discretion is relative and not an absolute infinitive. What we identified as actors and what we observed could be served totally in different ways if this thesis had to be done by other individuals. In this theory, what happened before is an important concept to understand as something which is done and might have little effect on future of an artifact or a social behavior, but ANT examines the associations between interrelation of its actors. We would like to discuss that, while we opted a deductive way in pursuing this thesis based on the theory that was already conducted and engineered, in investigation we had to resort ourselves in an inductive manner in describing things that we might think are of importance. Therefore, this might be a common concern for us to have a deductive research with inductive findings which makes an abductive reasoning throughout the method of reasoning.

Our research questions have the focus on the strategies and the social influences that all, or part of actors influenced with, but one of the weaknesses of using such theory is to accept that our level of knowledge about what really happened was to the extend of what we heard in a narrative manner from actors and we could believe nothing but what is told by them. The reality might have been slightly or different from what we collected, but without any doubt it could be a life time endeavor to prove that if what is told was true or part of the truth.

Another important aspect of this thesis can be evolved around the idea that Callon (1986a) and Law (1992) emphasized on, as the construction of the network which is a dynamics of social and technical patterns. This is perhaps why they delegated the name as "moments" to it. Moments, are not static in ANT theory, therefore what might consolidated the network is perhaps subject to be altered if some other actors will be involved in the future of the network. The theory itself proposes a way to avoid dissidence, but it is something which had happened with the former circumstances. This has to be made sure that the construction of the network in different environments remain as same as it was used to be.

Argumentation about the result is the other part we would like to present in our discussion. What this thesis conducted might be limited the perception of the reader to the extend of a single application in a university library. Nevertheless, the result of such a thesis might be generalalizable to a bigger environment with more sophisticated social and technical sides. This thesis is not only applicable in studying the applications and technologies which might be used frequently in a day to day manner inside academic environments, but could also contribute something to the technologies in organizations and other industries, since what we presented was only a corner of a big room. 
The last part of discussion goes to the use of Healthcare's department and their use of the subject guide application. We acknowledge that the intrinsically, Healthcare's department has higher need for the information. Hence, articulation of the journals and databases is more comprehensive and kaleidoscopic in their department. We argue that, in the mathematic department, for instance, as its nature requires, the way the journals or articles are used is not as frequent as it is in Healthcare. Nonetheless, this could also be a reason of why a particular application was sustained in a sociotechnical environment. In more detail, we would also like to discuss who might be interested in such a research. Apparently, beside subject librarians and university libraries as obvious beneficiaries to such a thesis, enterprises and industries might also be interested if they want to analyze how well a certain technology can be sustained inside their business.

\subsection{Reflection}

The process of writing this master dissertation has been a constant involvement of the both of us in all the parts it consists of. We had an initial idea to divide the work in half so we both could focus on different contents of the thesis to make it more time efficient and effective. At a start it worked out but when we realized that all the parts are interconnected we changed the whole idea of writing this thesis. Instead of dividing the work we now began to work together with the chapters and realized that this was the way it needed to be done in. To clarify this even more, we started to write $2 \mathrm{~h}$ individually on a part and then we switched and took the work being done of the other, we then read through it, check with the references we used and came to a conclusion whether to keep the text or not. This iterative process was carried out through the entire thesis and we can more then just recommend this technique when it comes to writing a master dissertation in a pair.

We discussed often that the strength of being two researchers instead of one is the part where you can share, discuss and elaborate your ideas with someone, and this discussion calls out for a need that both of the authors know the subject in detail, especially when it comes to grasp the fundamentals of Actor-Network Theory which isn't the easiest theory to read and understand according to us. Before proceeding further we would now like to spread some light upon the important and crucial work with our tutor Håkan Sterner. We generally believe that what a tutor is obliged to for his dissertations student is quite vague and sometimes misunderstood. In our case have Håkan Sterner worked as a person who we could sit down and discuss methodologies, ideas, theories and everything that comes with this. For all the sessions we had we came with either a statement or a question that we wanted to extract or deconstruct and Håkan Sterner has proven to be a more then well capable authority to do this with, your effort is much appreciated Håkan, Sterner.

Moving on, once we finally came to an agreement of what we wanted to do and we thought after several days(!) of discussion that ANT would be a suitable lens in order to provide an answer to our research question. However, we must say that it wasn't the easiest decision we made in our academic lives. It comes first with the way of using ANT as a theoretical lens to look through. The fact that ANT can be interpreted and used into two major paths; The Old and the New way did create something of a problem for us in the start. So how did we solve all our issues with the choice of our theoretical framework? Simple, we sat down discussed, twisted and cleared it out together which is the strength of writing a master dissertation as a pair. It is nearly impossible to clarify who did what and why in this thesis since both of our impacts are imbedded in every sentence of this thesis, and it wouldn't be fair to give one of us the entire credit of any of the headlines included. Finally, we would like to thank each others for this journey, not only writing the master dissertation but throughout the entire 
master program here in the University of Linnaeus in Sweden. By working together through almost every course this has led to a friendship that is hard to find somewhere else. In spite of that we are probably living in two different contents are we more than sure that are friendship will last and that we will spend many glorious and wonderful moments together.

\subsection{Question of Grounded Theory}

Through the process of writing this master dissertation we have a numerous times discussed how the concept of grounded theory is related to our work or not. As known, Glaser \& Strauss (1967) developed this method with an aim to generate new theories that are either rooted or grounded through the eyes of the researcher (reality), that he or she wants to develop this explanatory theory based on the studies in the environment where they take place. At several occasions we agreed with the fact that an ANT study is closely aligned to what Glaser \& Strauss (1967) said, but our main argument of not choosing that path for this research is grounded on that we as two researchers on the level of writing a master dissertation doesn't have enough of experience and knowledge for being capable to accomplish it, plus the additional claim that the conclusions of the study haven't been tested in terms of its generalization.

We have been reading about Actor-network for approximately 12 months through the case of ours and been studying at a university level for 5years up to a masters level in informatics and we don't find it even close to enough in order to call ourselves theory creators, for us the theory is a framework which is capable of being applicable in more areas than only one field. In addition to this, we have also one of our lectures, which stated that a research with a ground theory as methodology almost per definition invites the audience to criticize the work of the researchers from an almost complete different perspective. We also looked at Strauss \& Corbin's (1997) work of how to evaluate a newly generated theory, and after this we came with to the conclusion that we are not capable of conducting a research with this type of methodology. Secondly, maybe the most important of all the arguments that this isn't aligned our initial purpose. 
In this chapter will our ideas and believes about the limitations for the research be discussed with an additional section that defines what we claim to be suitable future research topics based on the conducted work.

\subsection{Limitations}

One of the first concerns we faced during the progression of the thesis was aligned to the data part. We conducted a number of semi structured interviews in order to gather the data to tell the story through ANT which is the moments of translation. However this wasn't the desired way of gathering the data. We initially tried to form a focus group including all the identified informants where the questions should be asked, to understand the process of negotiations in a better way. However we realized that this couldn't be done since some of our identified actors that were going to take part in the research were living far enough from us for not being able to participate face-to-face. We solved this issue by adding some extra questions for the interview and sometimes even asked more then two or three follow-up questions to clear this out. Another limitation during this process was interwoven with our choice to use ANT, with its descriptive nature for which we were supposed to describe the story from the lens of ANT. This narration would ask us to double check the legibility of what we told and apparently in some points would conflict with the information about the themes we created. This would limited us to put the desired information inside the themes, but ethically we had to put the right information which was in some point an endeavor.

\subsection{Future Research}

In this part, we would like to discuss and suggest topics based on the conducted work for future researches. What we discussed and put the Healthcare's department in canonical center of the arguments, can be in future researches contribute to another applications inside the university. The question we raised in the chapter 1 under background and problem statement was clearly answered in the chapter 5, when we elaborated that the study on Healthcare is apparently extendable to other department with some minor considerations. Another interesting topic to discuss in future research would be analyzing the need for such an application (LibGuide). The ANT would again be a powerful asset if we in the future want to investigate a social problem such as students' inability to find the relevant articles and journals and how a technical artifact such as LibGuide would be imposed by another focal actor to deal with the situation. 


\section{Bibliography}

Alvesson, M. \& Sköldberg, K. (2009). Reflexive methodology: New vistas for qualitative research (2nd edition). London: SAGE Publications Ltd.

Akrich, M. (1992). The De-Scription of Technical Objects. In W. Bijker and J. Law (Eds.) Shaping Technology, Building Society: Studies in Sociotechnical Change. Cambridge, Mass, MIT Press: 205-224.

Amandine, J-B (2010). Technological Choices in International Environmental Negotiations: An Actor-Network Analysis, Sage Journals Business \& Society, vol.49, issue 4, pp570-590

Amsterdamnska, O. (1990). Surely, You Must be Joking, Monsieur Latour!, Science, Technology and Human Values 1990 Vol. 15, 10p.

Anderson, P (2007). What is Web 2.0? Ideas, technologies and implications for education, JISC Technology \& Standards Watch

Andrychuk, D et.al (2012). Subjectguide, accessed at: http://library.queensu.ca/files/subjectguide2.0-wg-report.pdf 2012-01-16

Anttiroiko, A-V; Savolainen, R, (2011). Towards Library 2.0: The Adoption of Web 2.0 technologies in Public Libraries, International Journal of Libraries \& Information Services, Vol.61 Issue 2, pp87-99

Baskerville, R-L \& Myers, M (2002). Information System as a Reference Decipline, Management Information System Quarterly, vol.26 issue 1

Baue, B \& Murningham, M (2011). The accountability Web: Part 2: Weaving Corporate Accountability and Interactive Technology, Journal of Corporate Citizenship, Issue 43, pp7-44.

Bled, A (2010). Technological Choices in International Environmental Negotiations: An Actor-Network Analysis, Business \& Society, Vol. 49, Issue 4, pp.570-590

Boell, S. \& Cecez-Kecmanovic, D. (2010). Literature reviews and the hermeneutic circle, Australian Academic \& Research Libraries, Jun2010, Vol. 41 Issue 2, p129-144, 16p

Boland, R.J. Jr (1991). Information System Use as a Hermeneutic Process, in Information Systems Research: Contemporary Approaches and Emergent Traditions, H-E. Nissen, H.K. Klein, R.A. Hirschheim (eds.), NorthHolland, Amsterdam, 1991, pp. 439-464.

Brooks, L et.al (2008). Adapting Structuration Theory to understand the role of reflexitivity: Porblemitization, clinical audit and information systems. International journal of Information Management. 28(6) pp.453-460

Bruun, H \& Hukkinen, J. (2003). Crossing boundaries: An integrative framework for studying technological change, Social Studies of Science, 33(1), 95-116

Bryant, L. (2007). Emerging trends in social software for education, Emerging Technologies for Learning, Vol. 2, pp. 9-22 
Bryman, A \& Bell, E (2007). Business research methods, New York: Oxford University Press

Callon, M (1986). Some elements of a sociology of translation: Domestication of the scallops in the fishermen of St Brieuc Bay. Sociological Review Monograph v.32 pp.196-233

Callon, M (1986). The Sociology of an Actor-Network: the Case of the Electric Vehicle. In M. Callon, J. Law and A. Rip (Eds.) Mapping the Dynamics of Science and Technology: Sociology of Science in the Real World. London, Macmillan: 19-34

Callon, M. (1987). Society the Making; the Study of Technology as a Tool for Sociological Analysis. in Bijker Wj., Hughes T., Pinch T. (ed.), New Directions in the Social Studies of Technology, Cambridge, MIT Press, 419 p.

Callon, M \& Latour, B (1992). Don't throw the baby out with the Bath School! A reply to Collins and Yearly' in Science as practice and culture. A. Pickering (ed.), 343-368. London: University of Chicago Press.

Campbell, T. (1996). Technology, multimedia, and qualitative research in education. Journal of Research on Computing in Education, 30(9), 122-133.

Castor, T \& Cooren, F-O (2006). Organizations as hybrid forms of life. Management Communication Quarterly, 19(4), 570-600

Creswell, J. W. (2009). Research design: qualitative, quantitative, and mixed methods approaches, 3rd ed. Thousand Oaks, CA: Sage Publications

Creswell, J-W. \& Miller, D-L (2000). Determining validity in qualitative inquiry. Theory into Practice, 39(3), 124-131

Cressman, D. (2009). A Glossary of Terms for Philosophical and Constructivist Approaches to Technology. ACT Lab/Centre for Policy Research on Science \& Technology (CPROST) School of Communication, Simon Fraser University.

Denzin, N-K., \& Lincoln, Y-S, (2000). Introduction: The discipline and practice of qualitative research. In N. K. Denzin \& Y. S. Lincoln (Eds.), Handbook of qualitative research (2nd ed., pp. 1-28. Thousand Oaks, CA: Sage.)

Dye, J-F, Schatz, I-M., Rosenberg, B. A., \& Coleman, S. T. (2000). Constant comparison method: Akaleido - scope of data. The Qualitative Report, 4(1/2).

Eccles, R. \& Krzus, M-P (2010). Intergrated Reporting for a sustainable Strategy, Financial Executive, Vol.26 Issue 2, p28-32. 5pp

Effah, J (2012). Mobilizing culture for e-business in developing countries: An Actor Netweork Theory Account, accessed 1th September 2012 through:

http://www.ejisdc.org/ojs2/index.php/ejisdc/article/viewFile/951/412

Eisner, E-W (1991). The enlightened eye: Qualitative inquiry and the enhancement of educational practice, New York, NY: Macmillan Publishing Company.

Elgali, Z \& Kalman, M (2010). The construction of failure and success concepts in K-12 ICT integration program. Interdisciplinary Journal of E-Learning and Leaning Objectives 2010, vol.6, pp.281-292 
Engstrom, M-Y \& Escalante, V (1996). Mundane tool or object of affection? The rise and fall of the Postal Buddy, Human-Computer Interaction, Cambridge, The MIT Press

Farkas, M. (2007). Subject guide 2.0: Reinventing resource lists with Wikis. American Libraries, 38(5), 33.

Foster, M et.al (2010). Marketing research guides: An online experiment with LibGuides. Journal of Library Administration, v50 pp.602-615

Fuchs, M et.al (2004). Digital libraries in knowledge management: an e-learning case study, International journal on Digital Libraries, Volume 4(1) pp. 31-35, Springer

Fox, S (2000). Communities of practice, Foucault and actor-network theory. Journal of Management Studies 37(6): 853-67.

Gadamer, H-G (1976). Philosophical Hermeneutics. Berkeley, CA: University of California Press.Literature reviews and the hermeneutic circle

Gardois, P et.al (2012). Implementation of Web 2.0 services in academic, medical and research libraries: a scoping review. Health Information \& Libraries Journal, Vol. 29 Issue 2, p90-109. 20p

Giddens, A (1984). The constitution of society: Outline of the theory of structure. University of California Press, Berkeley, CA

Glaser, B-G \& Strauss, A-L, (1967). The discovery of grounded theory: Strategies for qualitative research, New York: Aldine de Gruyter

Golafshni, N (2003). Understanding Ratability and Validity in Qualitative Research, The Qualitative Report Volume 8 Number 4 December 2003 597-607, University of Toronto

Gonzalez, A \& Westbrock, T (2010). Reaching out with LibGuides: Establishing a working set of best practices. Journal of Library Administration, v50, pp.638-656

Greenhalgh, T \& Stones, R (2010). Theorizing big IT programs in healthcare: Strong structuration theory meets actor-network theory. Social Science \& Medicine 79(9) pp. 1285-1294

Hamilton, B (2011). The School Librarian as Teacher: What kind of teacher are you?, Vol. 39 Issue 5, p34-40, 7p. Retrieved from EBSCO host

Hanseth, O et.al (2004). Actor-network theory and Information System: What so special?, information Technology and People, Vol. 17, Issue 2

Hoepfl, M-C (1997). Choosing qualitative research: A primer for technology education researchers, Journal of Technology Education, 9(1), 47-63. Retrieved March 25, 2012, from http://scholar.lib.vt.edu/ejournals/JTE/v9n1/pdf/hoepfl.pdf

Holstrom, J. \& Robey, D. (2005). Inscribing Organizational Change with Information Technology, in Czarniawka, B. \& Hernes, T. (Eds.) Actor-network Theory and Organizing. Malmo, Liber. 
Howcroft, D et.al (2004). What we may learn from the social shaping of technology approach. In: Willcocks, Leslie P. and Mingers, John, (eds.) Social theory and philosophy for information systems. Wiley series in information systems . John Wiley, Chichester, UK, pp. 329-371

Humrickhouse, E (2011). Information Literacy Instruction in the Web 2.0 Library, Education Resource Information Center (ERIC), pp.16

Jacobsen, D-I (2002). Vad, hur och varför: om metodval i företagsekonomi och andra samhällsvetenskapliga ämnen. Lund: Studentlitteratur

Johansson, I \& Liedman, S-E (1993). Positivism \& Marxism, Göteborg, Daidalos

Johnson, L, R, Smith, A-L, \& Haywood, K, (2010). The 2010 Horizon Report: K-12 Edition. Austin, TX: New Media Consortium

Joint, N (2010). Web 2.0 and the library: a transformational technology?, Library Review, Vol. 59 Iss: 7, pp.489 - 497

Josephson, J.R., and Josephson, S.G. (1994). Abductive inference: Computation, philosophy, technology. Cambridge University Press,

Karyda, M., Kiountouzis, E. and Kokolakis, S. (2005). Information systems security policies: a contextual perspective. Computers \& Security, 24 (3), 246-260.

Kiviniemi, V, Laitenin, M \& Saarti, J (2008). Are Libraries Worth Investing in? Journal of European Research Libraries, vol.19, no.2, pp.159-170

Koch, C, (2001). BPR and ERP: Realizing a Vision of Process with IT, Business Process Management Journal \{1-3), 2001, pp. 258-265.

Kroski (2012). A Librarians guide to creating 2.0 subject guides, accessed at: http://oedb.org/blogs/ilibrarian/2007/a-librarians-guide-to-creating-20-subject-guides/ 2012-02-12

Langley, A. (1999). Strategies for theorizing from process data. The Academy of Management Review, 24( 4): 691-711.

Latour, B. (1987). Science in Action: How to Follow Scientists and Engineers through Society, Cambridge, Harvard University Press.

Latour, B. (1992). Where are the missing masses? The sociology of a few mundane artifacts. In W. E. Bijker and J. Law (Eds.), Shaping Technology/Building Society: Studies in Sociotechnical Change (pp. 225 -258). Cambridge, MA: The MIT Press.

Latour, B \& Woolgar, S (1986). Laboratory life: The construction of scientific facts. Chichester: Princeton University Press

Latour, B. (1999). On recalling ANT, in Law, J. \& Hassard, J. (Eds.) Actor-network Theory and After. Oxford, Blackwell Publishers.

Latour, B (1999). The trouble with Actor Network Theory. Soziale Welt, 47, pp 369-381

Latour, B (2004). Why Has Critique Run out of Steam? From Matters of Fact to Matters of Concern. Critical Inquiry, Vol. 30, No. 2, pp. 225-248 
Latour, B (2005). Reassembling the social: An introduction to actor-network-theory. Oxford: Oxford University Press.

Law, J (1986). 'On the Methods of Long Distance Control: Vessels, Navigation and the Portuguese Route to India', in Power, action and belief: A new sociology of knowledge? J. Law (ed.), 234-263. Sociological Review Monograph, 32, London: Routledge and Kegan Paul.

Law, J (1991). 'Introduction: Monsters, Machines and Sociotechnical Relations' in A sociology of monsters: Essays on power, technology and domination. J. Law (ed.), 125. Routledge: London.

Law, J (1992). Notes on the theory of the actor network ordering, strategy and heterogeneity, System Practice (5), p379-393

Law, J \& Hassard, J (1999). Actor Network Theory and After, Sociological Review and Blackwell, Oxford.

Law, J (2007). 'Making a Mess with Method', in William Outhwaite and Stephen P. Turner (eds), The Sage Handbook of Social Science Methodology, Sage: Beverly Hills and London, pp 595-606.

Lee, A. S., (2004). Thinking about Social Theory and Philosophy for Information Systems', in L Willcocks \& J Mingers (eds), Social Theory and Philosophy for Information Systems, John Wiley \& Sons, Chichester, 1-26

Leonardi, P. (2009). Crossing the Implementation Line: The Mutual Constitution of Technology and Organizing Across Development and Use Activities Communication Theory, 19, 278-310.

Linnéuniverstetsbiblioteks årsberättelse (2011)

Linnéuniverstetsbiblioteks årsberättelse (2010)

Lewis, B \& Griffin, M (2011). Special Collections and the new web: Using LibGuides to Provide Meaningful Access, Journal of Electronic Resources Librarianship, v23, n1, pp70-79

Martin, J-V. (1996). Subject specialization in British university libraries: a second survey. Journal of Librarianship and Information Science, 28, (3), 159-169.

Martins, L (2009). IT Alignment through ANT: A case of sustainable decision in the educational sector. Science and technology for Humanity. Toronto International Conference 26-27 Sept.2009

Mohammed, T.A \& Richardson, H-J (2007). Implementation of a customer services information systems strategy in a higher education context. International Federation for Information Processing (IFIP), v.235, pp.283-295

Morris, S \& Bosque, D-D (2010). Forgotten Resources: Subject Guides in the Era of Web 2.0. Technical Services Quarterly, 2010, Vol. 27 Issue 2, p178-193, 16p

Mutch, A (2002). Actors and networks or agents and structures: Towards a realist view of information systems . Organization 9/3: 477-496 
O'Reilly, T. (2005). What is Web 2.0-design patterns and business models for the next Generation of software, Retrieved from:

http://www.oreillynet.com/pub/a/oreilly/tim/news/2005/09/30/what-is-web-20.html. Accessed: 2012-07-20

Ouellelte, D (2011). Subject Guides in Academic Libraries: A User-Centered Study of Uses and Perceptions, Canadian Journal of Information \& Library Sciences. Vol. 35 Issue 4, p436-451. 16p.

Patel, R \& Davidson, B (2003). Forskningsmetodikens grunder: att planera, genomföra och rapportera en undersökning. 3'rd edition, Lund: Studentlitteratur

Patton, M-Q. (2002). Qualitative research and evaluation methods (3rd ed.). Thousand Oaks, CA: Sage.

Perrone, V-G (2005). The changing role of librarians and the online learning environment University of Waikato New Zealand. Accessed $20^{\text {th }}$ May 2012 through: http://pandora.nla.gov.au/pan/24005/20020403-

0000/www.com.unisa.edu.au/cccc/thesiss/refereed/thesis34/Thesis34-1.htm

Pinfiled, S (2001). The changing role of subject librarians in academic libraries Journal of Librarianship and Information schience, 33 (1) March 2001, 32-38)

Ponti, M (2012). Undercovering Casuality in Narrative of collaboration: Actor Network Theory and Event Structure Analysis. Qualitative social research sozialforschung. vol 13, No.1 Art. 11 - January 2012

Potts, L. (2008). Diagramming with actor network theory: A method for modeling holistic experience, International Professional Communication Conference. 2008 Montreal, Canada : IEEE, p1-6, 6p.

Probert, S.(2004). Adorno: A Critical Theory for IS Research. In J.Mingers \& L.Willcocks (Eds.). 2004. Social Theory and Philosophy for Information Systems. John Wiley and Sons: Chichester. pp 129-156

Rajshekhar, A-P (2008). Building dynamic Web 2.0 websites with Ruby on Rails create database-driven dynamic websites with this open-source web application framework, Birmingham, UK: Packt

Reeb, B \& Gibbons, S (2004). Student, Librarians, and subject guides: Improving a poor rate of return. Libraries and the Academy, v4 n1, pp.123-130

Richardson, W et.al (2008). Knowledge discovery in digital libraries of electronic theses and dissertation: an NDLTD case study, International Journal on Digital Libraries, Volute 9 pp.163-171, Springer

Rodon, J., Pastor, J. A., Sese, F. \& Christiaanse, E. (2008). Unravelling the Dynamics of IOIS Implementation: An Actor-network Study of an IOIS in the Seaport of Barcelona, Journal of Information Technology, 23, 2, 97-108

Ruikar, S \& Pei-Chia, C (2012). Achieving Network Stability Through Convergence: Case Study of an E-Government Project Using Actor-Network Theory. System Science, 2012 45th Hawaii International Conference on Digital Object Identifier pp.2593-2602 
Sarker, S. \& Sidorova, A. (2006). Understanding Business Process Change Failure: An Actor-Network Perspective, Journal of Management Information Systems 23, 1, 51 86

Schultz, J-B, (2010). Knowledge Quest, Journal of Librarianship and Information schience, Vol. 39 Issue 2, p12-18, $7 \mathrm{p}$,

Shang, S et.al (2011). Understanding Web 2.0 service models: A knowledge-creating perspective, Journal of information \& Management, Vol 48 pp.178-184, Elsevier

Shenton, A-K (2004). Strategies for ensuring trustworthiness in qualitative research projects Division of Information and Communication Studies, School of Informatics, Lipman Building, Northumbria University, Newcastle upon Tyne, NE1 8ST, UK

Shepard, C-E \& Skrabut, S (2011). Rethinking Electronic portfolios to promote sustainability among teachers, TechTrends, Vol.55 Issue 5, pp.31-38

Shepherd, C, \& Aagard, S. (2011). Journal writing with Web 2.0 tools: A vision for older adults. Educational Gerontology, 37(7), pp.606-620.

Shin, D.-H., Choo, H. \& Beom, K. (2010). Socio-technical Dynamics in the Development of The Electronic Journal of Information Systems in Developing Countries Next Generation Mobile Networks Moments of Translation Processes of Beyond 3G, Technological Forecasting and Social Change, 75, 9, 1406-1415.

Smith, M (2008). 21st Century readers' aids: Past history and future directions. Journal of Web Librarianship v2. pp.511-523

Stenbacka, C (2001). Qualitative research requires quality concepts of its own. Management Decision, 39(7), pp-551-555

Strauss, A, \& Corbin, J. (1998). Basics of qualitative research: Grounded theory procedures and techniques (2nd ed.). Thousand Oaks, CA: Sage.

Sullivan, L (2010). LibGuides: Web 2.0 Content Management and Library Knowledge Sharing, System.Detail Vol. 1 Issue 1, p68-69, 2p

Tatnall, A. (2009). Innovation Translation as a Research Approach to Theorising Information Systems Implementation, International Journal of Networking and Virtual Organisations, 6, 1, 64-76.

Tineke, B et.al (2010). Opening the black box of quality improvement collaboratives: An actor-network theory approach. BMC Health Service Research, v.10 pp.265-273

UniWeb (2012). http://lnu.se/ub/, accessed: 2012-08-25

USA Today (2011). Study: Collage student rarely use librarians' expertise. Accessed at:http://www.usatoday.com/news/education/story/2011-08-22/Study-Collegestudents-rarely-use-librarians-expertise/50094086/1 2012-03-12

Verbit, D \& Klene, V (2011). Libguides: A CMS for Busy Librarians, Computers in Libraries, Vol.31, Issue 6 
Walsham, G (1995). Interpretive Case Studies in IS:Research Nature and Method. In M.D.Myers \& D. Avison. 2002. Qualitative research in information systems, London: SAGE publications pp 101-113

Walsham, G. \& Sahay, S. (1999). GIS for district-level administration in India: problems and opportunities. MIS Quarterly, 23, 39-66.

Walsham, G. (1997). Actor-network Theory and IS Research: Current Status and Future Prospects, in Lee, A., Liebenau, J. \& Degross, J. (Eds.) Information Systems and Qualitative Research. London, Chapman and Hall.

Wang, B (2011). The Research of Web 2.0 Interface and Interaction, Advances in Electronic Engineering, Communication and Management Vol.1 Lecture Notes in Electrical Engineering Volume 139, pp 449-454

Whittle, A \& Spicer, A (2008). Actor network theory critique? Organization studies, vol, 29, Issue 4, pp.611-629

Willcocks, L-P, \& Mingers, J, (2004). Social theory and philosophy for information systems. Wiley series in information systems Chichester, UK,

Yang, S. (2009). Subject guide 2.0: A dream or reality? Journal of Library and Information Science, 35(1), 90-98

Yasemin, S et.al (2009). Adoption of Web 2.0 tools in distance education, Social and behavioral sciences, vol.1, no.1, pp.818-823

Zhan, A et.al (2010). Understanding the standardization strategies in China from the perspective of Actor-Netowrk Theory, Seond Internation Conference on Information Science and Engineering.

Zuiderent, T et.al (2009). Sociological remigrations of patient safety; Ontologies of improvement and acting with quality collaborative in healthcare. New approaches to researching patient safety. Social Science \& Medicine 69(12) pp.1713-1721 


\section{Appendix}

\subsection{Interview guide}

\begin{tabular}{|c|c|c|}
\hline & Goal & Reason: \\
\hline 1 & Problem -situation & $\begin{array}{l}\text { - To identify the actors } \\
\text { - Capturing the problematic situation } \\
\text { - What are the role of all these actors? } \\
\text { - What activities they are carrying out }\end{array}$ \\
\hline 2 & $\begin{array}{l}\text { Experiencing the } \\
\text { real problem }\end{array}$ & $\begin{array}{l}\text { - To understand the problem which they experience } \\
\text { - For them to accept that the current situation is problematic }\end{array}$ \\
\hline 3 & Expectations & $\begin{array}{l}\text { - What each actor is expected to do or to behave or to act } \\
\text { according to other actors! } \\
\text { - How do student lecturers and subjectLibrarians meet the } \\
\text { intersection of their desired expectations? }\end{array}$ \\
\hline 4 & & $\begin{array}{l}\text { - What to do to make sure, that the students, } \\
\text { subjectlibrarians, lectureres and focal actor go with the }\end{array}$ \\
\hline
\end{tabular}




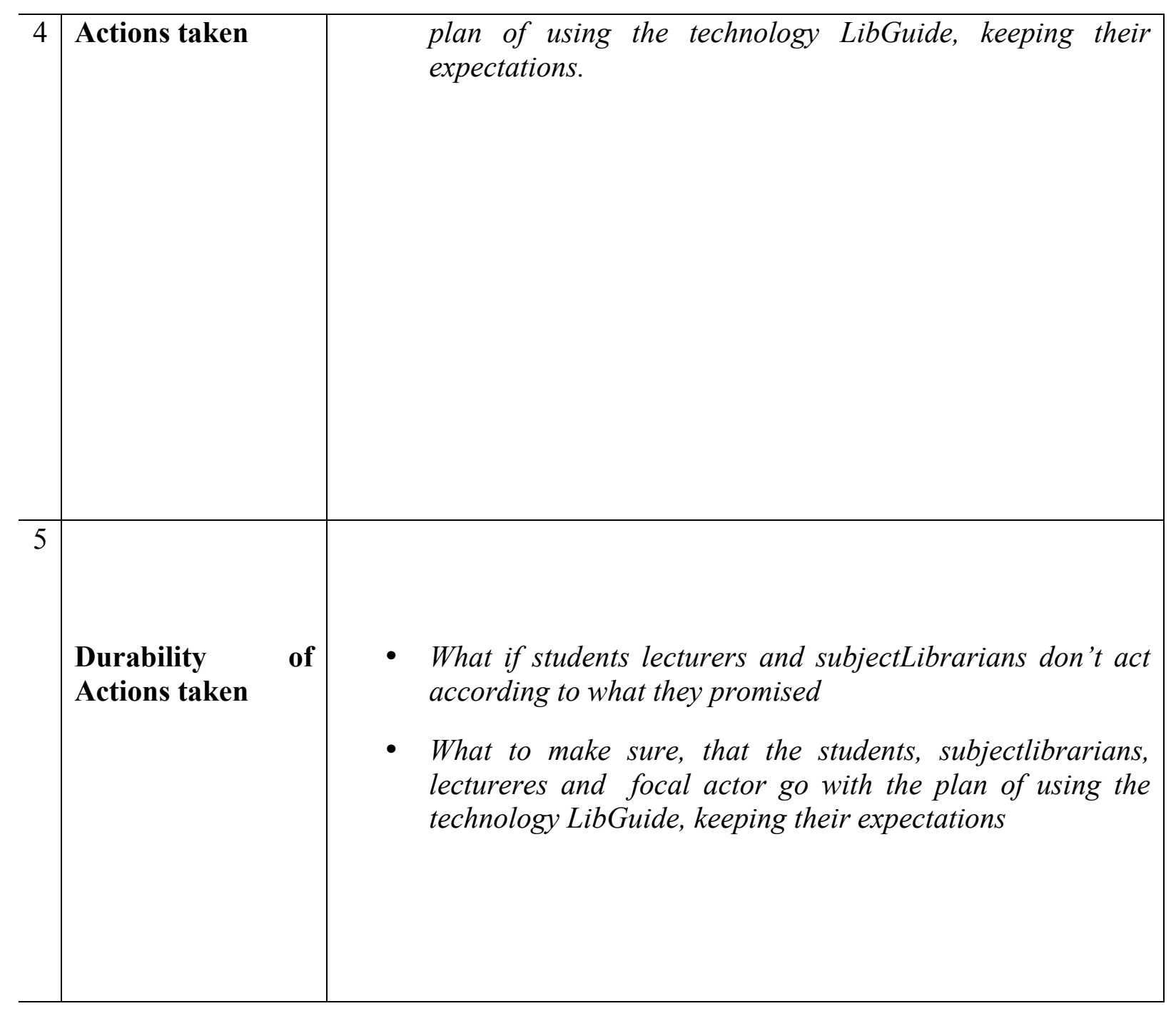




\subsection{Template for analysis of data}

\begin{tabular}{|l|l|}
\hline No & Interview with: \\
\hline Area 1: \\
\hline
\end{tabular}

1.

2.

3.

4.

Area 2:

5.

6.

7.

8.

Area 3:

9.

10.

11.

12.

Area 4:

13.

14.

15.

16.

Additional Questions:

17.

18.

19.

20. 


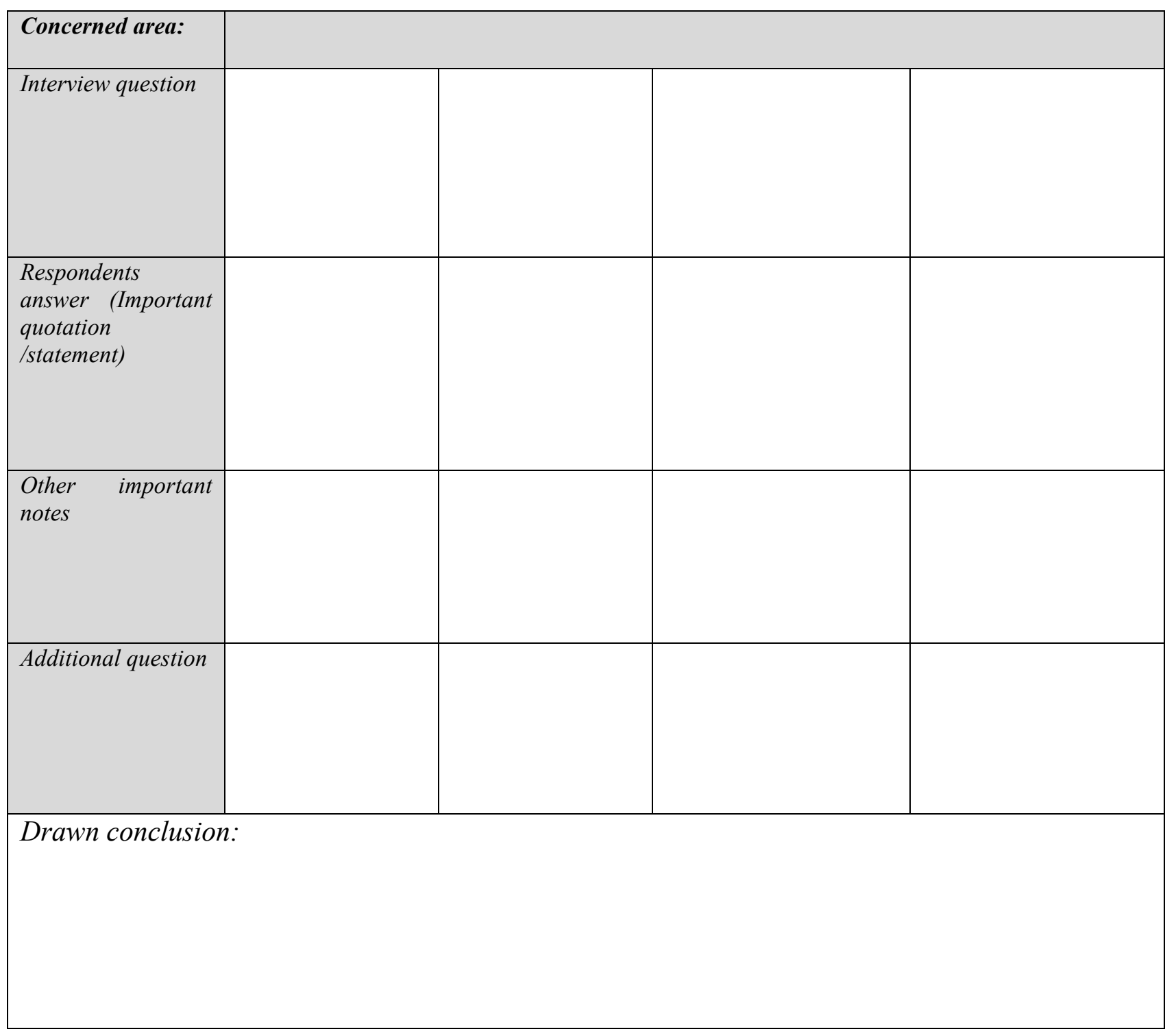




\subsection{Survey - To see the general use of LibGuide}

This survey study aims to investigate the relationship between students and their Subject Librarian.

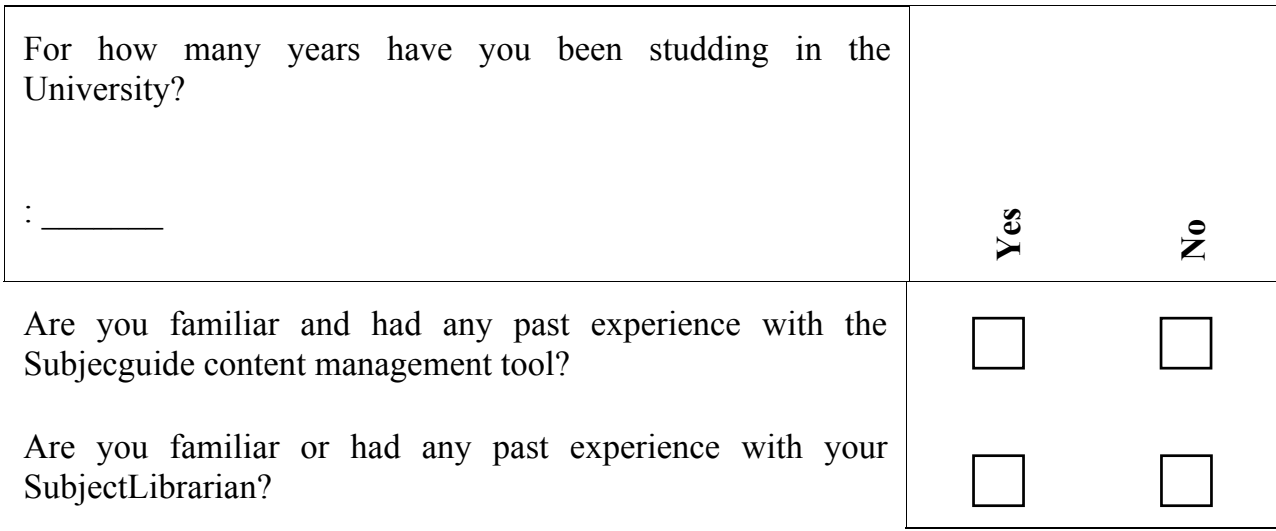

Only read further if you answered YES on one of the previous asked questions

\begin{tabular}{|l|l|l|l|}
\hline $\begin{array}{l}\text { How often do you visit your SubjectGuide page or Subject } \\
\text { Librarian in a month? }\end{array}$ & (n) \\
\hline & $\begin{array}{l}\text { SubjectGuide or the SubjectLibrarian contributes to your } \\
\text { overall learning experience? }\end{array}$
\end{tabular}

Thank you for your participation in our survey

Best regards Andreas \& Sina 


\subsection{Survey - To see the use and impact of LibGuide for healthcare students}

Denna studie inriktar sig på att undersöka relationen mellan vårdvetenskaps studenter och deras ämnesguide

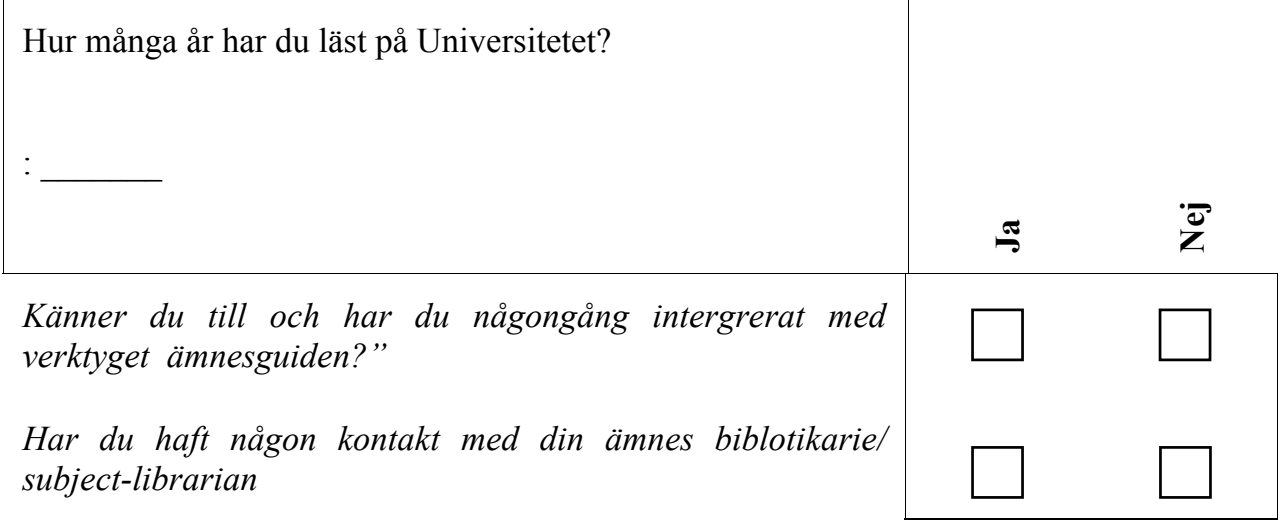

Om du svarat ja på någon av de tidigare frågorna, vänligen forsätt. Om nej, då är du klar med undersökningen

\begin{tabular}{|c|c|c|c|c|c|}
\hline & 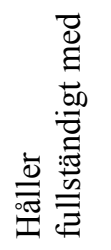 & 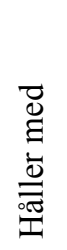 & 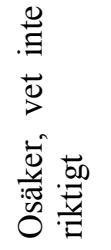 & 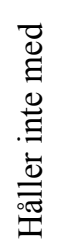 & 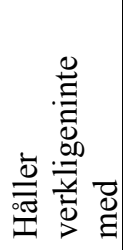 \\
\hline $\begin{array}{l}\text { Har detta verktyg och kontaktperson bidragit till ditt lärande } \\
\text { å ett possitivt sätt" }\end{array}$ & 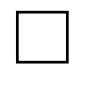 & & 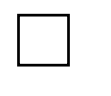 & & $\square$ \\
\hline
\end{tabular}

Tack för ditt deltagande!

Vänliga hälsningar Andreas \& Sina 


\subsection{Interview guide - Student}

\section{Interview Guide: Student}

Interview nr:

Date:

Question1. How well you would find the relevant materials as the sources of your information for your studies?

Question2. What do you study and for how long have you been doing it?

Question3. How did you come in contact with the tool LibGuide?

Question4. Did the work with your subject librarian and subject guide contribute to your academic results?

Question5. Would you describe your course introduction where your subject librarian is present?

Question6. What topics were the main focus of your discussion in the meeting with subject librarian?

Question7. Do you evaluate the given courses where your subject librarians were involved?

Question8. What makes you to use your subject guide page?

Question9. How often do you visit your subject librarians?

Question10. What kind of assistant do you get from your subject librarians?

Question11. Is your subject librarian involved when it comes to marking your assignments? 


\section{Interview Guide: Lecturer}

Interview nr:

Date:

Question 1. Describe your work with subject librarian inside your department.

Question 2. What is the common problems your students have when it comes to their essays and assignments

Question 3. What is the expectation of the student and subject librarian from you?

Question 4. Were there any changes when it came to forming the course instruction when subject responsible became subject librarians?

Question 5. How well do you see your relationship with the subject librarian?

Question 6. Do you personally think that the subject guide contributed to better use of literature?

Question 7. Which directives do you receive from the program responsible regarding the work with subject guide and subject librarians?

Question 8. If yes! Then what policies and regulations do you follow?

Question 9. In lecture level, how do you contribute to program a year forstudents? 


\section{Interview Guide: Subject Librarian}

Interview nr:

Date:

Question1. As the number of hits were significant in the department of Healthcare, what do you think the Program coordinator imposed as strategies in order to maintain or leverage this number?

Question2. When LibGuide was introduced, what directives were you given regarding this application?

Question3. Is there any activities which bounded students to use LibGuide or visiting SubjectLibrarian? ( how to control this? specially if there were any regulation involved?)

Question4. Did Springshare deliver LibGuide with the template you asked for?! Could you modify it yourself to suit better with the way you use it?

Question5. Do you think Linnaeus Library differs in quality comparing to other Swedish Universities?

Question6. As a healtchare Subject Librarian, what is your interaction to the Lecturers that teach in that department? What kind of conversation about the use of LibGuide have you been through?

Question7. How often do you meet with students every semester? Is there any limit as minimum amount? How is this decided? By whom?

Question8. How can the program coordinators make sure that the number of hits will remain as same in future? What strategies do you think could maintain the high amount in number of hits? Do you think embedding LibGuide as one module inside Blackboard could help? Please tell us any other strategies that you think program coordinators took or will take in order to keep this number maintained? 


\subsection{Interview guide - Program Coordinator}

\section{Interview Guide: Program Coordinator}

Interview nr:

Date:

Question 1. Tell us about the work with subject librarians, lecturers and students?

Question 2. What are your responsibilities in programming a year? And how is the subject librarian involved in this?

Question 3. Why is the subject librarian involved?

Question 4. Tell us what your beliefs are regarding the use of LibGuide?

Question 5. Could you tell us if there is any policies or regulations embedded in the involvement of LibGuide in students' learning activities? What are the implications?

Question 6. Could you tell us what happened regardin the introduction of subject librarians in your department in the year of 2010 ? 


\subsection{Pre-study result 1}

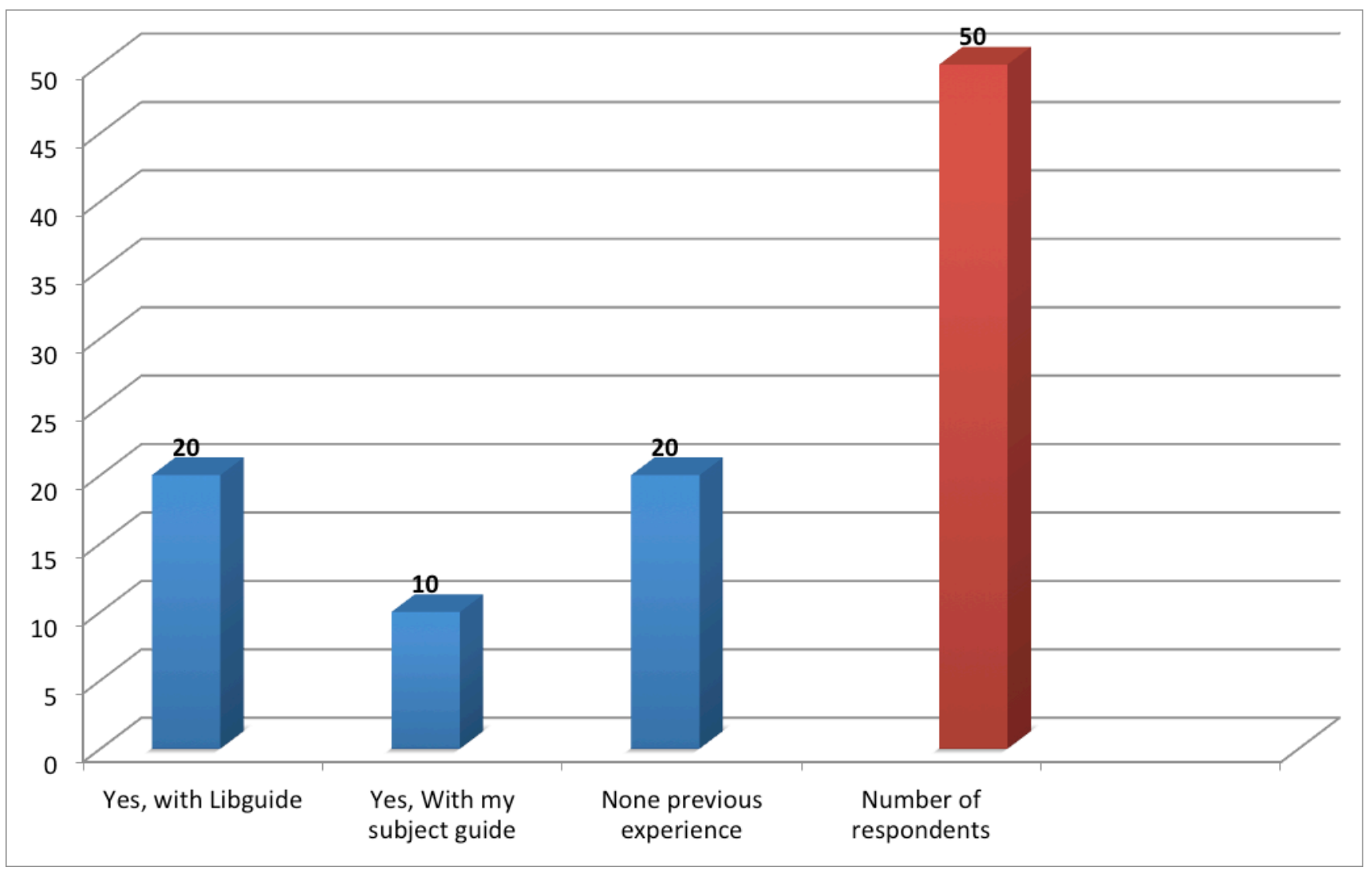

9.10 Subject Guide: Healthcare Department - statistics

\begin{tabular}{|l|l|l|l|l|l|l|l|l|l|l|l|l|l|l|l|}
\hline Guide & Jan & Fe & Mar & Apr & May & Jun & Jul & Aug & Sep & Oct & Nov & Dec & Total \\
\hline \hline Subject 1 & - & $?$ & $?$ & $?$ & $?$ & - & - & $?$ & $?$ & $?$ & $?$ & $?$ & $?$ \\
\hline Subject 2 & - & - & - & - & - & - & - & - & - & - & - & - & - \\
\hline
\end{tabular}




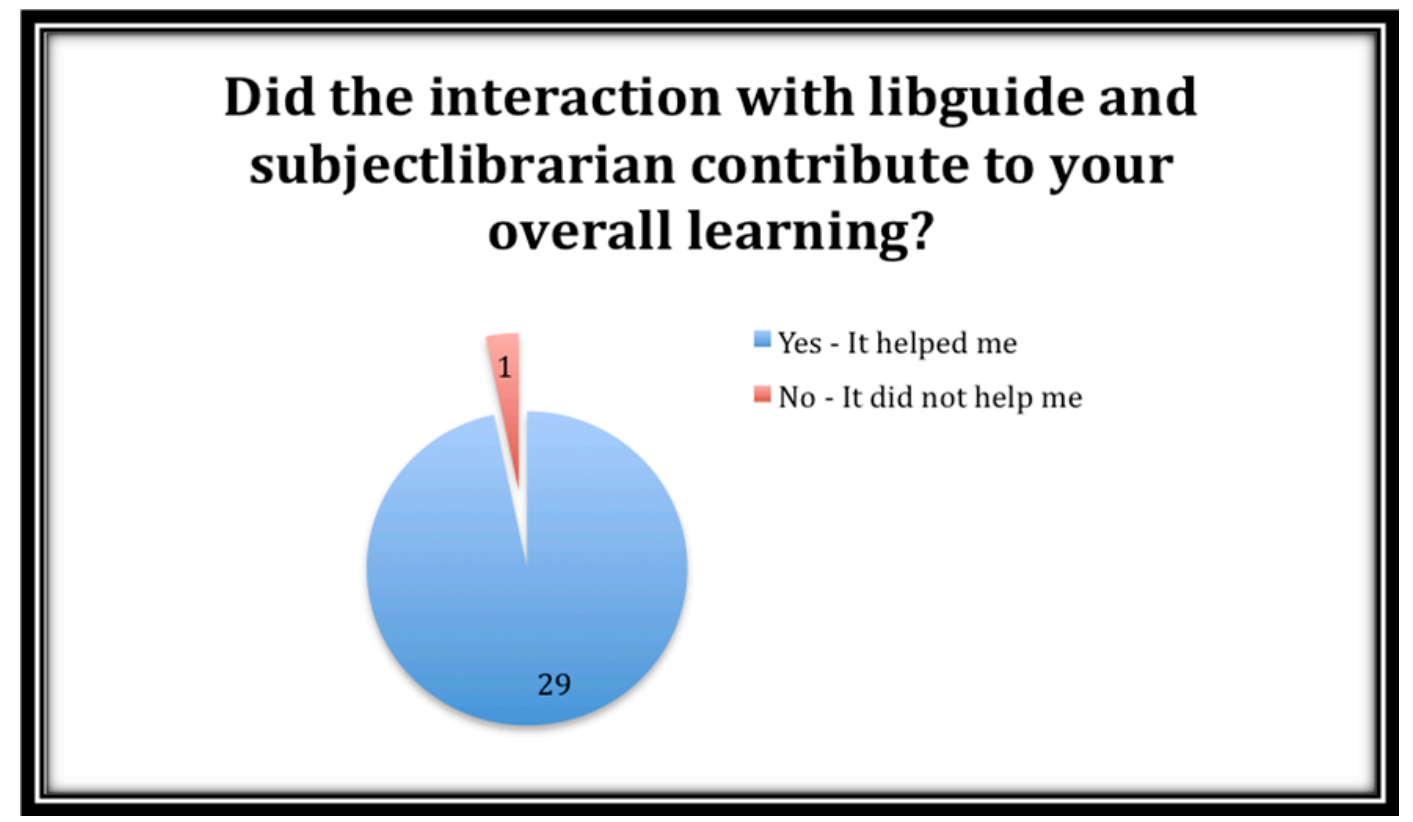

